Portland State University

PDXScholar

Spring 6-8-2017

\title{
Investigation in to the Stabilizing Effects of the Modified Base Archaeosine in tRNA and the Identification of the Fluorescent Product of Base Treatment of $\mathrm{NAD}(\mathrm{P})+$ Cofactors
}

Ben Turner

Portland State University

Follow this and additional works at: https://pdxscholar.library.pdx.edu/open_access_etds

Part of the Chemistry Commons

Let us know how access to this document benefits you.

\section{Recommended Citation}

Turner, Ben, "Investigation in to the Stabilizing Effects of the Modified Base Archaeosine in tRNA and the Identification of the Fluorescent Product of Base Treatment of NAD(P)+ Cofactors" (2017). Dissertations and Theses. Paper 3646.

https://doi.org/10.15760/etd.5530

This Dissertation is brought to you for free and open access. It has been accepted for inclusion in Dissertations and Theses by an authorized administrator of PDXScholar. Please contact us if we can make this document more accessible: pdxscholar@pdx.edu. 
Investigation in to the Stabilizing Effects of the Modified Base Archaeosine in tRNA and the Identification of the Fluorescent Product of Base Treatment of NAD $(\mathrm{P})^{+}$Cofactors

by

Ben Turner

A dissertation submitted in partial fulfillment of the requirements for the degree of

Doctor of Philosophy

in

Chemistry

Dissertation Committee:

Dirk Iwata-Reuyl, Chair

Niles Lehman

John Perona

Ken Stedman

Portland State University

2017 


\begin{abstract}
This dissertation covers two projects linked by their involvement in the modification of tRNA bases.

The first project focused on an investigation of a role for the modified base Archaeosine, the ubiquitous modification in tRNA in the archaeal domain. Initial work was performed on a set of in vitro prepared tRNA modified to feature either the canonical guanine base at

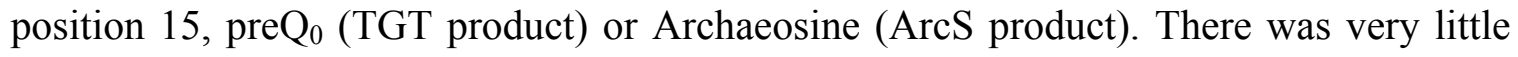
difference in the thermal stability of tRNAs containing these modifications in the halophilic H. volcanii $\mathrm{tRNA}^{\mathrm{Ser}}$ or $E$. coli $\mathrm{tRNA}^{\mathrm{Gln}}$. In tRNA ${ }^{\mathrm{Gln}}$ taken from $M$. thermautotrophicum however, there was a $2^{\circ} \mathrm{C}$ increase in melting point in $50 \mathrm{mM} \mathrm{MgCl}_{2}$ upon modification to archaeosoine.
\end{abstract}

Benefitting from the development of genetic tools for the generation of specific deletion mutants of the thermophile Thermococcus kodakarensis, it was possible to start investigation of tRNAs that have been hypomodified in vivo due to the lack of arcTGT (TK0760) and ArcS (TK2156). In vitro modified equivalents of the Gln ${ }^{\mathrm{CUG}}$ isoacceptor were also prepared. Thermal stability of these tRNAs show virtually identical melting transitions, with a biphasic denaturation occurring at all magnesium concentrations tested. Isolation of the CUG isoacceptor from the in vivo maturated total tRNA pool allowed melts of specifically hypomodified tRNAs. Those containg Archaeosine (WT) and genetically encoded guanine $(\Delta \operatorname{tg} t)$ showed identical melting profiles with $\mathrm{T}_{\mathrm{m}}$ beyond the $98^{\circ} \mathrm{C}$ limit 
of the experiment. In the preQ $_{0}$ containing in vivo RNA the shows a lag in its magnesium response, and a more persistent biphasic melting profile. At $10 \mathrm{mM} \mathrm{Mg}^{2+}$ concentration the preQ $Q_{0}$ containing tRNA is approaching a $\mathrm{T}_{\mathrm{m}}$ of $98^{\circ} \mathrm{C}$ though the turn over point in the melt is not well defined.

The second project was to investigate the product of base treatment of the oxidized cofactor $\mathrm{NAD}(\mathrm{P})^{+}$. This cofactor is involved in the biosynthesis of $\mathrm{preQ}_{1}$ from $\mathrm{preQ}_{0}$ in bacterial systems and at low concentrations it can be difficult to quantify enzyme activity based on direct quantitation. Under these conditions a fluorescence based method where by the production of $\mathrm{NAD}(\mathrm{P})^{+}$is measured rather than the consumption of $\mathrm{NAD}(\mathrm{P}) \mathrm{H}$.

Base treatment of the oxidized cofactor generates a fluorescent species with an efficiency of $95 \%$. The assay has been used extensively by our group to track activity of various enzymes including QueF, however the identity of the fluorophore had not been established. Purification of the fluorescent product was achieved by isocratic HPLC in water using a reverse phase column. It was found that the assay conditions previously used (7.5M NaOH for 2 hours) wer actually counterproductive for maximizing fluorescence yield. Incubation at $2 \mathrm{M} \mathrm{NaOH}$ gave a $35 \%$ increase in product yield. The isolated product was determined to have molecular weight of 123.0318 (3.6 ppm by accurate mass ESI MS). ${ }^{1} \mathrm{H}$ and ${ }^{13} \mathrm{C}$ NMR were used to confirm the structure to be that of 2-hydroxynicotinaldeyde. It was also possible to determine the quantum yield for the molecule to 0.11 . Work carried out previously on pyridinium based NADP analogs is consistent with the identity of the fluorophore presented here. 


\section{Acknowledgements}

I would like to thank my thesis committee for the support and encouragement throughout the time working on this project. This extends to the valuable discussion with the many members of to the CLEE Group at Portland State University and also Dr David Draper.

I also have to extend my gratitude to Dr Tom Santagelo and Brett Burkhart for providing the TKO knockout cell lines and Dr Ben Rauch, Dr Anna Louise Reysenbach and Mr Liu for advice on how to grow them.

I would like to thank Rob Ross of the Limbach group for processing MS analysis of in vivo material. 


\section{Table of Contents}

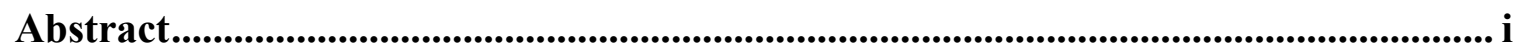

Acknowledgements ............................................................................................ ii

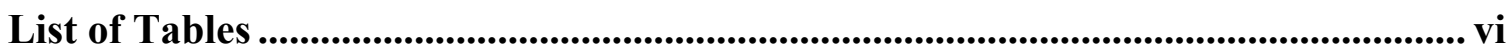

List of Figures............................................................................................................. vii

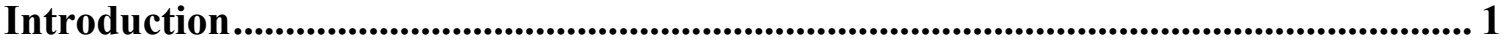

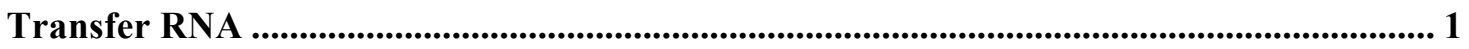

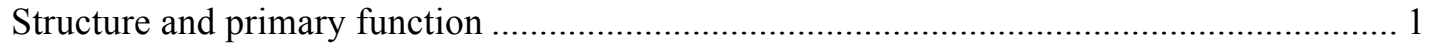

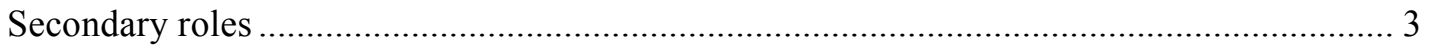

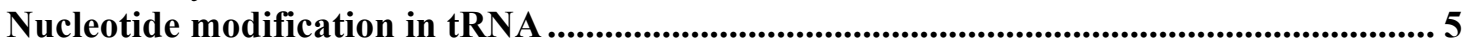

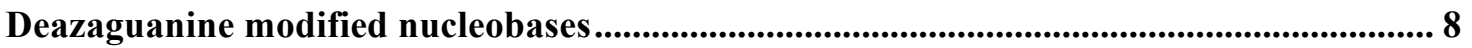

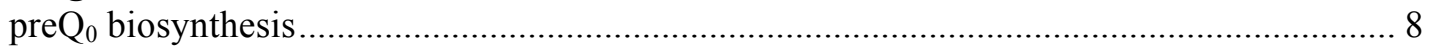

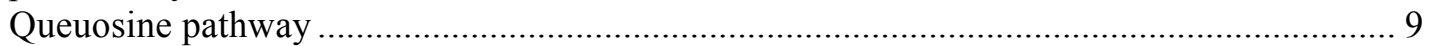

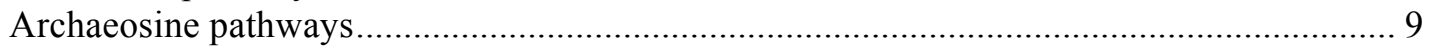

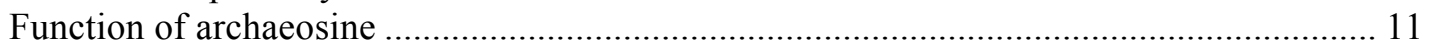

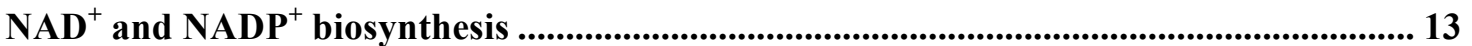

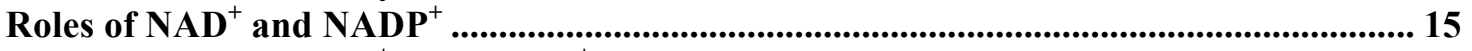

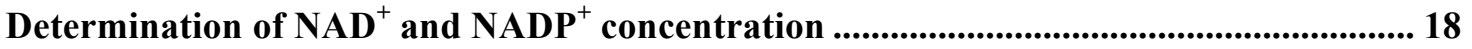

Materials and Methods ....................................................................................... 20

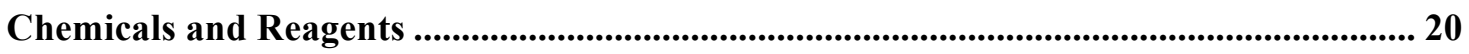

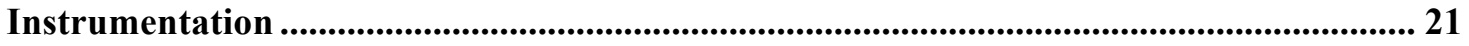

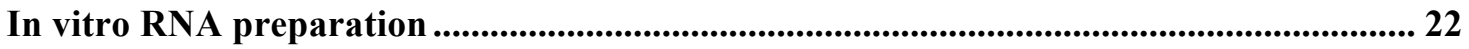

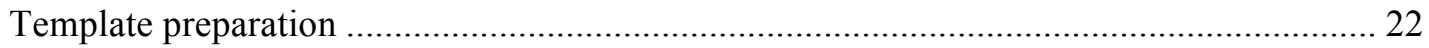

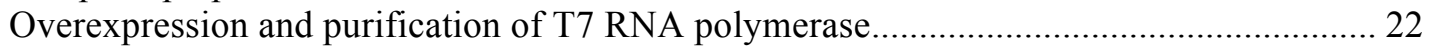

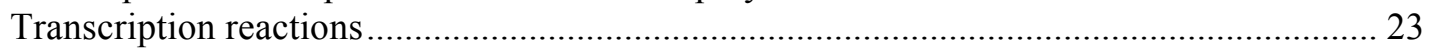

RNA modification enzyme expression and purification and use .......................................... 24

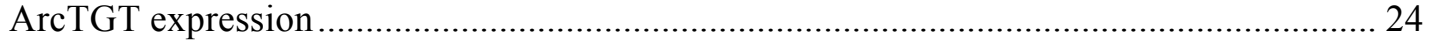

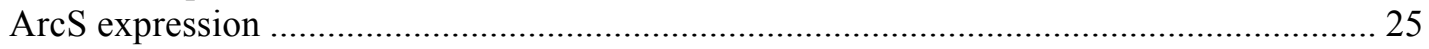

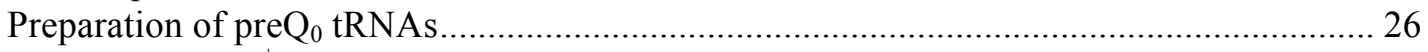

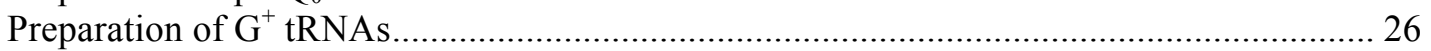

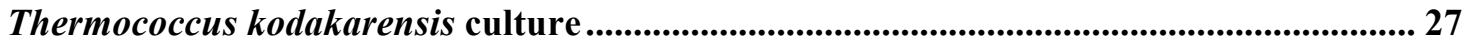

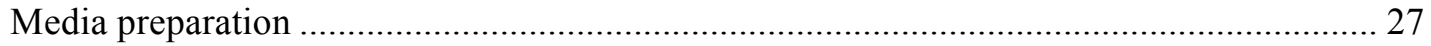

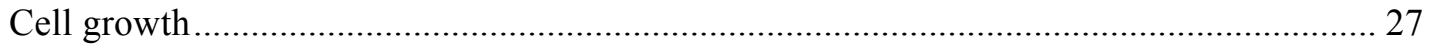

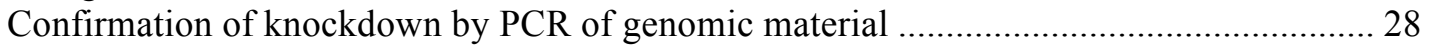

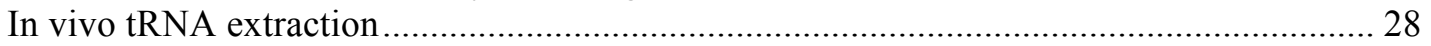

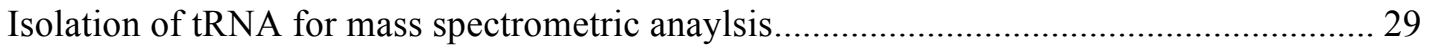

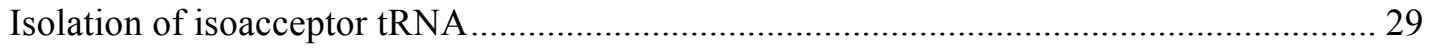

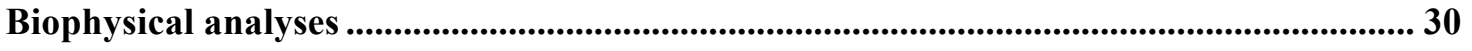

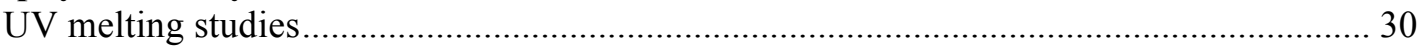

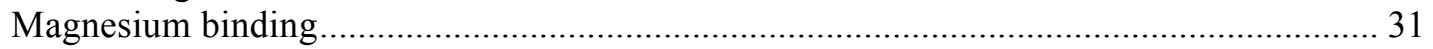

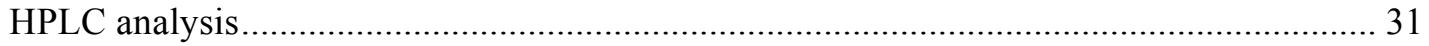

Product synthesis and purification .............................................................................................. 32

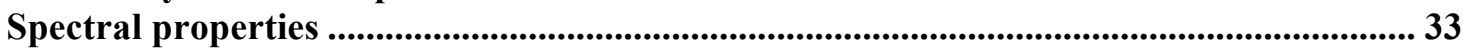

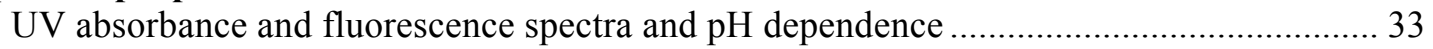

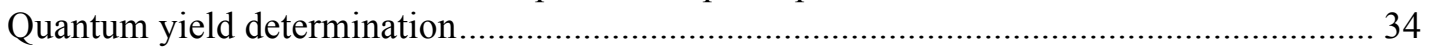




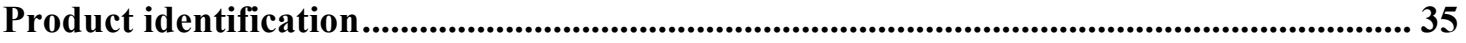

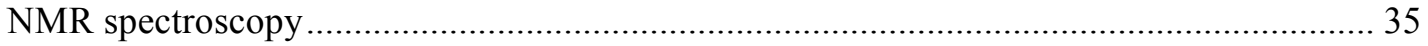

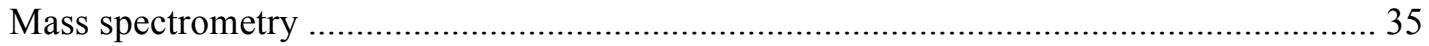

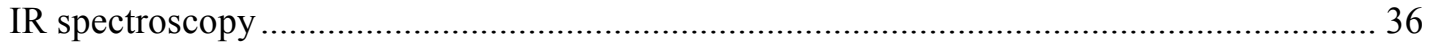

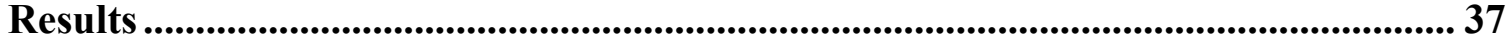

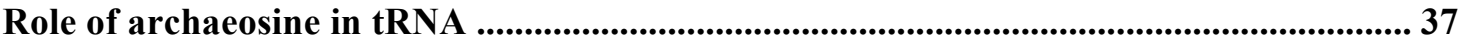

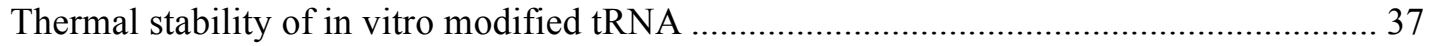

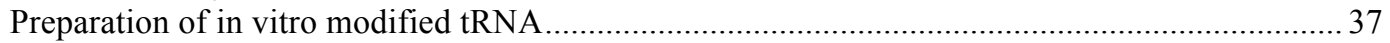

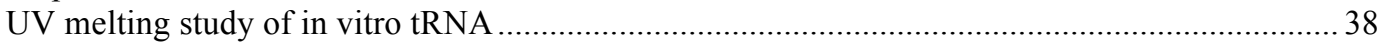

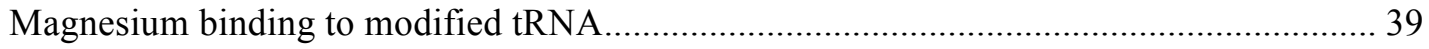

In vivo modified tRNA from Thermococcus kodakarensis ............................................... 41

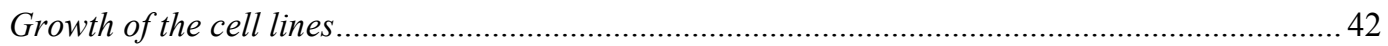

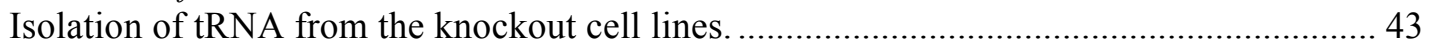

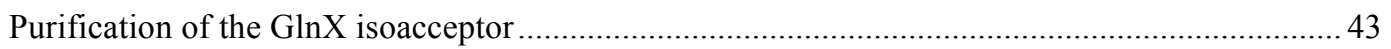

Thermal stability of single isoacceptor tRNA ………................................................................. 44

Identification and characterization of $\mathrm{NAD}(\mathrm{P})^{+}$base product ............................................. 46

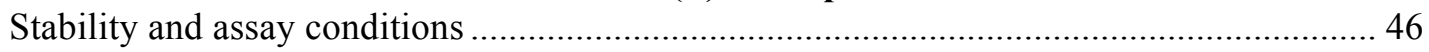

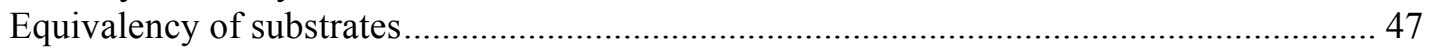

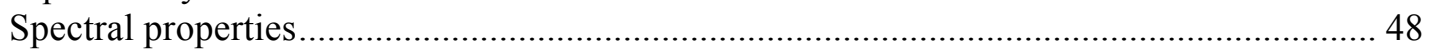

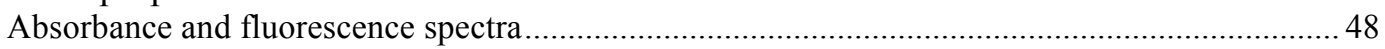

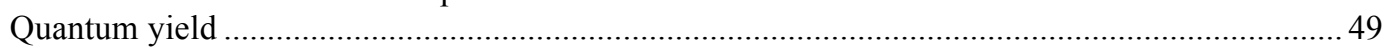

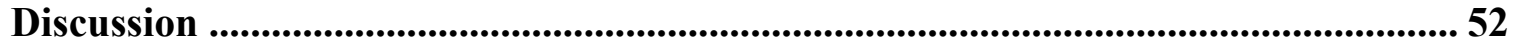

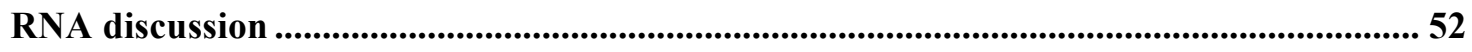

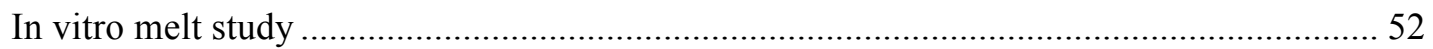

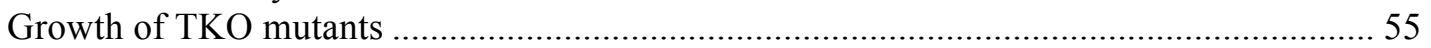

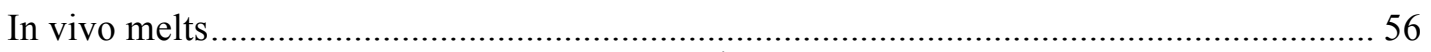

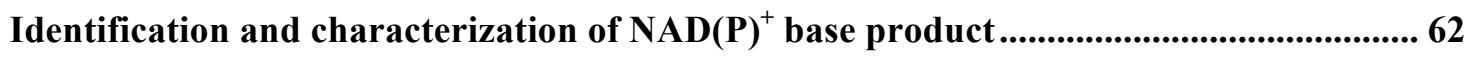

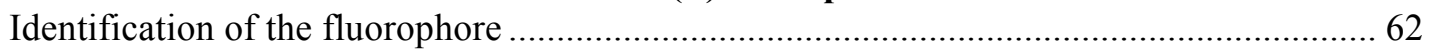

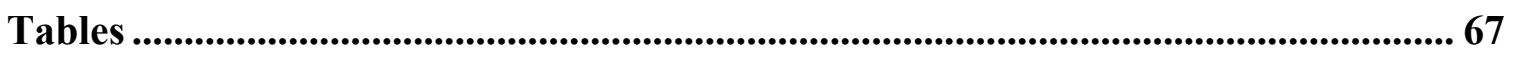

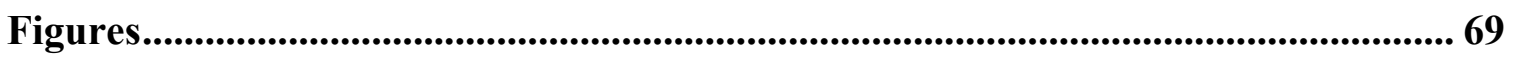

Bibliography ......................................................................................................................... 109 


\section{List of Tables}

Table 1 Sequences of tRNA used in initial thermal stability experiments..................... 67

Table 2 Sequences of tRNA used in TKO in vitro melting study................................ 68 


\section{List of Figures}

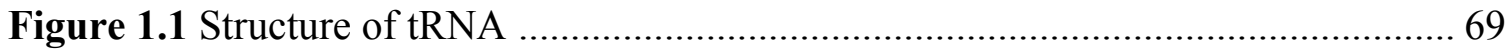

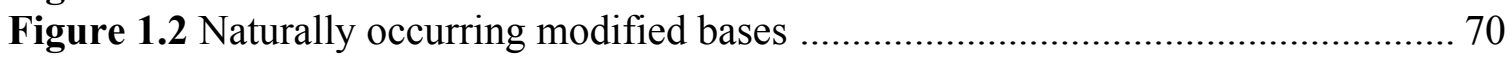

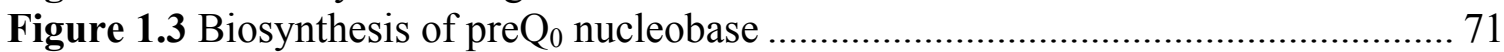

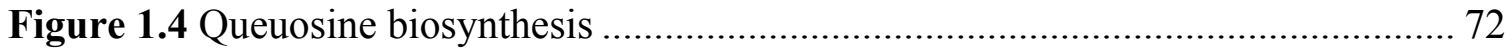

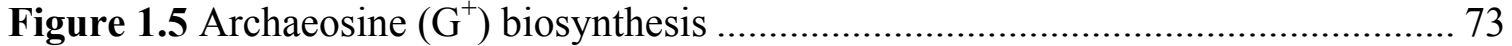

Figure 1.6 Electron density computed for Guanine and modeled $\mathrm{G}^{+}$.......................... 74

Figure 1.7 The positioning of $\mathrm{Mg}^{2+}$ and $\mathrm{Mn}^{2+}$ in the proximity of $\mathrm{N} 7$ in guanine $15 \ldots . .75$

Figure 1.8 Thermal melting of tRNA structure....................................................... 76

Figure 1.9 The de novo synthesis and salvage pathways of NADH …......................... 77

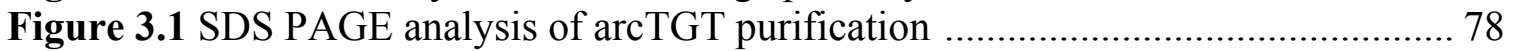

Figure 3.2 SDS PAGE analysis of ArcS purification .................................................. 79

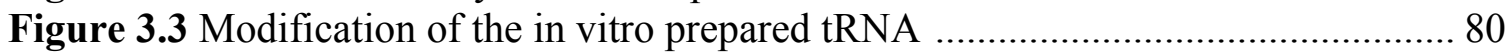

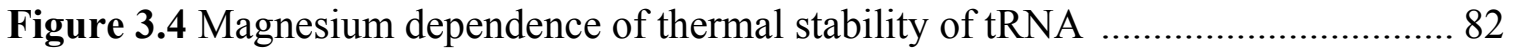

Figure 3.5 Magnesium dependence of thermal stability of tRNA ............................... 84

Figure 3.6 Magnesium binding by fluorescence of HQS.............................................. 85

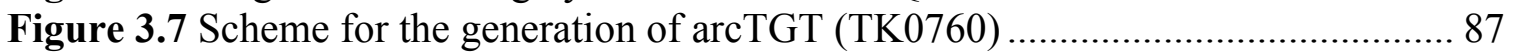

Figure 3.8 Confirmation of knockout in TKO cell line by PCR .................................. 88

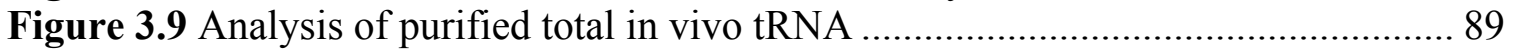

Figure 3.10 Mass spectrometry of the in vivo modified tRNA …............................... 90

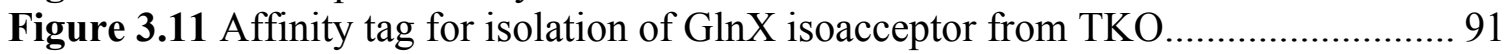

Figure 3.12 Purification of the $\mathrm{Gln} X$ isoacceptors ................................................... 92

Figure 3.13 Confirmation of in vivo isoacceptor purity .......................................... 93

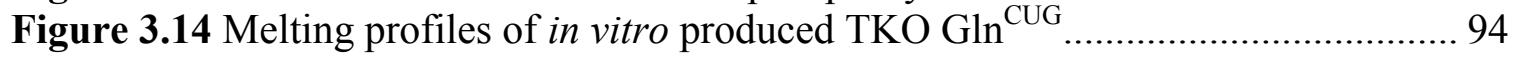

Figure 3.15 Melt profiles of in vivo TKO GlnX isoacceptor tRNA ............................. 95

Figure 3.16 The products of acid treatment of reduced NADPH ................................. 96

Figure 3.17 Time dependence of fluorophore yield ................................................. 97

Figure 3.18 UV spectra of NADPH, NADP ${ }^{+}$and NMN derivatives ............................ 98

Figure 3.19 UV absorbance and fluorescence of isolated fluorophore product.............. 99

Figure 3.20 Determination of quantum yield for the base product ............................ 100

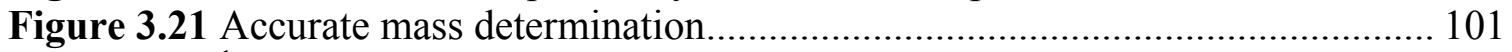

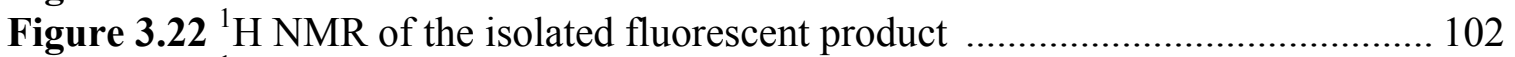

Figure 3.23 ${ }^{1} \mathrm{H}$ NMR of the isolated fluorescent product in basic conditions ............... 103

Figure 3.24 ${ }^{13} \mathrm{C}$ NMR of the isolated fluorescent product ......................................... 104

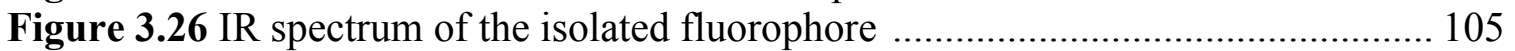

Figure 4.1 Growth phenotype of the T. kodakarensis mutants ................................... 106

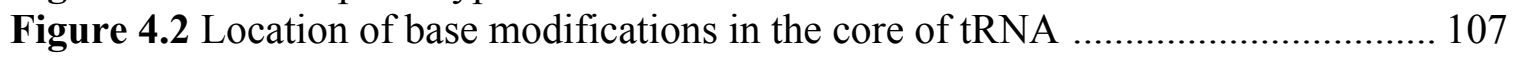

Figure 4.3 Mechanism of base reaction to yield 2-hydroxynicotinaldehyde ............... 108 


\section{Introduction}

The metabolism of nucleic acids is integrated into most regulatory steps of cell proliferation. The process of synthesizing, maintaining and recycling RNA in particular is both highly dynamic and sensitive to the external conditions of the cell. In order to maintain viability under the vast range of condition under which life can persist, strategies capable of adapting fundamental processes such as DNA replication and gene expression have evolved. The archaea are particularly abundant in extreme environments of temperature, $\mathrm{pH}$ and osmotic potential. Modification of archaeal RNAs and the enzymes involved therein have been a source of unique biological chemistries. Here we study the effects of one such modification, archaeosine, found exclusively in the archaea. We also examine the pyridine nucleotide cofactors NADH and the phosphorylated NADPH which are utilized in the biosynthetic pathways involved in RNA metabolism, including base modification.

\section{Transfer RNA}

\section{Structure and primary function}

Transfer RNA, or tRNA, has evolved to serve as the adaptor molecule in converting a nucleic acid based genetic code into an amino acid sequence of a protein gene product. The amino acid to be incorporated into the growing polypeptide is selected for by specific charging of a particular tRNA by an aminoacyl tRNA synthetase. The aminoacyl tRNA (aa-tRNA) product of this reaction is then carried into the translation machinery where it 


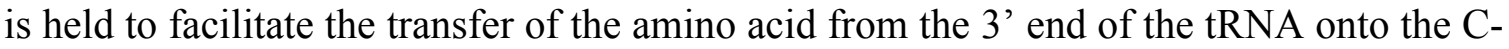
terminus of the growing protein product.

Interactions between macromolecules in the translation process require multiple assembly steps and dynamic contacts. This makes sequence and structure of a given tRNA molecule crucial. Identifiers that ensure the maintenance of fidelity derive from not only nucleotide sequence but also from the correct placement of those nucleotides in space.

Unlike DNA, which is most often found in stable, double stranded form (where every base has a maintained cognate pair), RNA is more likely to be found as a single stranded polymer. This promotes a collapse into a range of more complex secondary and tertiary structures that are grouped into well-defined motifs, often utilizing non-Watson-Crick base pairing ${ }^{1,2}$. Helical regions dominate the modes of interaction, but are punctuated by singlestranded regions, permitting high degrees of flexibility ${ }^{3,4}$. Inter-helical and loop-loop interactions allow for further stabilization and longer-range contacts ${ }^{5}$.

tRNA molecules range from 70-95 bases in length ${ }^{6,7}$. Although there are a large number of codons that must be accounted for by the tRNA molecules, the nature of the interactions within the ribosome means that they must all adopt a very similar general folded structure. The secondary structure of most tRNAs includes four helical regions, allowing tRNA to be represented by a cloverleaf diagram when portraying $2^{\circ}$ structural contacts (Figure 1.1a). The stems are referred to as the acceptor stem (comprised of the 5' and 3' terminal residues and hence the position at which the amino acid is attached during charging), the 
dihydrouridine stem (named for the conserved modification of uridine to the dihydroderivative), the anti-codon stem (the loop formed by this stem contains the 3 base anticodon which base pairs with the codon found in mRNA during translation) and finally the

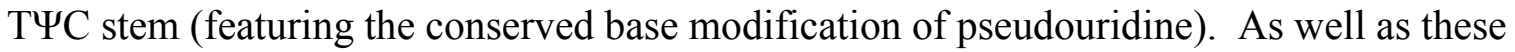
stemloop structures, there is a variable loop which often has no predicted secondary structure contacts, but facilitates the formation of tertiary contacts at the core of the tRNA.

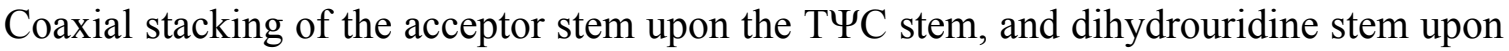
the anti-codon stem, respectively, initiates the native fold of tRNA. Further rearrangement allows these to form the now extensively studied L-form structure of fully folded tRNA associated with normal function (Figure 1.1b).

\section{Secondary roles}

Though the function of tRNA described here is well characterized, alternative roles for these molecules is a significant field in its own right. Regulation of gene expression through control of transcription and translation initiation and processivity have been shown to be dependent on tRNA through numerous mechanisms.

The $\mathrm{T}$ box riboswitch is utilized by Gram-positive bacteria in the 5' UTR to sense levels of aa-tRNA, and so regulating the expression of tRNA synthetase genes based on product levels. This occurs via differential binding to the riboswitch aptamer and effecter regions depending on the presence or absence of the amino acylated tRNA ${ }^{8}$. During active translation, occurrences of mis-incorporation will often lead to stalling of the ribosome. It 
has been shown that a family of tRNA related molecules (tmRNA) are involved in the rescue of the stalled complex, and tagging the incorrectly formed peptide for degradation ${ }^{9}$.

Cleavage of tRNA under oxidative stress and nutritional deprivation induces the production of fragments (cleavage occurs predominantly in the ASL but also in the D-loop and variable loops). These fragments signal various forms of stress response, shutting down proliferation by blocking translation machinery and inducing mRNA degradation by the RISC complex and RNaseZ activity ${ }^{10}$. tRNA fragments appear to be utilized to halt cell growth, but have also been shown to stimulate proliferation. Indeed, tRNA derived fragments were found to make up a significant population (40\%) of small RNAs in a prostate cancer cell line ${ }^{11}$.

In a process reminiscent of the role of tRNAs is translation, tRNA dependent aminoacylation of phospholipid phosphotidylglycerol occurs at the cell membrane of bacteria. The enzyme aa-PGS catalyses the transfer of the amino acid group from the 3' terminus of alanyl-, lysyl-, arginyl- and ornithyl-tRNA to the glycerol group of a phospholipid. These modifications alter the overall charge of the membrane surface, reducing the susceptibility of the bacterium to Cationic Anti-Microbial Peptides ${ }^{12,13}$. It is clear that in all of these roles, the structures adopted by not only intact tRNA but also by tRNA fragments are crucial for correct cellular functions and cell cycle events to be maintained. 


\section{Nucleotide modification in tRNA}

When considering the structure of tRNA and its function, it is important to appreciate the extent to which tRNA molecules are modified to contain non-genetically encoded nucleotides. Variable degrees of modification occur within different tRNAs but they are on the whole the richest source of modified bases of any class of RNA, with a significant number of bases in each RNA being modified in vivo. These changes extend the types of interaction that may occur and so can modulate both the structure and function of a mature RNA compared to the unmodified counterpart.

Of the 109 naturally occurring nucleotide modifications currently identified, 92 of these are found in the tRNA pool ${ }^{14}$, and any given tRNA has $10-25 \%$ of the genetically encoded nucleotides modified $^{7,15}$. The degree to which a given base is modified varies greatly. Simple modifications such as methylation and the $U$ to $\Psi$ isomerisation are often directed by the action of a single enzyme ${ }^{16}$, the substrate nucleotide being defined by its position within the tRNA structure. This is also often the case for $N$-methylation of the four genetically encoded bases that are so modified. $O$-methylation (Figure 1.2) occurring on the ribose moiety will more often occur in a multi-protein/guide RNA complex (also the case in the Cbf5 family of $\psi$-synthases $)^{17}$. The guide RNA will base pair with the RNA to be modified and the enzyme binds to the complex in a manner that places it in close proximity of the substrate nucleotide. 
More complex modifications require multiple enzymatic steps to produce the final biologically relevant modification. The 7-deazaguanosine modified nucleosides archaeosine and queuosine (discussed below) are prime examples of the potential complexity of both the biosynthetic pathways and the biological function of tRNA modification.

Roles for these modifications in tRNA vary greatly and indeed most are still unknown. Of those characterized, there is a significant number occurring in the ASL, with both the wobble position 34 and position 37 being particular hotspots. Since there is such an important role for the wobble position in successful translation and in the regulation thereof, it is not surprising that many modifications have evolved that relate to correct presentation of the anticodon loop to the translation machinery.

One of the only universally conserved modifications occurring in the ACL is N6threonylcarbamoyladenosine (t6A) ${ }^{18}$ (Figure 1.2) which is located at position 37 . It is produced in all domains of life in a multi-enzyme biosynthetic pathway that has recently been elucidated ${ }^{19}$. Already a complex modification it can be further derivatized to the 2methylthio form ${ }^{20,21}$. Both of these can in turn be cyclized to increase the complexity of the modification ${ }^{22}$.

The biosynthesis begins with the formation of threonyl-carbamoyl AMP, from $\mathrm{CO}_{2} / \mathrm{HCO}_{3}$, ATP and threonine by $\mathrm{TsaC} / \mathrm{TsaC} 2$ (bacteria) or Tsc1/Tcs 2 (archaea and 
eukaryotes) ${ }^{23}$. TsaB TsaD and TsaE (or their homologs) will then transfer the threonylcarbomyl moiety specifically on to ANN decoding tRNA in an ATP driven reaction ${ }^{24}$.

The role of the modification itself was elucidated by structural studies of the isolated anticodon loop ${ }^{25}$. The structure of the base in the stem loop adopts a conformation that sets up an effective third heterocycle, stabilized by an internal H-bond between N1 and N11. The threonyl moiety remains relatively unstructured but the added bulk rotates the adenine ring out of range from predicted stacking interactions with U36. Instead of this interaction, it forms cross strand stacking with A1 of the codon it is set to decode.

7-methylguanine (7mG) (Figure 1.2) is well known in the role of capping mRNA transcripts to stabilize and direct the processing of that RNA in eukaryotic translation ${ }^{26,27}$. However, the occurrence of the modification at position 46 of tRNA has a significant influence on the viability of bacterial cells living at high temperature ${ }^{28} . \mathrm{m} 7 \mathrm{G}$ is found in both eukaryal and bacterial tRNA and is generated by methyl transferases trmB homodimer (bacteria), Trm8/82 (yeast) ${ }^{29}$ and hMETTL1/hWDR4 (human) ${ }^{30}$.

The modification itself involves the transfer of a methyl group (SAM dependent) to position 7 of the genetically encoded guanine. A deletion of the trmB gene in $T$. thermophilis was shown to have a growth phenotype when incubated above $70^{\circ} \mathrm{C}$. Analysis of the produced tRNA showed that lack of the trmB gene product not only removed the modification at position 46 , but also produced hypomodification in $\mathrm{m}^{2} \mathrm{G}, \mathrm{m}^{5} \mathrm{U}, \mathrm{m}^{6} \mathrm{~A}$ and $\mathrm{m}^{1} \mathrm{G}$. The melting point of the class I tRNA of this knockout was also found to be lowered 
by $3.5^{\circ} \mathrm{C}$ when the cells were grown at $70^{\circ} \mathrm{C}$ and when grown at higher temperatures, the change was reduced to $-1.2^{\circ} \mathrm{C}$ (transcribed yeast tRNA ${ }^{\text {phe }}$ had no significant change in $T_{m}$ by in vitro methylation). This decrease in thermal stability to is compounded by the increased rate of in vivo degradation of specific tRNA (Phe and Ile). These effects result in loss of translational fidelity and lead to the observed growth phenotype ${ }^{28}$.

Structural information is available regarding the interaction between $7 \mathrm{mG} 46$ and surrounding bases. The crystal structure of tRNA ${ }^{\text {Phe }}$ was solved with the modification in place and it shows a non-canonical base pairing system with G22 $2^{31}$. Hydrogen bonds form between N1(46) and N7(22) and between N2(46) and O6(22) generating a trans WC/Hoogsteen interaction. The bonding has been analysed using molecular modeling and it has been calculated that the methylation confers a stabilizing effect of $-15.12 \mathrm{kJmol}{ }^{-1}$ compared to the unmodified basepair ${ }^{32}$.

\section{Deazaguanine modified nucleobases}

pre $Q_{0}$ biosynthesis

GTP is the first substrate in a series of reactions that create the queuosine and Archaeosine ${ }^{33-35}$ intermediate, preQ $_{0}$ (7-cyano-7-deazaguanine). The first enzyme, GTP cyclohydrolase I (GCYH-I) acts upon GTP to form 7,8-dihydroneopterin-3'-triphosphate, releasing formate $^{36}$. This step is shared with the pterin and folate pathways. The product is then converted to 6-carboxy-5,6,7,8-tetra-hydropterin $\left(\mathrm{CPH}_{4}\right)$ by the enzyme QueD ${ }^{37}$. The next step is a rearrangement performed by QueE generating 7-carboxy-7deazaguanine (CDG), 
the first deaza- moiety in the pathway ${ }^{38}$. The final step is an amido transferase (QueC) reaction, using ammonia as a nitrogen source to create the nitrile of $\mathrm{preQ}_{0}(\text { Figure } 1.3)^{37}$. From this point the biosynthetic pathways diverge for the complete synthesis of $\mathrm{Q}$ and $\mathrm{G}^{+}$.

\section{Queuosine pathway}

In bacteria the free base $\mathrm{preQ}_{0}$ is transformed into 7-aminomethyl-7deazguanine (preQ $\left.\mathrm{Q}_{1}\right)$ by the only known example of a nitrile reductase, $\mathrm{QueF}^{35}$. $\mathrm{PreQ}_{1}$ is integrated into substrate tRNA by the enzyme tRNA-guanine transglycosylase (TGT). This enzyme concomitantly removes the genetically encoded guanine base at position 34 (of those tRNAs with GUN anticodon) and replaces it with preQ ${ }_{1}$. PreQ $Q_{1}$ is the substrate for QueA, an Sadenosylmethionine:tRNA ribosyl transferase isomerase. In the penultimate step of this pathway, the ribosyl moiety from SAM is not only transferred to the aminomethyl of preQ $\mathrm{Q}_{1}$, but it is also isomerized to a carboxylate to give epoxyqueuosine (oQ-tRNA) ${ }^{39}$. The final step in the pathway has been in part solved by the identification of an epoxyqueuosine reductase (QueG) that utilizes cobalamine for the production of queuosine tRNA ${ }^{40}$ (Figure 1.4). Though queuosine is integrated into the tRNA of both bacteria and eukarya, de novo synthesis of the modified nucleotide is only possible in bacterial systems ${ }^{41}$. In eukaryotic systems the free queuine base can be integrated into tRNA by a eukaryotic specific TGT enzyme ${ }^{42}$

\section{Archaeosine pathways}

Unlike the queuosine pathway, the first step to occur in archaea after preQ $\mathrm{Q}_{0}$ synthesis is the direct insertion into substrate tRNA. This occurs in tRNA that feature a genetically encoded 
guanine at position 15. ArcTGT has been shown to perform a similar reaction to bacTGT in which a transglycosylation reaction replaces the genetically encoded guanine with the $\operatorname{preQ}_{0}$ base $^{43,44}$. The conversion of $\mathrm{preQ}_{0}$ to archaeosine was first shown to be performed by the enzyme Archaeosine Synthase (ArcS). This enzyme (isolated from M. jannaschii) has been shown to be an ATP independent amidinotransferase, utilizing glutamine, asparagine or ammonia for direct transfer to the nitrile carbon of $\operatorname{preQ}_{0}{ }^{45}$.

Though this discovery has completed the biosynthetic pathway in species which possess the arcS gene, it is not the case that the enzyme is universally conserved. In those species which do not produce ArcS, two alternative genes have been implicated in this final step ${ }^{46}$. With particular bias toward the Crenarcheota, the genes queF-like and gat-queC have been found to exist either in isolation or in some cases, in combination with arcS. E. coli cells deleted of the queF-like gene, but transformed with a plasmid containing either queF-like or gat-queC were found to produce tRNA modified with $\mathrm{G}^{+}$(Figure 1.5). Furthermore, mass spectrometric analysis of the RNA gave evidence for the modification taking place at position 34, suggesting the activity of bacTGT was still functioning to replace that genetically encoded guanine. The in vitro activity of QueF-Like has since been confirmed to be the generation of archaeosine, acting on preQ ${ }_{0}-\mathrm{tRNA}$ as its substrate ${ }^{47}$. The enzyme has also been tested on free preQ $_{0}$ base which showed no activity. Finally, the enzyme is more selective for the nitrogen source used compared to $\mathrm{ArcS}$ as only ammonia has been shown to be active in this role and no $\mathrm{G}^{+}$was generated when Gln or Asn were used. 


\section{Function of archaeosine}

The modification of $\mathrm{G} 15$ to $\mathrm{G}^{+}$has been shown to be a ubiquitous modification throughout the Archaeal kingdoms except for the unusual species Haloquadratum walsbyi ${ }^{46}$. Since it is absent from the other domains, it suggests that the role of $\mathrm{G}^{+}$is either particular to the Archaea, or its function has been supplanted by an alternative modification in the Bacteria and Eukarya. The location of $\mathrm{G}^{+}$at the very core of the tRNA structure, at the universally conserved Levitt base pair, is also suggestive of a structurally significant role for this modification.

Little information has been gleamed as to how this modification functions in vivo. The nature of archaeosine's role may be in forming enhanced contacts that stabilize a folded RNA against more challenging environmental conditions. In silico studies, founded on the structure of tRNA ${ }^{\text {Phe }}$, have shown that the presence of $\mathrm{G}^{+}$will significantly change the bonding engergies between two bases of the Levitt base pair (Figure 1.6) ${ }^{48}$. The positive charge developed at position 7 on the deazaguanine, is believed to subsume the effects of coordinated metal ions (in the model described, a magnesium is bridged between the N7 and a solvent water oxygen).

This coordinated metal ion also serves as second mode by which the tRNA is stabilized. Metal ions have been found to localize in the pocket between the N7 position and a series of phosphate groups from U7, A14 and G15 itself (Figure 1.7). This dense pocket of negative charge is neutralized by coulombic interactions with the metal ion (has been found 
to be $\mathrm{Mg}^{2+}$ or $\mathrm{Mn}^{2+}$ in crystals structures). The formation of the positively charged center of the formamidino ground of archaeosine, may be making a similar coulombic contribution to the stabilization of the tRNA structure.

In this study we aim to investigate if archaeosine does in fact directly contribute to the stability of tRNA. RNA structural stability is often analyzed by dissecting it in to individual stems, stem loops and junctions that represent components of the overall folded RNA ${ }^{49-51}$. These can then be used to build an ensemble image of both folded structure and dynamic rearrangements that occur during the folding process.

UV absorbance hyperchromicity is one of the most direct methods of tracking the stability of a given RNA. The absorbance of UV light as an RNA unfolds will increase as the molar absorptivity increases. Using combinations of fluorescence, circular dichroism ${ }^{52}$ and various other biophysical techniques ${ }^{53-57}$, the transitions seen in UV melts has been correlated to specific elements of the tRNA falling apart. The first differential plot of change in absorbance per temperature change reveals subpopulations of the structural transitions that are often unclear in the direct melting profile (Figure 1.8). The generalized folding pathway for tRNA established the importance of the interaction between the Dstem and T-stem in holding the native structure together ${ }^{58,59}$. Loss of these structures and intramolecular interactions trigger the complete loss of structure in biologically relevant concentrations of $\mathrm{Mg}^{2+}$, leading to an effective two state model for the unfolding process. 
We plan to use this technique to exam the effect of $\mathrm{G}^{+}$on the stability of in vitro transcribed and modified tRNAs. This will provide a foundation to then study the effects of the modification in the context of in vivo produced tRNA which has been maturated under native cellular conditions and therefore contains all other modifications. Access to knockout cell lines of the archaeaon Thermococcus kodakarensis, allows for the progression of studying the genetically encoded guanine to $\operatorname{pre}_{0}$ and $\mathrm{G}^{+}$by extracting tRNA from cells lacking arcTGT, ArcS or wildtype cells respectively.

\section{$\mathrm{NAD}^{+}$and NADP ${ }^{+}$biosynthesis}

The activity of nicotinamide adenine dinucleotide (NAD) was first shown in an extract of yeast in the early $1900{ }^{\prime 60}{ }^{60}$. A dried extract which showed no independent fermentive activity was able to enhance the rate at which a second yeast extract was able to ferment glucose. This work would contribute to the awarding of the Nobel prize in 1929 to Harden along with Von Euler for their work on coenzyme discovery and the fermentation of carbohydrates. Indeed, von Euler was the first to identify the components of NAD, those being the two ribose units, two phosphate units and one each of the adenine and nicotinamide nucleobases. The involvement of nicotinic acid and its amide derivative in NAD formation were implicated in a feeding study of dogs suffering from pellagra ${ }^{61}$. Within the next twenty years, research had elucidated the complete biosynthetic pathway to NAD and in a double publication both the intermediates involved in the synthesis and the enzymes responsible for the chemistry were laid out ${ }^{62,63}$. 
De novo synthesis of NAD (Figure 1.9) begins with the generation of nicotinic acid mononucleotide $(\mathrm{NaMN})$ which can proceed by two primary routes. Aspartic acid or tryptophan can both be used as the starting reactant, undergoing 2-enzyme or 5-enzyme steps respectively ${ }^{64}$. Both routes yield quinolinate as the immediate precursor which undergoes a phosphoribosyl transfer step generating nicotinic acid mononucleotide $(\mathrm{NaMN})^{65}$. Adenylation of NaMN yields nicotinic acid dinucleotide $(\mathrm{NaAD})^{66}$ and this is the final intermediate before the action of $\mathrm{NAD}^{+}$synthetase generates $\mathrm{NAD}^{+}$using an exogenous supply of nitrogen ${ }^{67}$.

As well as the de novo pathway there are multiple steps at which salvage pathways can be implemented to replenish $\mathrm{NAD}^{+}$levels. The Preiss-Handler pathway established that nicotinic acid can be ribosylated directly to generate NaMN and then move through to $\mathrm{NAD}^{+}$as per the de novo route ${ }^{62,63}$. Nicotinamide released by most of the non-redox related processes of $\mathrm{NAD}^{+}$metabolism is also ribosylated to yield nicotinamide mononucleotide $(\mathrm{NMN})$ and then adenylated to form $\mathrm{NAD}^{+6 \sigma}$. Finally, nicotinamide riboside (NR) has been shown to be regenerated to $\mathrm{NAD}^{+}$by nicotinamide riboside kinase generating nicotinamide mononucleotide which then undergoes an adenyltransferase step to generate $\mathrm{NAD}^{+}$. This process can be performed by a single gene product in some systems by the enzyme nadR ${ }^{68}$.

Although globally the two routes to quinolinate are split between the domains (Asp typical of prokaryotes and Trp largely found in eukaryotes), there is a high degree of interplay within them. There are organisms from all three domains which apparently do not possess 
the genes needed for de novo synthesis. Likewise, there are bacteria that utilize tryptophan ${ }^{64}$ and fungi that metabolize aspartate. Other examples have redundancies that allow for switching between pathways depending on nutrient supply.

The activity of the related cofactor, NADP ${ }^{+}$, was discovered in the 1930s by Warburg and Christian, when an erythrocyte extract and later hepatocyte extract were shown to be able to reduce previously oxidized glutathione ${ }^{69,70}$. The modification to $\mathrm{NADP}^{+}$is a single phosphorylation event at the $2^{\prime}$ position of the adenosyl moiety in $\mathrm{NAD}^{71}$. The $\mathrm{NAD}^{+}$ kinase is conserved through all domains of life and utilizes ATP to transfer the phosphate group on to $\mathrm{NAD}^{+}$. This makes the biosynthesis of $\mathrm{NADP}^{+}$explicitly coupled to the biosynthesis of $\mathrm{NAD}^{+}$.

\section{Roles of $\mathrm{NAD}^{+}$and NADP ${ }^{+}$}

The primary role of both $\mathrm{NAD}^{+}$and $\mathrm{NADP}^{+}$have long been known to be in redox reactions where they act as electron carriers. Their structural similarities lead to them having near identical redox potentials under physiological conditions and therefore, it could appear that there is a redundancy in having these two species active in the cell. However, the need to further modify $\mathrm{NAD}^{+}$to $\mathrm{NADP}^{+}$consumes $\mathrm{ATP}$ and so the energetic requirement alone would suggest that there is a rationale for this redundancy. Upon inspection of the reactions that the two cofactors are involved in, it becomes clear that they are partitioned between anabolic processes $\left(\mathrm{NADP}^{+}\right)$and the oxidative processes for generating ATP $\left(\mathrm{NAD}^{+}\right)$. The phosphate group, held significantly away from the redox center, allows for the cofactors to 
have different binding modes. Within the cell, in order to help drive these two different directions of reactivity, $\mathrm{NAD}(\mathrm{H})$ is held in an excess of the oxidized form and likewise, $\mathrm{NADP}(\mathrm{H})$ is largely in the reduced $\left(\mathrm{NAD}^{+}: \mathrm{NADH}\right.$ in humans has been measured to be as high as $1820 ; \mathrm{NADP}^{+}$:NADPH can be as low as 0.017$)^{72}$.

Due to the fundamental nature of the reactions that these cofactors are utilized by, they have been studied extensively in their role as redox partners for vast numbers of reactions in all domains of life (2200 of the reactions described on the KEGG database employ NAD ${ }^{+}$ or $\left.\mathrm{NADP}^{+}\right)^{73}$. It has also been determined that both $\mathrm{NAD}^{+}$and $\mathrm{NADP}^{+}$are involved in more diverse reactions that take them beyond simple cofactors. It expands their role to cell signaling and direct protein modification which brings in to play modulation of activity.

Both $\mathrm{NAD}^{+}$and $\mathrm{NADP}^{+}$can be processed to form secondary messengers. $\mathrm{NAD}^{+}$is acted on by ADP-ribosyl cyclase to generate cyclic-ADP ribose (cADPR), with the elimination of nicotinamide. It has been shown that an increase in the cellular concentration of this molecule (from endogenous synthesis and import) results in activation of the ryanodine receptor channel on the endoplasmic reticulum and so increases cytosolic $\mathrm{Ca}^{2+}$ concentration. There is also activation of cell membrane channels to increase import of $\mathrm{Ca}^{2+}$ ions. This is mirrored in the activity of the $\mathrm{NADP}^{+}$metabolite (again with the release of nicotinamide) nicotinic acid ADP, which causes a release of $\mathrm{Ca}^{2+}$ ions from lysozyme related organelles, as well as the ER and activation of the same membrane channels as cADPR. A third calcium mobilizing signal cascade is facilitated by $\mathrm{NAD}^{+}$consuming reactions. ADPR is able to upregulate calcium import by the TRMP2 channel. ADPR is 
synthesized by multiple routes but can be produced by the direct hydrolysis of $\mathrm{NAD}^{+}$with release of the nicotinamide moiety ${ }^{74,75}$.

A second route by which ADPR is generated is by the activity of the PARP enzymes that are responsible for the maintenance of genome integrity in the nucleus. PARP or polyADPribose polymerase, use ADP-ribose to flag sites of single strand breaks in DNA. Proteins in proximity to the break are modified by poly-ADP ribosylation, using $\mathrm{NAD}^{+}$as the source of the ADPR. Upon break down of this polymer, ADPR is released and this is translocated in to the cytosol where its effects are described above ${ }^{76}$.

Finally, one of the more recent roles of $\mathrm{NAD}^{+}$is in the activity of sirtuins. $\mathrm{NAD}^{+}$is utilized by this universally conserved family of regulatory enzymes to deacetylate proteins that have previously been modified to feature acetyl lysine. $\mathrm{NAD}^{+}$is consumed, releasing nicotinamide, along with $O$-acetyl-ADP ribose. Along with the deacetylase activity, some members of the sirtuin families have also been shown to exhibit mono-ADP ribosylation activity where the ADPR moiety is connected to the substrate protein via a bond to $\mathrm{C}^{77}$, ${ }^{78}$. However, the rates of these reactions is found to be several orders of magnitude lower than the deacetylation reaction, and so it may be that the ribosyltransferase is merely a side reaction. This notwithstanding, the activity of sirtuins implicates $\mathrm{NAD}^{+}$in the regulation of inflammatory response, apoptosis, glucose homeostasis, and the cellular stress responses. 


\section{Determination of NAD ${ }^{+}$and NADP $^{+}$concentration}

During the studies of these systems, there is an inherent need to obtain to determine the concentration of the cofactors at a given point in a reaction being studied. Luckily, given the nucleobase component of the molecules, there is significant absorbance within the UV spectrum and the redox state of the cofactors results in a significantly different absorbance spectrum. Both forms of $\mathrm{NAD}(\mathrm{P})$ show a strong absorbance peak centered at $260 \mathrm{~nm}$. However, the reduced form alone has a second significant peak centered at $340 \mathrm{~nm}$. This is true for both NADH and NADPH. The extinction coefficient for this $340 \mathrm{~nm}$ peak is well characterized as being $6.22 \times 10^{3} \mathrm{~cm}^{-1} \mathrm{M}^{-1}$. This permits the trajectory of an NAD(P) dependent reactions to be followed by either loss or appearance of this peak. ${ }^{79}$

Use of the absorbance is limited to instrumental sensitivity. This can be overcome thanks to a phenomenon where by treatment of $\mathrm{NAD}(\mathrm{P})^{+}$with strong base can generate a degradation product which is fluorescent. This was initially observed in the analog molecules diphosphopyridine nucleotide and methyl nicotinamide, where treatment with $5 \mathrm{~N} \mathrm{KOH}$ would yield a fluorogenic product with varied fluorescence yields ${ }^{80}$. This treatment was found to be applicable to the $\mathrm{NAD}(\mathrm{P})^{+}$systems and so a work up method was established that allowed for robust quantitation of trace amount of $\mathrm{NAD}(\mathrm{P})^{+}$in a background of high NAD(P)H.

This section of work initially aims to reappraise the conditions used in this standard assay. The conditions have remained unchanged since those proposed in the 1950s and though it 
is robust and consistent, it has not been investigated as to whether these can be improved upon for working up $\mathrm{NAD}^{+}$or $\mathrm{NADP}^{+}$. We also aim to finally confirm the identity of the fluorescent species produced in the assay using these biological cofactors. The fluorophore is usually measured in the background of other assay components, and so a purification strategy will be employed to identify the fluorophore using standard spectroscopic and spectrometric techniques for small molecules. 


\section{Materials and Methods}

\section{Chemicals and Reagents}

Buffers and salts of the highest grade available were purchased from Sigma unless otherwise noted. DEPC (diethylpyrocarbonate) treated water was used for all solutions used for RNA related assays ${ }^{81}$. All buffers and solutions were otherwise prepared with Millipore MQ grade water. Dithiothreitol (DTT), isopropyl- $\beta$-D-thiogalacto-pyranoside (IPTG), kanamycin sulfate, DEPC and ampicillin were purchased from RPI Corporation. The radiochemicals $\left[8-{ }^{14} \mathrm{C}\right]$-guanine and $\left[\mathrm{U}_{-}{ }^{14} \mathrm{C}\right]$-L-glutamine were purchased from Perkin Elmer. Adenosine, guanosine, ATP, GTP, UTP, CTP were all purchased from Sigma. Nickel- nitrile tetraacetic acid $\left(\mathrm{Ni}^{2+}-\mathrm{NTA}\right)$ was purchased from Qiagen and Sigma. Whatman GF-B filter disks were purchased from Fisher. Amicon centrifugal concentrators were from Millipore. Dialysis tubing was obtained from Pierce. Plasmid Mini-Kits were from Fermentas and Qiagen. Oligonucleotides were obtained from IDT. All reagents for SDS-PAGE were purchased from BioRad. SDS-PAGE analysis was carried out using 12 \% (29:1 Acryl:Bisacrylamide) gels and visualized with Coomassie Brilliant Blue. DNA sequencing was carried out by the OHSU core facility in the Department of Molecular Microbiology and Immunology. The substrate preQ $_{0}$ was synthesized as described previously and purified by reverse phase HPLC and stored at room temperature in $\mathrm{DMSO}^{82}$. ß-Nicotinamide mononucleotide (NMN) was obtained from Sigma-Aldrich. Both $ß$-nicotinamide adenine dinucleotide $\left(\mathrm{NAD}^{+}\right)$and the phosphorylated form (NADP ${ }^{+}$) were obtained from RPI Corporation. Sodium hydroxide, hydrochloric acid, sulfuric acid, 
ammonium acetate and acetonitrile were purchased from Fisher. Quinine sulfate was obtained from AnaSpec Inc. Deuterated solvents (water and sodium hydroxide) were obtained from Sigma-Aldrich.

\section{Instrumentation}

Analytical HPLC was performed on an Agilent 1100 series HPLC (G1312A binary pump, G1315A diode array detector). Preparative scale separation was achieved using a Hitachi HPLC (L-6200 pump and L-4000 single wavelength detector). Rapid fluorescence screening was performed using a Gemini XPS microplate reader from Molecular Dynamics. Steady state fluorescence was carried out using a Quantamaster 400 from Photon Technologies International. UV-Vis spectroscopy was carried out on a Varian Cary 100 Bio spectrophotometer fitted with a thermostatted multi-cell holder. Mass spectrometry was performed on a ThermoElectron LTQ-Orbitrap Discovery high resolution mass spectrometer with a dedicated Accela HPLC system utilizing ESI in the Department of Chemistry at Portland State University. NMR studies were performed on either $400 \mathrm{~Hz}$ or $600 \mathrm{~Hz}$ Brüker instruments belonging to the Department of Chemistry at Portland State University. Infrared spectroscopy was carried out on a Nicolet iS10 spectrometer using a diamond ATR attachment. 


\section{In vitro RNA preparation}

\section{Template preparation}

Double stranded template DNA was prepared from two DNA primers which were designed with a ten base pair overlap at the center of the target sequence ${ }^{83}$. The native gene sequence was supplemented with the standard T7 promoter (5'TAATACGACTCACTATA3') at the 5 ' end of the upper oligo. The complete template is generated by primer extension using the Klenow fragment (Fermentas) to create two fully complementary strands. The two oligos are mixed to a final concentration of $4 \mu \mathrm{M}$ each, in the presence of dNTPs $(600 \mu \mathrm{M}$ each) and using the manufacturers reaction conditions. The primers are extended by cycling 25 times between $37^{\circ} \mathrm{C}$ and $10^{\circ} \mathrm{C}$ in 30 second pulses (Applied Biosystems 2720 thermal cycler). The DNA was then extracted by phenol chloroform extraction (equal volume of 25Phenol:24Chloroform:1 Isoamyl alcohol vortexed and then centrifuged at $13000 \mathrm{rpm}$ for 5 minutes) and ethanol precipitation of the aqueous phase. The template was then resuspended in water at $10 \mu \mathrm{M}$.

\section{Overexpression and purification of T7 RNA polymerase}

The del172-73 mutant of T7 RNA polymerase was prepared by the overexpression of a 6His-tagged clone provided by Dr John Perona. Frozen cell stock (E. coli BL21(DE3)) was grown on $200 \mu \mathrm{g} / \mathrm{mL}$ ampicilin agar plate and a fresh colony picked to start a liquid culture. Cells were grown in LB with $200 \mu \mathrm{g} / \mathrm{mL}$ ampicilin and raised to an OD of $\sim 0.9$ at $37^{\circ} \mathrm{C}$ with shaking at $220 \mathrm{rpm}$. Expression was carried out at RT with induction occurring upon the addition of IPTG to a final concentration of $0.5 \mathrm{mM}$ and growth occurring overnight. 
Cells were harvested by centrifugation at $5000 \mathrm{rpm}$ (Sorval SLC-4000) and homogenously mixed in buffer (100 mM Phosphate (pH 7.5), $100 \mathrm{mM} \mathrm{NaCl}, 1 \mathrm{mM} \beta$-ME, $200 \mu \mathrm{M}$ PMSF). To this was adeed Lysozyme (to $1 \mathrm{mg} / \mathrm{mL}$ ), and incubated for 20 minutes at $37^{\circ} \mathrm{C}$ to breakdown cell wall before three rounds of $-80^{\circ} \mathrm{C}$ freeze/thaw to lyse cell membranes. Fully lysed cells are treated with DNaseI $(20 \mu \mathrm{g} / \mathrm{mL})$ and the lysate clarified by centrifugation at $15000 \mathrm{rpm}$ (Sorval SS-34) for 20 minutes at $4^{\circ} \mathrm{C}$. Cell free extract was loaded on to a Ni-NTA resin column, pre-equilibrated with $100 \mathrm{mM}$ Phosphate (pH 7.5), $100 \mathrm{mM} \mathrm{NaCl}, 1 \mathrm{mM} \beta$-ME. Non-bound proteins were washed off with 10 column volumes and then fractions were eluted with a stepwise gradient of 10, 20, 50 and $200 \mathrm{mM}$ imidazole. The target protein elutes with some contaminating proteins and so the $200 \mathrm{mM}$ fraction was dialysed (100 mM Phosphate (pH 7.5), $100 \mathrm{mM} \mathrm{NaCl}, 1 \mathrm{mM} \beta$-ME overnight at $4^{\circ} \mathrm{C}$ using snake skin dialysis membrane) to remove the imidazole present and then run through a Heparin column (GE Healthcare, HiTRAPP, $5 \mathrm{~mL}$ ), the cleaned protein eluting at $600 \mathrm{mM} \mathrm{NaCl}$ on a linear gradient. The protein was dialysed (overnight at $4^{\circ} \mathrm{C}$ ) and stored in $100 \mathrm{mM}$ Phosphate, $100 \mathrm{mM} \mathrm{NaCl}, 1 \mathrm{mM} \beta$-ME, 25\% glycerol and stored at $80^{\circ} \mathrm{C}$.

\section{Transcription reactions}

RNA molecules were transcribed from $1 \mu \mathrm{M}$ DNA template in $30 \mathrm{mM}$ Tris- $\mathrm{HCl}(\mathrm{pH} 8.0)$, 40mM $\mathrm{MgCl}_{2}, 10 \mathrm{mM}$ DTT, $0.1 \%$ Triton X-100, $100 \mu \mathrm{M}$ spermidine, $2.5 \mathrm{mM}$ NTP (individual nucleotides obtained from Sigma, stock made up in DEPC water and stored at $\left.-80^{\circ} \mathrm{C}\right), 50 \mu \mathrm{g} / \mathrm{mL}$ of $\mathrm{T} 7 \mathrm{RNA}$ polymerase and $1 \mathrm{U} / \mathrm{mL}$ of inorganic pyrophosphatase (Sigma). The reactions are run for $4 \mathrm{hrs}$ at $37^{\circ} \mathrm{C}$ and quenched by ethanol precipitation. The 
recovered pellet was solubilized in DEPC water and then mixed with an equal volume of formamide $/ 5 \mathrm{mM}$ EDTA. The reaction products were denatured at $95^{\circ} \mathrm{C}$ and then separated by denaturing urea PAGE (7M urea, 10\% acrylaminde, $1 \mathrm{x}$ TBE, gel run at $18 \mathrm{~W}$ ). The full length product band is excised from the gel and the RNA extracted by overnight crush and soak in to $800 \mathrm{mM}$ ammonium acetate. The purified RNA was then precipitated and the pellet resuspended in $1 \mathrm{mM}$ sodium citrate and stored at $-80^{\circ} \mathrm{C}$.

\section{RNA modification enzyme expression and purification and use}

\section{ArcTGT expression}

The tRNA-Glycosyl Transferase gene from M. jannaschii had been previously cloned in to $\mathrm{pET} 30$, providing a 6-His fusion protein for expression in BL21 (DE3) E. coli cells. The vector confers kanamycin resistance and so cells were grown in $\mathrm{LB}(\mathrm{pH}$ 7.5) with kanamycin at $50 \mu \mathrm{g} / \mathrm{mL}$, to an $\mathrm{OD}$ of approximately 0.9 at $37^{\circ} \mathrm{C}$. Expression of the fusion protein is induced by addition of IPTG to a final concentration of $1 \mathrm{mM}$. Induction occurred at $37^{\circ} \mathrm{C}$ for around 6 hours and resultant cells were harvested by centrifugation at $5000 \mathrm{rpm}$ (Sorval SLC-4000) for 15 minutes. These were resuspended in lysis buffer (50 mM Tris$\mathrm{HCl}$ at $\mathrm{pH} 8.0,300 \mathrm{mM} \mathrm{NaCl}, 1 \mathrm{mM} \beta-\mathrm{ME}, 200 \mu \mathrm{M}$ PMSF, $1 \mathrm{mg} / \mathrm{mL}$ lysozyme) and incubated at $37^{\circ} \mathrm{C}$ for 20 minutes before being put through three cycles of freeze thaw to lyse. DNase I ( $20 \mu \mathrm{g} / \mathrm{mL})$ treatment followed by centrifugation ( $15000 \mathrm{rpm}$ for 15 minutes in a Sorval SS-34 rotor) generates a cleared lysate that can be passed over a Ni-NTA column for affinity chromatography of the target enzyme. The protein elutes at $50 \mathrm{mM}$ 
imidazole from a stepwise gradient $(0,10,50$ and $200 \mathrm{mM})$. The appropriate fraction is collected, concentrated and dialysed in to storage buffer.

\section{ArcS expression}

Archaeosine synthase from $M$. jannaschii had previously been cloned in to a range of plasmids, but for all expression in this work the clone is in pET32-Xa. This provides a thioredoxin domain at the $\mathrm{N}$-terminus to assist in the folding process. Expression of the protein requires it be transformed into Rosetta (DE3) E. coli. These cells were grown in LB supplemented with kanamycin $(50 \mu \mathrm{g} / \mathrm{mL})$, sorbitol $(0.5 \mathrm{M})$ and betaine $(5 \mathrm{mM})$ at $37^{\circ} \mathrm{C}$. At an OD of approximately 0.9 the cells were induced to express with IPTG at a final concentration of $0.25 \mathrm{mM}$. Induction was carried out at room temperature for 8 hours. The cells were harvested by centrifugation at $5000 \mathrm{rpm}$ (Sorval SLC-4000). Cells are resuspended in lysis buffer (100 mM HEPES pH 7.0, $500 \mathrm{mM} \mathrm{NaCl}, 1 \mathrm{mM} \beta$-ME and 200 $\mu \mathrm{M}$ PMSF). Cells are then incubated with lysozyme $(1 \mathrm{mg} / \mathrm{mL})$ and freeze thaw cycles used to lyse cells. Lysate was cleared by centrifugation at 15000rpm (Sorval SS-34 rotor) for 15 minutes. The enzyme was obtained by passing the protein suspension over a $\mathrm{Ni}$ NTA column isolating the 6His-TRX-ArcS fusion. Elution occurs at $50 \mathrm{mM}$ imidazole and the fraction was collected before being concentrated, dialysed into imidazole free buffer. Factor Xa was added so that $1 \mu \mathrm{g}$ was present for every milligram of fusion protein. The tag is removed by running back over a column of nickel resin to which the cleaved protein no longer binds. The protein is concentrated and dialysed in to storage buffer $(100 \mathrm{mM}$ HEPES pH 7.0, $500 \mathrm{mM} \mathrm{NaCl}, 1 \mathrm{mM} \beta$-ME, $25 \%$ glycerol) and kept at $-80^{\circ} \mathrm{C}$. 


\section{Preparation of pre $Q_{0} t R N A s$}

All appropriate tRNAs were modified to feature $\mathrm{preQ}_{0}$ base by the action of arcTGT. Standard reaction conditions were $50 \mathrm{mM}$ succinate (pH 5.5), $20 \mathrm{mM} \mathrm{MgCl} 2,100 \mathrm{mM}$ $\mathrm{KCl}, 2 \mathrm{mM}$ DTT, $100 \mu \mathrm{M}$ tRNA and $1 \mathrm{mM} \mathrm{preQ}_{0}{ }^{45}$. RNA was heated at $80^{\circ} \mathrm{C}$ for 3 minutes before adding in ArcTGT to a final concentration of $10 \mu \mathrm{M}$ and incubating for a period long enough to ensure complete incorporation. Activity of the enzyme was assayed by reacting the RNA with the enzyme in the presence of ${ }^{14} \mathrm{C}$-Guanine in place of the preQ $\mathrm{Q}_{0}$ native substrate. Incorporation of radionuclide was determined by scintillation counting of ethanol precipitated RNA trapped on glass fiber filter papers. The reaction was terminated by the addition of $1 / 10^{\text {th }}$ volume of $8 \mathrm{M}$ ammonium acetate. Reaction components were removed by phenol/chloroform extraction, and the aqueous phase precipitated by the addition of two volumes of ethanol. The reaction was repeated for two more rounds of incorporation to ensure complete integration of preQ $_{0}$ base.

\section{Preparation of $G^{+} t R N A s$}

The modification to Archaeosine tRNA was produced by the enzyme ArcS. Previously modified preQ ${ }_{0}$-tRNA is suspended $(50 \mu \mathrm{M})$ in $100 \mathrm{mM}$ HEPES (pH 7.0), $0.5 \mathrm{M} \mathrm{NaCl}, 20$ $\mathrm{mM} \mathrm{MgCl} 2,5 \mathrm{mM}$ Glutamine, $1 \mathrm{mM}$ DTT with $10 \mu \mathrm{M}$ ArcS. The sample was reacted for 1 hour at $40^{\circ} \mathrm{C}$. The modified RNA was isolated by ethanol precipitation using $800 \mathrm{mM}$ $\mathrm{NH}_{4} \mathrm{OAc}$, quenching reaction and removing the other reaction components 


\section{Thermococcus kodakarensis culture}

\section{Media preparation}

Stock solutions $(500 \mathrm{x})$ were prepared for both vitamins and trace elements. The components and end concentrations of these are; vitamin mix $(8 \mu \mathrm{M}$ biotin, $5 \mu \mathrm{M}$ folic acid, $50 \mu \mathrm{M}$ pyridoxine, $15 \mu \mathrm{M}$ thiamine, $15 \mu \mathrm{M}$ riboflavin, $40 \mu \mathrm{M}$ nicotinic acid, $20 \mu \mathrm{M}$ Ca-pantothenate, $7 \mu \mathrm{M}$ p-aminobenzoic acid and $75 \mathrm{nM} \mathrm{B12})$ and trace minerals $(50 \mu \mathrm{M}$ $\mathrm{FeCl}_{3}, 5 \mu \mathrm{M} \mathrm{MnCl}_{2}, 18.5 \mu \mathrm{M} \mathrm{CoCl}_{2}, 7 \mu \mathrm{M} \mathrm{CaCl}_{2}, 7.5 \mu \mathrm{M} \mathrm{ZnCl}, 1.5 \mu \mathrm{M} \mathrm{CuCl}_{2}, 1.6 \mu \mathrm{M}$ $\left.\mathrm{H}_{3} \mathrm{BO}_{3}, 1 \mu \mathrm{M}\left(\mathrm{NH}_{4}\right)_{2} \mathrm{MoO}_{4}, 5 \mu \mathrm{M} \mathrm{NiCl}_{2}, 850 \mathrm{nM} \mathrm{NaSeO}_{4}, 2 \mu \mathrm{M} \mathrm{AlCl}_{3}\right)$.

Additional components per liter of growth medium:

Yeast extract (2.5g), tryptone (2.5g), $\mathrm{NaCl}(10.2 \mathrm{~g}), \mathrm{MgCl}_{2} .6 \mathrm{H}_{2} \mathrm{O}(2.4 \mathrm{~g}), \mathrm{MgSO}_{4}(0.8 \mathrm{~g})$, $\mathrm{CaCl}_{2} .2 \mathrm{H}_{2} \mathrm{O}(0.4 \mathrm{~g}), \mathrm{KCl}(0.3 \mathrm{~g})$, sodium pyruvate $(2.5 \mathrm{~g})$, agmatine sulfate $(0.6 \mathrm{~g})$.

Media is prepared under $\mathrm{N}_{2}$ to remove all dissolved $\mathrm{O}_{2}$ (resazurin added to $1 \mathrm{mg} / \mathrm{L}$ ) and autoclaved to sterilize. Before inoculation the head gas was exchanged for 80:20 N $\mathrm{N}_{2} / \mathrm{CO}_{2}$ to 10 psi. To ensure fully anaerobic conditions, the growth media was spiked with further $\mathrm{Na}_{2} \mathrm{~S}$ (from a $2.5 \% \mathrm{w} / \mathrm{v}$ stock) until resazurin remained colourless.

\section{Cell growth}

Starter cultures were grown at $60^{\circ} \mathrm{C}$ overnight in $10 \mathrm{~mL}$ cultures in Huntgate tubes with a 1 $\mathrm{mL}$ inoculation from stock culture. The cells were then grown in 1 litre culture volumes. The media and starter culture were brought to target growth temperature before the entire 
starter culture was transferred to the larger flask and cells allowed to grow for at least 16 hours.

\section{Confirmation of knockdown by PCR of genomic material}

Harvested cells were resuspended in $50 \mathrm{mM}$ Tris. $\mathrm{HCl}$ at $\mathrm{pH} 8.0$. The cells are melted by pheno/chloroform extraction. The genomic material is isolated by collecting the extraction aqueous supernatant and adding $1 / 10^{\text {th }}$ volume of $8 \mathrm{M}$ ammonium acetate and 2 volumes of cold ethanol. The genomic DNA is removed by sterilized glass rod and transferred in to $50 \mathrm{mM}$ TE. Primers used for amplification of the genes (Table) were provided by the Santangelo group and were designed to anneal upstream and downstream of the gene itself, producing bands larger than the gene if it is intact, and greatly reduced in size if it has been removed. PCR was performed using Phusion DNA polymerase (Thermo) with standard manufacturers reaction conditions and performing 25 rounds of amplification at $55^{\circ} \mathrm{C}$ annealing temperature (15 seconds) and extension at $72^{\circ} \mathrm{C}$ (90 seconds). Reactions were separated on a $0.6 \%$ agarose gel in TEAE buffer with ethidium bromide for visualization by transillumination.

\section{In vivo $t R N A$ extraction}

Incubation of whole T. kodakarensis cells from culture with phenol:choloroform:IAA $(25: 24: 1)$ is sufficient to release cell contents. In order to help separate protein, lipid and DNA from the bulk RNA species, the cells are first suspended in $100 \mathrm{mM}$ ammonium acetate (pH6.5) with $10 \mathrm{mM} \mathrm{MgSO}_{4}$ and $0.1 \mathrm{mM}$ EDTA. Upon addition of saturated phenol mix RNA remains in the aqueous phase and most other components move to the organic 
phase following centrifugation. The bulk RNA is precipitated by adding $1 / 10^{\text {th }}$ the volume of $8 \mathrm{M}$ ammonium acetate and two volumes of ethanol and cooling to $-20^{\circ} \mathrm{C}$ for two hours. The precipitated RNA is pelleted by centrifugation at $15000 \mathrm{rpm}$ (Sorval SS-34 rotor) for 25 minutes at $4{ }^{\circ} \mathrm{C}$. The pellet is resuspended in $100 \mathrm{mM}$ ammonium acetate $(\mathrm{pH} 6.5)$ with $10 \mathrm{mM} \mathrm{MgSO}_{4}$ and $0.1 \mathrm{mM}$ EDTA, an equal volume of $8 \mathrm{M} \mathrm{LiCl}$ was added and the mix cooled at $4{ }^{\circ} \mathrm{C}$ overnight. Precipitated rRNA species were removed by centrifugation, followed by tRNA precipitation with the addition of ammonium acetate/ethanol as above.

\section{Isolation of tRNA for mass spectrometric anaylsis}

Total RNA was extracted as above, however to prepare total tRNA for MS analysis solid phase extraction was employed to reduce the counter ion species present. Nucleobond RNA/DNA 400 columns (Macherey-Nagel) were employed to separate high mass RNA molecules and total tRNA. Pelleted total tRNA was suspended in the appropriate buffer according to the manufacturers guidelines. The fractionation is based on a step gradient of salt concentration with tRNA eluting in $0.65 \mathrm{M} \mathrm{KCl}$ and higher mass molecules eluting in $1.15 \mathrm{M} \mathrm{KCl}$. The RNA population in sub-fractions were confirmed by urea PAGE. The isolated tRNA is precipitated in $800 \mathrm{mM}$ ammonium acetate/ethanol. This is repeated three times to substitute the $\mathrm{K}^{+}$for ammonium ions. The sample was then dried and sent to the Limbach lab for analysis (University of Cincinnati).

\section{Isolation of isoacceptor $t R N A$}

The Gln isoacceptors for T. kodakarensis were isolated by affinity purification from the total tRNA pool. Streptavidin agarose (Thermo Scientific) was loaded with a biotinylated 
DNA oligo that complements a particular stretch of the target tRNA sequence. The resin was activated by binding the biotinylated oligo to the streptavidin (oligo at $15 \mu \mathrm{M}$ in $10 \mathrm{mM}$ Tris- $\mathrm{HCl}(7.5), 100 \mathrm{mM} \mathrm{NaCl})$. For annealing of the tRNA to the immobilized DNA, the total tRNA is dissolved in annealing buffer (10mM Tris- $\mathrm{HCl}(7.5), 900 \mathrm{mM} \mathrm{NaCl}, 1 \mathrm{mM}$ EDTA) and heated to $95^{\circ} \mathrm{C}$ for 5 minutes. After cooling to $85^{\circ} \mathrm{C}$ the resin (pre-equilibrated in annealing buffer) is added and the slurry is allowed to fully cool to room temperature with occasional mixing. The unbound RNA is removed by centrifugation and washing with elution buffer (10mmM Tris- $\mathrm{HCl}(7.5), 100 \mathrm{mM} \mathrm{NaCl})$ until OD260 was below $0.01 / \mathrm{mL}$. Elution was achieved by re-suspending the resin in $0.5 \mathrm{ml}$ of elution buffer and heating to $75^{\circ} \mathrm{C}$ for 5 minutes before centrifuging to collect the Glx tRNA.

\section{Biophysical analyses}

\section{UV melting studies}

All thermal denaturation studies were performed on the Cary 100 Bio UV-Vis spectrophotometer. Single wavelength absorbance was used to record the unfolding of the tRNA species being studied. Temperature was adjusted by a thermostatted cell block holder under peltier control. The thermal melt cycle was controlled by the Thermal program in the Cary Win UV software suite. Samples were prepared in $10 \mathrm{mM}$ sodium cacodylate at $\mathrm{pH}$ 7.0 with a background of $100 \mathrm{mM} \mathrm{NaCl}$. This was supplemented with either EDTA or $\mathrm{MgCl}_{2}$ where indicated. RNA was slow cooled from $98^{\circ} \mathrm{C}$ to $55^{\circ} \mathrm{C}$, at which point the sample was spiked with the additives mentioned previously and allowed to cool down to room temperature. During analysis, sample volume $(120 \mu \mathrm{L})$ is covered with mineral oil to 
prevent evaporation. The sample is monitored at $260 \mathrm{~nm}$ during the melt and the $\mathrm{T}_{\mathrm{m}}$ determined by performing the first derivative of the absorbance value.

\section{Magnesium binding}

In these experiments competition is set up between the binding affinity of the folded RNA for $\mathrm{Mg}^{2+}$ ions and that of the fluorescent molecule HydroxyQuinoline-5-Sulphonic acid (HQS). The dye was prepared by recrystalisation from boiling conc. hydrochloric acid (repeated six times). All solutions were prepared from Chelex treated deionized water to minimize metal ion contamination and stock buffers were kept with aliquots of resin to maintain this. The dye was quantified and diluted to $25 \mu \mathrm{M}$ in $10 \mathrm{mM}$ Sodium cacodylate pH 7.0, $100 \mathrm{mM} \mathrm{NaCl}, 10 \mu \mathrm{M}$ EDTA and kept at $37^{\circ} \mathrm{C}$. Magnesium chloride stocks were prepared from high grade salt and the concentration of an approximate $2 \mathrm{M}$ stock was accurately determined by back titration with EDTA. The dye solution was transferred to a quartz fluorescence cell and the signal at $550 \mathrm{~nm}$ (excitation at $395 \mathrm{~nm}$ ) recorded upon addition of magnesium chloride in minimal volume steps. The titration was then repeated in the presence of $25 \mu \mathrm{M}$ natively folded tRNA (purification of RNA in TE buffer effectively removes divalents and refolding was performed with sodium chloride as described previously)

\section{HPLC analysis}

All HPLC steps were performed on Agilent 100 system fitted with a multiwavelength diode array detector. Analytical work was performed on Gemini columns, either small scale (5 $\left.\mu \mathrm{m} \mathrm{C18}, 30 \times 4.6 \mathrm{~mm} ; 1.0 \mathrm{mLmin}^{-1}\right)$, or full analytic resolution $(5 \mu \mathrm{m} \mathrm{C} 18,250 \times 4.6 \mathrm{~mm}$; 
$0.3 \mathrm{mLmin}^{-1}$ ) both from Phenomenex. Large scale purification used a Luna column (5 $\mu \mathrm{m}$ $\mathrm{C} 18,250 \times 10 \mathrm{~mm} ; 3.0 \mathrm{mLmin}^{-1}$ ) from Phenomenex. All solutions were prepared in MQ water and using HPLC grade salts and solvents.

Preparation of nucleoside digest of tRNA samples begins by dissolving the sample in water. $100 \mu \mathrm{g}$ of RNA are adjusted for the first step by addition of $1 / 10^{\text {th }}$ volume of $100 \mathrm{mM}$ sodium acetate at $\mathrm{pH}$ 5.5. Nuclease P1 (Penicillium citrinum from Sigma) is added at $0.5 \mu \mathrm{g}$ per $100 \mu \mathrm{g}$ of RNA. This is allowed to digest at $50^{\circ} \mathrm{C}$ for 4 hours. The $\mathrm{pH}$ is adjusted by direct addition of $1 / 10^{\text {th }}$ volume of $1 \mathrm{M}$ ammonium bicarbonate. Snake venom phosphodiesterase is then added to the reaction mix $(0.01 \mathrm{U})$ and allowed to react for $1 \mathrm{hr}$ at $37^{\circ} \mathrm{C}$ before adding $2 \mathrm{U}$ of bacterial alkaline phosphatase for a further $1 \mathrm{hr}$ at $37^{\circ} \mathrm{C}$. This mixture can be directly analysed by RP-HPLC.

\section{Product synthesis and purification}

Each of the three possible substrates NMN, $\mathrm{NAD}^{+}$and $\mathrm{NADP}^{+}$were handled in the same way in order to generate the target fluorophore species. The required mass of material was dissolved in MQ water to a concentration not greater than $300 \mathrm{mM}$. To this was added an equal volume of $4 \mathrm{M} \mathrm{NaOH}$ leaving the reactant at $150 \mathrm{mM}$ and the base concentration at $2 \mathrm{M}$. This mixture was allowed to react for $2 \mathrm{hrs}$ in the dark. At this time the reaction was quenched by the addition of conc. $\mathrm{HCl}$ until $\mathrm{pH}$ was neutral. The reaction mixture was then initially analysed by reverse phase HPLC using a Gemini column $(5 \mu \mathrm{m} \mathrm{C18,30} \mathrm{x} 4.6 \mathrm{~mm}$;

$1.0 \mathrm{mLmin}^{-1}$ ) from Phenomenex and a linear gradient from $100 \% 100 \mathrm{mM} \mathrm{NH}_{4} \mathrm{OAc}(\mathrm{pH}$ 
6.8) to a final concentration of $30 \%$ acetonile in the same aqueous solution. This utilized the Agilent instrument and recorded spectra from 220-400 nm throughout the elution. Purification was scaled up and utilized an isocratic elution of either $100 \mathrm{mM} \mathrm{NH}_{4} \mathrm{OAc}(\mathrm{pH}$ 6.8) or just MQ water. Large scale purification employed a Luna column (5 $\mu \mathrm{m}$ C18, 250

x $10 \mathrm{~mm} ; 3.0 \mathrm{mLmin}^{-1}$ ) from Phenomenex, and elution tracked by monitoring the absorbance at $360 \mathrm{~nm}$. The initial fraction containing the fluorophore was reinjected through the same column and mobile phase conditions for further purification. This fraction was recovered in $1 \mathrm{~mL}$ fractions and the fluorophore content determined by adding $10 \mu \mathrm{L}$ in to $200 \mu \mathrm{L}$ of $2 \mathrm{M} \mathrm{NaOH}$ and collecting fluorescence spectra (ex $360 \mathrm{~nm}$ and em 400$500 \mathrm{~nm}$ ). The purity of the fraction was also determined by injecting a $10 \mu \mathrm{L}$ aliquot of the fraction on to the Gemini column described above.

\section{Spectral properties}

\section{UV absorbance and fluorescence spectra and $p H$ dependence}

Absorbance spectra for the isolated fluorophore were measured on the Cary 100. HPLC fractions, containing the highest purity of the fluorophore, were diluted in to either Millipore water or $0.5 \mathrm{M} \mathrm{NaOH}$ in order to determine solvent effects on the chromophore. The spectra were collected using $2 \mathrm{~nm}$ slits on the excitation path and scanning between 220 and $400 \mathrm{~nm}$. In measuring emission spectra, the samples were analysed on the PTI Quantamaster measuring emission between 390 and $600 \mathrm{~nm}$ with excitation centered at $360 \mathrm{~nm}$ and $2 \mathrm{~nm}$ slits (5 $\mathrm{nm}$ slit on the emission path) 


\section{Quantum yield determination}

The fluorescence quantum yield for the product was measured in $0.5 \mathrm{M} \mathrm{NaOH}$ and carried out at concentrations that gave an absorbance between 0.01 and 0.1 OD to minimize any internal quenching effect. At each concentration the absorbance was measured at $25^{\circ} \mathrm{C}$ on the Cary $100 \mathrm{UV}$-Vis spectrometer (200-400 $\mathrm{nm}$ scans with excitation slit set to $2 \mathrm{~nm}$ and 0.5 second averaging time). The samples were held in a 9F-Q-10-GL14 cuvette (Starna Cells) and $1 \mathrm{~mL}$ of sample was measured to minimize noise. A second aliquot of the sample at each concentration step was then measured in the steady state fluorimeter (PTI Quantamaster 400) using the same cuvette. The fluorescence spectra were recorded at 25 ${ }^{\circ} \mathrm{C}$ (thermostatted with a circulating water bath) from 400 to $600 \mathrm{~nm}$ (5 $\mathrm{nm}$ slits on emission) with excitation at $360 \mathrm{~nm}$ (2 nm slits on excitation). Each absorbance and emission spectrum was collected in triplicate and averaged before being plotted to determine the linear response. This process was repeated using the standard quinine sulfate in $0.5 \mathrm{M} \mathrm{H}_{2} \mathrm{SO}_{4}$. Concentrations in the same absorbance range were prepared and the absorbance and emission spectra were collected with exactly the same instrumental set ups. The two linear responses were then used to calculate the quantum yield of the base product using the standard value for quinine of 0.54 and the following relationship:

$$
\Phi_{\mathrm{x}}=\Phi_{\text {quinine }}\left(\frac{\text { Gradient }_{\mathrm{x}}}{\text { Gradient }_{\text {quinine }}}\right)\left(\frac{\eta^{2} \mathrm{x}}{\eta^{2} \text { quinine }}\right)
$$




\section{Product identification}

\section{NMR spectroscopy}

After bulk purification as detailed above (mobile phase was Millipore water), the sample was concentrated in order to perform NMR studies. This was achieved by drying under a low flow of nitrogen gas at room temperature in the dark. To the concentrated aqueous sample was added $10 \% \mathrm{D}_{2} \mathrm{O}$ to allow for locking signal. Water suppression experiments on the neutral solution along with sample supplemented with sodium deuteroxide to $100 \mathrm{mM}$ were collected on the $400 \mathrm{~Hz}$ Bruker instrument. This system was also used to collect $\mathrm{C}^{13}$ and $\mathrm{H}^{1} / \mathrm{C}^{13} \mathrm{HSQC}$ spectra. Finally, $\mathrm{N}^{15}$ and $\mathrm{H}^{1} / \mathrm{N}^{15}$ HSQC experiments were run on the $600 \mathrm{~Hz}$ instrument. Standard pulse sequences provided by the core facility were used in each case.

\section{Mass spectrometry}

In order to obtain an accurate mass for the fluorophore being studied the sample was freshly prepared and passed through the Gemini $(30 \times 4.6 \mathrm{~mm})$ column. The eluted fluorophore was at this point in water and so to increase volatility for ESI methodology it was mixed 50:50 with methanol. The prepared sample was immediately injected on to the mass spectrometer by direct infusion and the mass profile recorded in positive mode. The ESI interface was operated in the positive mode using the following settings: spray voltage 3.8 $\mathrm{kV}$; capillary temp $300^{\circ} \mathrm{C}$; capillary voltage 13.89 ; tube lens voltage $120 \mathrm{~V}$. 
IR spectroscopy

FT-IR spectra were collected on a Nicolet iS10 spectrometer using a diamond ATR attachment. The sample was extracted from aqueous solution using ethyl acetate which was then dried to concentrate. The sample was drop cast on to the crystal and the ethyl acetate dried before analyzing the unknown against the appropriate background zero. 


\section{Results}

\section{Role of archaeosine in tRNA}

\section{Thermal stability of in vitro modified $t R N A$}

The initial work for this section of research began by studying the effects of magnesium on the stability of a set of tRNA molecules that have been modified in vitro to feature either the genetically encoded guanine, preQ $_{0}$ or $\mathrm{G}^{+}$nucleobases at position 15 . For this reason, $\mathrm{Ser}^{\mathrm{CGA}}$ from Haloferax volcanii was initially selected as it had been used to study the activity of the two biosynthetic enzymes in the pathway ${ }^{45}$. A second archaeal tRNA was selected that features a reduced variable loop compared to the type II Serine sequence. Methanothermobacter thermautotrophicus Gln ${ }^{\mathrm{UUG}}$ was chosen here for it having been studied extensively in its folding pathways ${ }^{84,85}$. Finally, the Gln ${ }^{\text {UUG }}$ sequence from Escherichia coli was chosen as a non-archaeal system that could be modified to feature the archaeal modifications.

Preparation of in vitro modified tRNA

The RNA molecules were prepared from duplex DNA template synthesized by primer extension using Klenow fragment ${ }^{83}$. The native sequences for all three RNAs were used, no modification to enhance transcription yield was introduced (Table 1). The Klenow templates were transcribed using in house expressed and purified T7 RNA polymerase. The reaction mixtures were stopped and precipitated before being purified by slab denaturing PAGE. The isolated full length RNA products were then modified in vitro to 
have the genetically encoded $\mathrm{G}$ converted to preQ $_{0}$ by the action of ArcTGT (Figure 3.1). The purified enzyme was assayed for activity by measuring the incorporation of $\left[8-{ }^{14} \mathrm{C}\right]$ guanine into a small preparation of the tRNA, establishing the conditions for quantitaive incorporation of substrate base. These conditions were then scaled and substituted with $\mathrm{preQ}_{0}$ base to substitute the guanine (Figure 3.3). A portion of the $\mathrm{preQ}_{0}$ modified tRNA was set aside for melting studies and the remainder serving as a substrate for the next reaction using ArcS (Figure 3.2) to produce $\mathrm{G}^{+}$modified tRNA. Quantitation of conversion to $\mathrm{G}^{+}$was determined by digesting the tRNA to free nucleoside and confirming the loss of preQ $Q_{0}$ and appearance of the $\mathrm{G}^{+}$in the chromatogram (Figure 3.3).

UV melting study of in vitro tRNA

The nine RNA samples described above, were then carried on to perform melting studies of the tRNA under the effects of increasing magnesium concentration. Each sample was slow cooled in melting buffer $(10 \mathrm{mM}$ sodium cacodylate $\mathrm{pH} 7.0,100 \mathrm{mM} \mathrm{NaCl})$ from 98 down to $25^{\circ} \mathrm{C}$. If magnesium was to be added, the RNA was heated back up to $55^{\circ} \mathrm{C}$ before the required amount magnesium chloride stock solution was added and re-cooled to $25^{\circ} \mathrm{C}$.

The raw melt data was first processed to obtain a melting profile (first differential plot of $\left.\mathrm{dAbs}_{260 \mathrm{~nm}} \mathrm{vs}\left[\mathrm{Mg}^{2+}\right]\right)$ to allow the apparent $\mathrm{T}_{\mathrm{m}}$ to be deduced. The extracted $\mathrm{T}_{\mathrm{m}}$ value was then plotted against magnesium concentration to reveal the magnesium induced stabilization of the tRNA structure. The isotherm was fitted using a two state model giving a calculated lower and upper limit for the magnesium response (Figure 3.4). It also extracts 
a half magnesium concentration for each RNA species relating to sensitivity of the response to magnesium concentration.

As summarized in Figure 3.5 it can be seen that by increasing the concentration of magnesium ions (up to a maximum of $50 \mathrm{mM}$ ) to which a given RNA is exposed produces an increase in melting temperature of around 20 degrees. By comparing the magnesium free $T_{m}$ values across the samples we see that two Gln ${ }^{\text {UUG }}$ isoacceptors have the higher initial melting point compared to the HV Ser ${ }^{\mathrm{CGA}}$. Both $\mathrm{HV}^{\text {ser }}$ and $\mathrm{EC}^{\text {gln }}$ show very little change in the calculated maxima and minima with the addition of either preQ $\mathrm{Q}_{0}$ or $\mathrm{G}^{+}$. The only significant change is seen in the $\mathrm{MT}^{\mathrm{gln}} \mathrm{RNA}$ where the magnesium free $\mathrm{T}_{\mathrm{m}}$ increases from $68.3^{\circ} \mathrm{C}$ to $70.5^{\circ} \mathrm{C}$ and finally $71.2^{\circ} \mathrm{C}$ as the modifications are introduced. This is mirrored by the high magnesium concentrations producing nearly a two-degree increase in $\mathrm{T}_{\mathrm{m}}$ when the RNA is modified to $\mathrm{G}^{+}$from pre $\mathrm{Q}_{0}$. The lack of any real change in the $[\mathrm{Mg}]_{1 / 2}$ value indicates that there is not a sudden increase in the sensitivity of the RNA to magnesium upon introduction of the modifications. If the midpoint had shifted to a significantly lower magnesium concentration it might be argued that there was a particular stabilizing effect relating to magnesium binding that was being titrated.

\section{Magnesium binding to modified tRNA}

Since the formamidino group introduced at N7 in Archaeosine is implicated in changing the electronics of the base and also the coulombic interaction with surround phosphates, normally facilitated by a coordinated divalent ion, we next investigated the effect of modification on magnesium binding. Methodology used extensively by the Draper group 
had shown that the fluorescent dye molecule 8-hydroxyquiniline-5-sulfonic acid (HQS) can be used to set up an equilibrium competition experiments that can sense magnesium affinities in RNAs. The binding of magnesium ions is partitioned between the HQS and a target RNA. To examine the change in magnesium binding caused by modification to $\mathrm{preQ}_{0}$ and $\mathrm{G}^{+}$, the modified in vitro $\mathrm{RNA}$ was used in the assay.

The baseline response to magnesium needs to be established to achieve a differential in the presence of the subject tRNA. The dye was prepared by recrystalisation from boiling conc. hydrochloric acid (repeated six times). This ensures that the dye was completely demetallated before use (spectral properties confirmed before use) (Figure 3.6). The dye solution was transferred to a quartz fluorescence cell and the signal at $550 \mathrm{~nm}$ (excitation at $395 \mathrm{~nm}$ ) recorded upon addition of magnesium chloride in minimal volume steps. The titration was then repeated in the presence of $25 \mu \mathrm{M}$ natively folded tRNA (purification of RNA in TBE buffer effectively removed divalent metal ions and refolding was performed with sodium chloride as described previously). The increase in the fluorescence in response to magnesium was now delayed, reflecting a preferential binding to the RNA. The position of this equilibrium can be deduced by comparing the two titrations. As the $K_{d}$ of magnesium binding to the RNA becomes tighter, the apparent $\mathrm{K}_{\mathrm{d}}$ for HQS becomes weaker since more magnesium ions need to be added before they become free to associate with the dye. Analysis was performed on normalized data, using a reduced Hill equation to fit the raw data. This provides a minima and maxima for each RNA titration with which the normalization was performed. 
Titrating HQS against magnesium gave a $\left[\mathrm{Mg}^{2+}\right]_{1 / 2}$ of $343 \mu \mathrm{M}$ in the absence of competitor RNA (Figure 3.6). Addition of unmodified tRNA ${ }^{\text {Gln }}$ from M. thermoautotrophicum shifted the observed affinity to approximately $1.65 \mathrm{mM}$ clearly showing that the experiment was reporting the phenomenon appropriately. The preQ $_{0}$-tRNA shows a very similar response to unmodified tRNA with a $\left[\mathrm{Mg}^{2+}\right]_{1 / 2}$ of $1.62 \mathrm{mM} . \mathrm{G}^{+}$-tRNA however, gives an apparent $\left[\mathrm{Mg}^{2+}\right]_{1 / 2}$ of $961 \mu \mathrm{M}$. This means that at a given concentration of magnesium, unmodified and pre $_{0}$ have a stronger affinity for magnesium than $\mathrm{G}^{+}$modified tRNA. By applying the following equation ${ }^{86}$ :

$$
\Gamma_{2+}=\left(\frac{C_{2+}^{\text {sample }}-C_{2+}^{\text {reference }}}{C_{R \mathrm{NA}}}\right)
$$

it is possible to deduce a preferential binding constant $\left(\Gamma_{2+}\right)$ for an RNA at a given magnesium concentration and therefore the change in magnesium ions per nucleotide or RNA molecule. Although there is a change in the amount of magnesium binding to the $\mathrm{G}^{+}$ RNA, it appears to be more in line with diffusely interacting ionic contacts rather than the loss of a singular coordinated ion. The preferential binding coefficient increase with magnesium concentration, and at $1 \mathrm{mM}$ we see approximately 20 fewer ions binding per tRNA molecule in the G+ modified tRNA compared to the unmodified transcript.

\section{In vivo modified tRNA from Thermococcus kodakarensis}

Although it is possible to analyze the effects of singular modifications upon the stability of a given tRNA, in vivo samples would allow us to measure the effects of a given modification in an otherwise fully maturated molecule. In order to access tRNA which is 
either un-modified, preQ $_{o}$ modified or modified with $\mathrm{G}^{+}$it is necessary to obtain genetically modified cell lines that have had arcTGT or ArcS deleted from the genome of an archaeal species. There are limited numbers of archaeal systems that have sufficient genetics tools available to produce selective knockout cell lines. One of these is fortunately the hyperthermophile Thermococcus kodakarensis. The work of Tom Santangelo's lab is systematically cataloguing knockouts of all the genes in that species genome. The group kindly provided cell lines for TS559 (wild type), TK0760 ( $\Delta \operatorname{tgt})$ and TK1256 ( $\triangle \operatorname{ArcS})$. These are stable deletions where the gene of interest is not only removed from the genome but also the recombination vector is lost from the cell. The mechanism for creating the knockout is illustrated in (Fig 3.7) ${ }^{87}$.

\section{Growth of the cell lines}

The TS559 cell line is auxotrophic for agmatine by removal of the pyruvoyl-dependent arginine decarboxylase (TK0149). This means that although the $\operatorname{tgt}$ and $\operatorname{arcS}$ genes are stably deleted, in order to grow the cell lines, they must be supplemented with agmatine. Rich media was used to make as much biomass as possible. Under these conditions, cells were either grown overnight $(16 \mathrm{hrs})$ at $85^{\circ} \mathrm{C}$ or 20 hours at $60^{\circ} \mathrm{C}$ before harvesting by centrifugation. Up to 0.9 grams of cells can be harvested per liter of growth media. Before going forward with tRNA isolation, the deletions were confirmed by PCR amplification of each gene for the three cell lines. The genes of interest are appropriately removed (Figure $3.8)$. 
Isolation of tRNA from the knockout cell lines.

In order to access the pool of tRNA produced by the TKO cells, they are immediately suspended in Trizol solution after harvesting. The non-RNA components are stripped away by multiple round of PCA extraction leaving behind a total RNA pool. The RNA is cleaned of non-tRNA species by $\mathrm{LiCl}$ precipitation (Figure 3.9). Analysis of the nucleoside digest of the in vivo tRNA shows that the cell lines have the predicted pattern of modified bases. $\mathrm{PreQ}_{0}$ and $\mathrm{G}^{+}$nucleoside are absent from the $\Delta t g t$ strain. $\mathrm{PreQ}_{0}$ is present in the $\Delta A r c S$ strain and only the wildtype show $\mathrm{G}^{+}$detectable by absorbance in the HPLC chromatogram.

For mass spectrometry analysis (performed by the Limbach lab) tRNA was isolated by SPE column. This permits isolation of tRNA enriched samples without introducing any PAGE artifacts to the sample. Analysis of the three cell lines shows that though no $\mathrm{G}^{+}$is seen in either the TGT or ArcS knockouts by RP-HPLC, there is approximately $1.6 \%$ intensity of the wild type observed for the $\triangle A r c S$ sample by MS (Figure 3.10).

\section{Purification of the GlnX isoacceptor}

Since both isoacceptors for the Gln encoding tRNA are identical except for the anticodon, it was not possible to isolate just that of CUG. However, the environment of G15 in both sequences should be identical, and the sequence of the ACL should be of no consequence to the overall stability of the tRNA. In comparing the sequences of all the TKO tRNA genes, it was found that the area most unique for Gln was from the ACL leading to the 3' end of the molecule. DNA oligos were designed to walk along the length of the tRNA in 3 
nt steps (Figure 3.11). By slow cooling the transcribed tRNA ${ }^{\mathrm{CUG}}$ with the DNA oligos it was possible to identify the best candidate for forming a stable and appropriate complex. The oligo Aff3 was found to sequester most of the RNA in to a particle that moved through the gel rather than making a large multiple strand complex as seen in Aff1 and Aff2 (Figure 3.12). The selected sequence was prepared as a 5 ' biotinylated strand that was able to be loaded on to streptavidin sepharose to make an affinity resin for the GlnX tRNAs ${ }^{88}$. Isoacceptor was extracted from all three cell lines by elution of the RNA by heating the resin to $75^{\circ} \mathrm{C}$ in low salt buffer. The wash fractions and elution are shown in (Figure 3.12). The isolated tRNA was should to be homogenous in both denturing (Urea TBE PAGE) and native (TB, 100mM NaCl PAGE) (figure 3.13)

Thermal stability of single isoacceptor tRNA

To be able to directly compare the melt behavior of the tRNA extracted from the $T$. kodakarensis strains, the thermal stability of in vitro produced tRNA ${ }^{\mathrm{CUG}}$ (TKO sequence) was tested under increasing $\mathrm{Mg}^{2+}$ concentrations (Figure 3.14). The melts of the wt, $\mathrm{preQ}_{0}$ and $\mathrm{G}^{+}$modified tRNA are shown alongside the sequence details. The unmodified in vitro tRNA shows a shoulder in the differential plot at around $70^{\circ} \mathrm{C}$ along with the major melting transition at $85^{\circ} \mathrm{C}$ under $100 \mathrm{mM} \mathrm{NaCl}$. This has shown that the tRNA is inherently more stable than the three other tRNAs studied previously. Under the same salt conditions, the preQ ${ }_{0}$ and $\mathrm{G}^{+}$modified tRNAs also feature a slight shoulder nearer $65^{\circ} \mathrm{C}$, but the major melting transition occurs a few degrees above that of the unmodified CUG. As the concentration of magnesium ions is increased up to $10 \mathrm{mM}$, it is seen that the shoulder persists, though the peak does increases to around $71^{\circ} \mathrm{C}$ for all three RNAs. At the highest 
magnesium concentration, the melting transition is not completed by $98^{\circ} \mathrm{C}$ which is the highest temperature reached in the melt. This indicates that the tRNA is melting fully at least $10-12^{\circ} \mathrm{C}$ above the $\mathrm{HV}$ and MT tRNA with the same modifications in place.

When the in vivo produced and modified tRNA (Figure 3.15) is put through the same melting experiment, we see a significantly different trend. The WT (containing $\mathrm{G}^{+}$) and dTGT (the genetically encoded guanine base) behave almost identically. There is still a slight shoulder at around $71^{\circ} \mathrm{C}$ and a second melting point at around $83^{\circ} \mathrm{C}$. This higher melting temperature is similar for the $\mathrm{dArcS}$ (containing $\mathrm{preQ}_{0}$ ) but there is a more pronounced shoulder at around $63^{\circ} \mathrm{C}$ with this RNA. The addition of $10 \mu \mathrm{M} \mathrm{Mg}^{2+}$ introduced to the system has no measurable effect on the melting transitions. At $100 \mu \mathrm{M}$ $\mathrm{Mg}^{2+}$ however, the WT and $\Delta t g t$ profile has collapsed in to a single and well defined transition at about $82^{\circ} \mathrm{C}$. At the same concentration, the tRNA from $\triangle A r c S$ has the major transition occurring at $73^{\circ} \mathrm{C}$ with a shoulder at $86^{\circ} \mathrm{C}$. At $1 \mathrm{mM} \mathrm{Mg}$ all three RNAs are melting with a single transition, though $\Delta \operatorname{ArcS}$ is $4^{\circ} \mathrm{C}$ lower than the WT and $\Delta \operatorname{tgt}$. This is maintained at $10 \mathrm{mM} \mathrm{Mg}$ where all three RNAs are melting at a temperature beyond the $98^{\circ} \mathrm{C}$ limit of the experiment. 


\section{Identification and characterization of $\mathrm{NAD}(\mathrm{P})^{+}$base product}

\section{Stability and assay conditions}

The assay studied here begins with an initial acid quench step where by the total reaction mix is adjusted to be in $150 \mathrm{mM} \mathrm{HCl}$. This will not only stop the reaction by denaturing the protein component, but it also decomposes any unreacted reduced $\mathrm{NAD}(\mathrm{P}) \mathrm{H}$ so that no further production of $\mathrm{NADP}^{+}$can occur after the end point has been defined (Figure 3.16).

The conversion of NAD $(\mathrm{P})^{+}$to the fluorescent product is achieved by adding concentrated base, typically to a final concentration of $7 \mathrm{M} \mathrm{NaOH}$. This is incubated at room temperature for 2 hours to develop the fluorescent molecule, however it is unclear from the literature if their conditions are optimal for maximal production of fluorescent product and thus assay sensitivity. To determine the conditions for optimum yield, a $50 \mathrm{mM}$ solution of NADP ${ }^{+}$ was treated with $\mathrm{NaOH}$ over a concentration range from 1-10M. Immediately after being added to the sodium hydroxide solutions an increase in fluorescence is observed that correlates to with the concentration of $\mathrm{NaOH}$ (Figure 3.17). This trend does not persist upon longer incubation. Left at room temperature overnight and in the dark, the fluorescence yield is maximal at between 2 and $3 \mathrm{M} \mathrm{NaOH}$ and produces a $35 \%$ increase over the same treatment at $7 \mathrm{M} \mathrm{NaOH}$ (Figure 3.17).

The $2 \mathrm{M}$ base conditions were then used to track the progress of the reaction at lower base concentration. The same 2-hour incubation time prescribed by the original assay was analysed by RP-HPLC. It is shown that intact $\mathrm{NADP}^{+}$is entirely consumed by 20 minutes 
of exposure to $2 \mathrm{M} \mathrm{NaOH}$. The remaining time causes two unidentified products to exchange, both eluting long before $\mathrm{NADP}^{+}$or the fluorescent product.

\section{Equivalency of substrates}

In order to ascertain if the adenosine group is involved in the formation of the fluorophore, NADPH and nicotinamide mononucleotide (NMN), the latter of which lacks the adenosine moiety, were treated with the $2 \mathrm{M} \mathrm{NaOH}$ work up conditions. NADPH, $\mathrm{NADP}^{+}$and NMN were all prepared as $50 \mathrm{mM}$ aqueous solutions. The absorbance spectra of both NADP ${ }^{+}$ and NMN are dominated by a peak at $\sim 260 \mathrm{~nm}$ (Figure 3.18 ). The spectrum of the reduced form, NADPH is further characterized by a peak at $340 \mathrm{~nm}$. Upon treatment with sodium hydroxide (equal volume of $4 \mathrm{M} \mathrm{NaOH}$ added to the $50 \mathrm{mM}$ stock for 2 hours at room temperature, neutralized by addition of $\mathrm{HCl}$ ) the absorbance spectrum of NADPH remain relatively unchanged either when diluted in to MQ water or back in to basic conditions (1M $\mathrm{NaOH})$. The peak at $340 \mathrm{~nm}$ persists in water but there is a slight red shift when measured in base. In contrast, $\mathrm{NADP}^{+}$and NMN show a drastic change to their spectra. In the case of $\mathrm{NADP}^{+}$a new band appears at approximately $340 \mathrm{~nm}$ when measured at natural $\mathrm{pH}$, and shifts to $\sim 360 \mathrm{~nm}$ under alkaline conditions. This corresponds to the absorption band utilized in the assay. The spectrum still features a large peak at $260 \mathrm{~nm}$ which corresponds to the adenine moiety. In the reaction involving NMN which is the peaks observed in both water and $1 \mathrm{M} \mathrm{NaOH}$ match those observed for $\mathrm{NADP}^{+}$, but the spectrum at lower wavelengths is no longer swamped by the $260 \mathrm{~nm}$ peak, revealing base- sensitive fine structure below $260 \mathrm{~nm}$. This confirms that the fluorophore produced by base treatment of 
$\mathrm{NAD}^{+}$or $\mathrm{NADP}^{+}$is generated independently of any involvement of the bridging phosphates or adenosyl moiety.

Spectral properties

Absorbance and fluorescence spectra

To characterize the fluorescent product a purification strategy needed to be developed in order to isolate it from the rest of the reaction side products. Analytical scale purification by reversed phase HPLC using $100 \mathrm{mM}$ ammonium acetate $(\mathrm{pH}$ 7.0) showed good separation with just an isocratic run on a C18 column. In order to obtain the fluorescent product free of other species the preparative scale separation was performed from the neutralized reaction mix, using a mobile phase of just MQ water. The isolated product was then kept in solution and adjusted to be at a useful concentration for further analysis.

Under neutral conditions the absorbance spectrum exhibits a single symmetric peak centered at 330nm for the isolated fluorophore (Figure 3.19). Exciting at that maxima, the fluorescence is minimal when scanned between 400 and $600 \mathrm{~nm}$. When this is repeated in $0.5 \mathrm{M} \mathrm{NaOH}$ fine structure in the absorbance spectra forms, with a shoulder peak at $330 \mathrm{~nm}$ and a main peak that is shifted to $360 \mathrm{~nm}$. Again excitation at absorbance maximum results in the characteristic fluorescence emission at $450 \mathrm{~nm}$. Shifting the $\mathrm{pH}$ of the solution creates a fluorescence enhancement of $\sim 68$ fold compared to neutral solution (Figure 3.20). 
Quantum yield

While this assay has been used extensively to measure $\mathrm{NAD}(\mathrm{P})^{+}$concentrations however it has not been reported how efficient the fluorophore is. In order to do this the quantum yield $(\Phi)$ was determined for the base product using the standard quinine sulfate. The absorbance values were then plotted against the fluorescence integral for each of six concentration points. It was found that the quantum yield for the base product is 0.11 (c.f. 0.54 for quinine sulfate) (Figure 3.20).

Identification of the fluorescent species

\section{Mass spectrometry}

The first step in characterizing the unknown fluorophore was to obtain an accurate mass value for the product. Using freshly prepared and purified material, ESI MS was performed and provided a molecular ion $\left(\mathrm{MH}^{+}\right) 124.03948 \mathrm{~m} / \mathrm{z}$ (figure 3.21). A stabile sodiated adduct $\left(\mathrm{MNa}^{+}\right)$at $146.02176 \mathrm{~m} / \mathrm{z}$ was also found. To ensure that these masses represented the parent ion and not a daughter fragment, the tube lens voltage was reduced from 120 to 80 $\mathrm{V}$ with no appearance of higher mass species. This provided a molecular weight of 123.0315 a.m.u. and a predicted formula of $\mathrm{C}_{6} \mathrm{H}_{5} \mathrm{NO}_{2}$ with an accuracy of $3.94 \mathrm{ppm}$. 


\section{NMR}

${ }^{1} \mathrm{H}$

The sample was analysed under both neutral and basic conditions by hydrogen NMR. The sample in water was spiked with $\mathrm{D}_{2} \mathrm{O}$ to a final concentration of $10 \%$ to allow signal lock. Under these conditions, a singlet is seen at $9.88 \mathrm{ppm}$ consistent with an aldehyde hydrogen. There are three other resonances seen in the spectrum at 8.18 (dd), 7.81(dd) and $6.63 \mathrm{ppm}$ (t) (Figure 3.22), consistent with aromatic hydrogens. Upon addition of $1 / 10^{\text {th }}$ volume of $10 \mathrm{M}$ sodium deuteroxide, there was only a slight shift in the resonances. The aldehyde hydrogen resonance is shifted upfield by $0.01 \mathrm{ppm}$ and maintains a singlet structure. The aromatic hydrogens shift by a small amount, now appearing at 8.08 (dd), 7.83 (dd) and finally $6.5 \mathrm{ppm}$ (dd) (Figure 3.23). The latter resonance suggests that the triplet seen in the spectrum of the sample in neutral conditions is likely to be a doublet of doublets with a symmetrical J coupling value giving the appearance of a triplet.

${ }^{13} \mathrm{C}$

Prepared in ammonium acetate and dried under $\mathbf{N}_{2}$. The carbon spectrum of the isolated fluorophore shows seven peaks. One at $22.95 \mathrm{ppm}$ is attributed to the acetate from preparing the sample. The other six are consistent with one being part of a carbonyl (192.09ppm) and the five aromatic carbons (180.98, 148.07, 142.77, $124.25 \mathrm{ppm})$ (Figure $3.24)$. 
IR

The sample for IR analysis was prepared by extracting the purified material from water using ethyl acetate. The organic phase was concentrated under $\mathrm{N}_{2}$ gas. The IR spectrum was collected after drop casting onto the diamond surface and the solvent allowed to evaporate before collecting (Figure 3.25). No broad peak was seen for the sample in the region above $3000 \mathrm{~cm}^{-1}$ suggesting the absence of any hydroxyl groups in the compound. There are sharp peaks that dominate the spectrum in the range of 2800-3000 cm-1 which are likely to correspond to $\mathrm{C}-\mathrm{H}$ stretches in carbonyl groups. This is supported by strong peaks at 1690 and $1670 \mathrm{~cm}^{-1}$ consistent with $\mathrm{C}=\mathrm{O}$ stretching frequencies). 


\section{Discussion}

\section{RNA discussion}

The first experiments carried out here reported the effects of the $\mathrm{G}^{+}$modification and the precursor, preQ $_{0}$ on the structural stability of tRNA from $H$. volcanii (HV), $M$. thermautotrophicus (MT) and for non-archaeal comparison, E. coli (EC). These species grow optimally at 45,85 and $37^{\circ} \mathrm{C}$ respectively, so the sequences cover moderate and hyperthermophilic species. It is also notable that $H$. volcanii is a moderate halophile and requires around $2.5 \mathrm{M} \mathrm{NaCl}$ and $1.5 \mathrm{M} \mathrm{MgCl}_{2}$ for optimal growth ${ }^{89}$. This correlates to only $37 \%$ of the tRNA sequences from $H$. volcanii featuring a guanine at position 15 compared to $60 \%$ for M. thermautotrophicus and $100 \%$ for T. kodakarensis ${ }^{6,7}$.

\section{In vitro melt study}

The in vitro prepared ${ }^{45}$ tRNAs were melted at $\mathrm{NaCl}$ concentrations of $100 \mathrm{mM}$. It was decided to perform the melts in a background of monovalent cations in order to observe the magnesium specific stabilization of the modified RNA. The background sodium concentration ensures that the secondary structure and most tertiary contacts should be in place before the melting begins $52,57,90,91$.

At this concentration the in vitro transcribed $\mathrm{HV}^{\mathrm{Ser}}$ tRNA in all three modification states are identical, with the RNA melting at around $64.4^{\circ} \mathrm{C}$. Upon addition of $\mathrm{Mg}^{2+}$ ions the melting point rises steadily, with the fitted maximal melting temperature being $1^{\circ} \mathrm{C}$ lower 
than unmodified when $\mathrm{preQ}_{0}$ is present and $0.6^{\circ} \mathrm{C}$ higher for $\mathrm{G}^{+}$. For the in vitro transcribed $\mathrm{MT}^{\mathrm{Gln}}$ RNA, modifying the transcript to feature $\mathrm{preQ}_{0}$ and $\mathrm{G}^{+}$increases the $\mathrm{T}_{\mathrm{m}}$ in sodium by 1.2 and $1.0^{\circ} \mathrm{C}$ respectively. The high magnesium melting point for unmodified and preQ $Q_{0}$ RNA are identical at $89.7^{\circ} \mathrm{C}$. The high magnesium concentration $\mathrm{T}_{\mathrm{m}}$ in $\mathrm{G}^{+}$tRNA is however raised by $2.1^{\circ} \mathrm{C}$. In the in vitro transcribed $\mathrm{EC}^{\mathrm{Gln}} \mathrm{RNA}$ all three modification states have a maximum $T_{m}$ at high magnesium of $87.3^{\circ} \mathrm{C}$. The sodium $T_{m}$ for both transcript and $\mathrm{G}^{+}$are also identical, with the pre $\mathrm{Q}_{0}$ being $1{ }^{\circ} \mathrm{C}$ higher.

The largest change observed in this set of data is in the M. thermautotrophicus sample. However, even that is only a $2^{\circ} \mathrm{C}$ increase in the $\mathrm{T}_{\mathrm{m}}$ when the $\mathrm{G}^{+}$modification is in place. This does not seem a massive shift, especially for a modification that is purported to be involved in a structural role. However, in previous studies that have examined in vivo prepared tRNA where all modifications are in place, compared to a unmodified transcript, a change of $5-6^{\circ} \mathrm{C}$ is all that is observed ${ }^{92}$. Individual modifications have been shown to stabilize active structures (the modification $\mathrm{s}^{2} \mathrm{~T} 54$ in T. thermophilus was found to increase the $\mathrm{T}_{\mathrm{m}}$ by $3^{\circ} \mathrm{C}$ ) active structures and lock in conformations normally under equilibrium that are conducive for function ${ }^{93,94}$. The change in Tm observed with $\mathrm{G}^{+}$formation may be small, but it is not unusually low compared to other similar experiments with core base modifications. 


\section{Magnesium binding}

The fluorescent chelator HQS has been used in many studies to analyze the observed affinity of a given RNA for magnesium ions. The experimental technique used here was devised by the Draper group ${ }^{86}$, to examine the binding of a tightly coordinated magnesium ion in the adenine riboswitch. The phenomenon of magnesium being partitioned between HQS and RNA has been applied to various RNA structures, including tRNA. In 1975 the yeast tRNAPhe that was the basis for most of the structural information gathered on tRNA was used in a similar experiment ${ }^{53}$.

The results of that study was that the tRNA had two subclasses of magnesium interactions, a strong interaction with a $\mathrm{Kd}$ of approximately $9 \times 10^{4} \mathrm{M}^{-1}$ and a weaker binding mode of $6 \times 10^{3} \mathrm{M}^{-1}$. The occupancy of the two were 19 and 5 ions respectively.

The manual titrations performed using the HQS and the in vitro transcribed $M$. thermautotrophicus tRNA showed that there was very little difference between the magnesium binding displayed by the transcribed tRNA ${ }^{\mathrm{Gln}}$, and that of the $\mathrm{pre}_{0}$ modified molecule. The binding displayed for the $\mathrm{G}^{+}$RNA is significantly different to the first two, but the trend does not correlate to a difference of a singular magnesium ion being lost. At $1 \mathrm{mM} \mathrm{Mg}^{2+}$ we observe a decrease in the preferential binding factor 10 ions per RNA molecule when we compare the $\mathrm{G}^{+}$modified tRNA to the unmodified transcript. It appears that the technique used was to insensitive to capture a single loss of a tight binding event. The number of weakly associated ions swamps out the effects that are seen for other systems that have more defined binding pockets. 


\section{Growth of TKO mutants}

The knockouts of the TGT and ArcS genes from T. kodakarensis gave us the first opportunity to study the effects of losing the $\mathrm{G}^{+}$biosynthetic pathway in a hyperthermophilic archaeon. The cells were confirmed to have maintained the deletion with PCR confirming the loss of the two genes producing truncated extension products. Upon harvesting larger quantities of cells it was also possible to confirm loss of $\mathrm{pre}_{0}$ from the delTGT and $\mathrm{G}^{+}$from the delArcS cells by total nucleoside digest of the tRNA. The RNA was also prepared for accurate mass analysis by ESI LC-MS (performed by the Limbach group). This further confirmed loss of $\mathrm{preQ}_{0}$ and $\mathrm{G}^{+}$from the respective cell lines. This gave us the confidence to go on with the melting studies using these RNAs.

The Santangelo group who originally generated the cell lines had performed growth experiments (Figure 4.1). This showed that the cells were all able to grow well up to $85^{\circ} \mathrm{C}$ (the species normal optimal growth temperature). Although cell density in the deletion cell lines does not reach that of the wild type, the rate of growth appears comparable in all three. Raising the temperature to $95^{\circ} \mathrm{C}$ was found to significantly reduce the growth of both TK0760 ( $\Delta$ tgt) and TK2156 ( $\Delta$ arcS). In large culture the cells grown in house were found to show significantly reduced growth at $90^{\circ} \mathrm{C}$ as well. The growth phenotype was seen in cultures grown on both sulphur or pyruvate (cultures grown in house were on pyruvate media to allows for easier harvesting of biomass). The phenotype shows that modification to $\mathrm{G}^{+}$or apparently even preQ $\mathrm{Q}_{0}$ assists in the growth of TKO cells at high temperature. This is in line with the hypothesis we are trying to investigate, in that these modifications may 
be stabilizing tRNA at high temperature, and that their loss, and resultant instability hinders cell proliferation.

\section{In vivo melts}

The first step in approaching the thermal melting experiments was to ensure that we could obtain the isoacceptor from the total tRNA pool to make a clearer melting profile. The methodology has been used extensively ${ }^{88}$ to extract isoacceptors from in vivo prepared RNA but rarely on a species that grows at such a high temperature. To make sure this was not going to impede the purification process, test oligos were used along with transcribed RNA equivalents of the target tRNA. This allowed for the appropriate sequence to be used that avoided oligomeric high mass particles being formed. This was the case for the oligos that touched down directly on the most unique stretch of the tRNA sequence. Moving

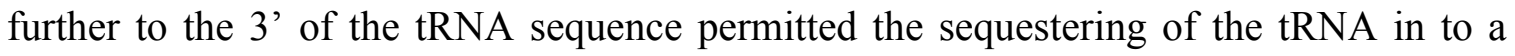
discrete complex with the affinity DNA.

The RNA recovered from the affinity tagging (eluted by heating the washed resin at $75^{\circ} \mathrm{C}$ ) was slow cooled and analyzed by denaturing and native PAGE to confirm both integrity of the RNA (no laddering in the denaturing gel) and single species being formed by slow cooling (single band on the native gel). This meant that the RNA was we purified and appeared to be structurally intact before melting analysis was performed. From 1 litre of cell culture the yield of isoacceptor was $30 \mu \mathrm{g}$ (WT), $38.4 \mu \mathrm{g}$ (dTGT) and $35.6 \mu \mathrm{g}$ (dArcS). This gave sufficient material for both melting and the above analysis of the same prep. 
The transcribed equivalent of the TKO CUG isoacceptor RNA was modified as in the experiment with HV, MT and EC tRNA. The melting transitions show a biphasic melting process, the lower melting occurring at around $65^{\circ} \mathrm{C}$ which rises to above $70^{\circ} \mathrm{C}$ at high magnesium, but persists even at $10 \mathrm{mM} \mathrm{MgCl}$. The second and more substantial melting point occurs at $85^{\circ} \mathrm{C}$ at the lowest magnesium concentrations, implying that the $\mathrm{TK}$ has a significantly more stable tRNA compared to the MT RNA. At high magnesium the $T_{m}$ cannot be determined as the half point occurs beyond the limit of the experimental conditions. Very little difference is seen between the three modification states, except that the unmodified RNA shows a tighter transition for the low $T_{m}$ than the other two samples.

The in vivo tRNA show a significantly different trend. The $\mathrm{WT}\left(\mathrm{G}^{+}\right)$and dTGT $(\mathrm{G})$ both behave almost identically. They both feature two melting transitions, the first, lower $T_{m}$ at $70^{\circ} \mathrm{C}$ at low magnesium, but at $100 \mu \mathrm{M}$ the two transitions have merged in to a single event at $82^{\circ} \mathrm{C}$. Increasing the magnesium further raises the $\mathrm{T}_{\mathrm{m}}$ to $95^{\circ} \mathrm{C}(1 \mathrm{mM})$ and beyond $98^{\circ} \mathrm{C}$ by $10 \mathrm{mM}$. In the dArcS sample which feature pre $\mathrm{Q}_{0}$, we observe a lower $\mathrm{T}_{\mathrm{m}}$ occurring at $60^{\circ} \mathrm{C}$ and remaining two phases until $1 \mathrm{mM}$ where the collapse in to singular transition at 90. This third RNA is also melting beyond $98^{\circ} \mathrm{C}$ however a greater proportion of the RNA is melted at this point seen in the greater dAbs value.

With all the other modifications in place, no significant increase in the $T_{m}$ of the tRNA is produced. However, given the inherently more stable sequence, we are already melting at higher temperatures than in the other RNAs in this study. The pattern of response to magnesium is similar that seen in the E. coli $\mathrm{RRNA}^{\mathrm{Phe}}$ in comparing in vivo matured vs in 
vitro material ${ }^{95}$. The change in $\mathrm{T}_{\mathrm{m}}$ at biologically relevant ionic concentrations are not massively different, but there are clear differences in how components of the folding process respond at different modification states.

Given that we do not see a significant loss of thermal stability at conditions equivalent to growth conditions, and yet we see a growth phenotype at higher temperature, the results may seem to be at odds. However, that assumes that the loss of viability of the cell lines at high temp is simply due to reduction of absolute melting point.

The original hypothesis for the function of archaeosine was that it took on a structural role to stabilize tRNA in thermophilic archaeal species. This is born out in the in vitro prepared tRNAGln from $M$. thermautotrophicus, where a $2.1^{\circ} \mathrm{C}$ increase in melting point was measured when archaeosine was present. This was not reproduced in the tRNA of fellow extreme thermophile $T$. kodakarensis, moderate thermophile $H$. volcanii or the bacterium E. coli, this would suggest that the effects of $\mathrm{G}^{+}$modification are dependent on the RNA in which it occurs and possibly the species in which it is being formed. Indeed, in the context of in vivo maturated tRNA with all modifications are steady state levels except for preQ $\mathrm{Q}_{0}$ or $\mathrm{G}^{+}$, we see that $\mathrm{G}^{+}$modification confers no additional stabilization beyond the genetically encoded guanine base. Somewhat surprisingly, in vivo material with $\mathrm{preQ}_{0}$ present, is actually less stable that the genetically encoded guanine. This creates the possibility of a more complicated structural consequence of the $\mathrm{G}^{+}$pathway, one that is dependent on the species, it's tRNA primary sequence and environmental conditions for the role that $\mathrm{G}^{+}$ultimately serves. 
Previously, similar studies have found that loss of a given modification doesn't always produce a significant change in overall thermal stability, but increased dynamics of the RNA makes it less functional at higher temperatures. Loss of $\mathrm{m} 7 \mathrm{G}$ at position 46 by a deletion of the methyltransferase trm8 in yeast caused reduced modification at other sites ${ }^{96}$. There was a temperature dependent growth response, where cell taken from $28^{\circ} \mathrm{C}$ to $37^{\circ} \mathrm{C}$ showed reduced growth. Analysis of the tRNA stability showed little difference in the stability of the tRNA, but increased dynamics of the RNA meant that subsequent modifications were not being produced. This led to the specific degradation of tRNA valine (other tRNAs normally featured the modification but were not degraded). This first instance of Rapid tRNA Decay (RTD) pathway for the targeted removal of misfolded tRNA showed that the observed temperature dependent growth phenotype might not be directly related to RNA stability but to the modification status of the tRNA.

Similarly, loss of a single pseudouridine at position 55 in T. thermophilus was found to have a significantly higher $\mathrm{T}_{\mathrm{m}}\left(8.4^{\circ} \mathrm{C}\right)$ if it was grown at low temperatures. It was proposed that loss of $\Psi 55$ actually increased the amount of other stabilizing modifications which made for a more rigid structure. This then in turn, decreased its ability to function in the cell giving a growth phenotype at low temperatures caused by an overly stable, misfolded RNA $^{97}$. The degradation of tRNA by a bacterial RTD was also first identified in $T$. thermophilus $^{28}$.

There is still a dearth of information regarding the function of base modifications that occur in the core region of tRNA (Figure 4.2). One of the most abundant of these modifications 
are methylations. Though some of these are specific to the archaea, there is often a parallel modification that occurs in the other domains, serving a similar role. Methylation events are often involved in directing the formation of hydrogen bonding at the core. In P. abysii for example, $\mathrm{m}_{2}^{2} \mathrm{G} 10$ creates steric hindrance that directs the formation of the D-stem, in the case of tRNA ${ }^{\text {Pro }}$, by enhancing a wobble base pairing with $U 25$, and in tRNA ${ }^{\text {Asp }}$, by preventing a 2 base slip that causes the D-loop to be expanded ${ }^{98}$. In $H$. volcanii the same modification regulates the formation of the AC stem in prolyl tRNA by a similar mechanism $^{99}$. In the region between the accepter stem and the variable loop, position 48 and 49 will often be methylated $\left(\mathrm{m}^{5} \mathrm{C}\right)$ but in this case, it is believed that the modifications are acting to enhance base pairing by shifting the electronics of the modified bases.

In archaea specifically, further modification of these methylated bases can occur where $O$ methylation at the $2^{\prime} \mathrm{OH}$ of the ribose takes place. The gradual addition of methyl groups has been shown to be an adaptive response to increasing growth temperatures ${ }^{100}$. The population of $\mathrm{m}_{2}^{2} \mathrm{G}_{\mathrm{m}}$ goes up as the precursor $\mathrm{m}_{2}^{2} \mathrm{G}$ decreases $(60-70 \%$ of the precursor is converted to the O-methyl derivative at the highest growth temperatures used).

Uridine is also commonly modified in the core, and the modifications are also sensitive to sequence and growth conditions. Pseudouridinylation will occur at position 13, stabilizing base pairing between itself and position 22 which forms in the D stem. It is only modified however if the base at position 22 is a $\mathrm{U}$ or $\mathrm{G}$, canonical base pairing to A22 does not induce the modification to be carried out. The occurrence of pseudouridine in the T-loop is well known, acting as one of the bases ( $\Psi 55)$ that creates loop-loop interactions with the 
D-loop. In archaea, the position 54 is also found to be modified to $\Psi, \mathrm{m}^{1} \Psi$ and also the related high temperature induced $\mathrm{m}^{5} \mathrm{~s}^{2} \mathrm{U}$. These modifications help to ensure the correct structure is adopted in the T-loop to maintain needed tertiary contacts.

Crystalographic studies have shown that arcTGT binds to tRNA in an alternative $\lambda$-form structure ${ }^{101}$ where the D-stemloop is fully disrupted, allowing the enzyme to "count" the first 15 bases of the substrate. Indeed, biochemical characterization of the P. horikoshii enzyme showed that the enzyme became increasingly active the higher the temperature of the exchange reaction was carried out at (up to $\left.100^{\circ} \mathrm{C}\right)^{44}$. It is possible that the addition of $\mathrm{preQ}_{0}$ to a new transcript will occur fairly early in the maturation process. If the disordered RNA needed for TGT activity is to be funneled in to an active form for further modification and function, it is possible that the G-preQ ${ }_{0}-\mathrm{G}^{+}$status at position 15 serves as a check point for viability of the tRNA. Since the more extreme halophiles are able to thrive with a lower number of their tRNA featuring the modification, it is possible that $\operatorname{preQ}_{0}$ and $\mathrm{G}^{+}$ modifications help direct the maturation process or the folding of extended transcript in to functional tRNA.

Synthetase charging assays would give an immediate answer as to the functionality of the in vivo produced tRNAs. Looking at the folding rates of tRNA in the same, stepwise modification status as has been carried out in this study, would be the likely next step to see if the role of $\mathrm{G}^{+}$lies in the direction of the folding pathway, rather than the stabilization of an already folded tRNA. 


\section{Identification and characterization of $\mathrm{NAD}(\mathrm{P})^{+}$base product}

The continued use of the methodology established in the $1950 \mathrm{~s}{ }^{102}$ shows it to be rigorous and flexible enough to still be of use to current research of systems consuming NAD(P). The exact nature and properties of the fluorophore however have been largely ignored since the protocol is so reliable. Here we have characterized the fluorophore to be 2-hydroxynicotinaldehyde.

\section{Identification of the fluorophore}

Isolated immediately from the assay work up conditions, the first step in determining the structure was recording an accurate mass. Since no mass higher than the mono-sodium adduct of the product species was found, it put an immediate bracket on the structures possible. The strong signal and accurate mass obtain in positive mode ESI meant that we could be confident in the molecular mass of $123.0315 \mathrm{~g} / \mathrm{mol}$. This allowed the formula to be calculated at $\mathrm{C}_{6} \mathrm{H}_{5} \mathrm{NO}_{2}$.

In order to confirm this, the fluorescent product needed to be characterized spectroscopically to identify structural features to finalize the structure. In order to collect the NMR spectra the product was collected by HPLC in MQ water. From here it was initially attempted to dry down under vacuum to remove the water, however it was found that the product was volatile. Under the vacuum supplied by a speedvac (30 in $\mathrm{Hg}$ below ambient) all material volatilized and so could not be recovered. To provide more gentle 
drying conditions, the sample was concentrated under nitrogen. After significant concentration, the sample, still in aqueous solution was spiked with deuterium oxide for signal locking. Since there was still such a strong residual water signal, the $\mathrm{H}^{1}$ spectra were recorded using a water suppression pulse sequence. Under these conditions, four protons were recorded. This would suggest that there is one exchangeable proton given the predicted formula. The resonances and splitting pattern suggested an aldehyde proton at $9.88 \mathrm{ppm}$ that showed no coupling. The remaining three protons are $8.18,7.81$ and 6.63 ppm. These are characteristic for aromatic protons, so it is highly likely that we have an intact ring structure. This is supported by the $C^{13}$ spectrum which suggests 5 aromatic carbon centers and an aldehyde resonance.

The three ring protons are in three distinct environments, and so it is likely that the ring structure is asymmetrically substituted. The observed resonances for the $\alpha(8.18), \beta(6.63)$ and $\gamma(7.81)$ match the deshielding pattern of pyridine. The splitting patterns for the three protons in water are also in support of this with the constants being $\alpha\left(\mathrm{J}_{\beta}=7.27 \mathrm{~Hz}, \mathrm{~J}_{\gamma}=\right.$ $2.19 \mathrm{~Hz}), \beta\left(\mathrm{J}_{\alpha, \gamma}=6.83 \mathrm{~Hz}\right)$ and $\gamma\left(\mathrm{J}_{\alpha}=2.20 \mathrm{~Hz}, \mathrm{~J}_{\beta}=6.32\right)$.

Maintenance of the pyridine ring, along with the formation of a formyl group leaves an oxygen and a fifth proton left to be accounted for based on the MS derived formula. The proton for a hydroxyl group would be exchangeable and so not seen in the proton NMR. Performing a $\mathrm{N}^{15}-\mathrm{H}^{1}$ coupled HSQC experiment (data not presented) on the sample also hinted that the nitrogen was not stably protonated as no signal was detected for protons excited by resonance to the only nitrogen atom. Using spectrum prediction software, the 
theoretical spectra for the 2-hydroxy derivative rather than the 3-hydroxy most closely matches the pattern seen empirically ${ }^{103,104}$. Although the simulations are calculated based on DMSO as the solvent, the observed resonances and splitting pattern can again give us confidence in our structural assignments.

Once the identity of the product was confirmed, literature searches for 2hydroxynicotinaldehyde (2HNA) brought up hits from the early 1970s where analogs of $\mathrm{NAD}^{+}$were studied to investigate the fluorophore first identified by Kaplan in 1951 . Comparison of pyridinium and nicotinamide derivatives showed that the carboxamide substitution at position 3 is able to significantly enhance the susceptibility of such molecules to nucleophilic attack at position 2. Indeed, the formation of the 2-hydroxy derivative in nictotimamides are found to have a rate $\sim 1000$ fold higher than that of the pyridinium equivalent. This in turn translates in to a $\mathrm{K}_{\mathrm{eq}}$ enhancement of 6000 fold for the formation of the open ring form of the two families ${ }^{105-107}$.

Guilbert and Johnson ${ }^{108}$ carried out the base work up on 1-(N,N-dimethylcarbamoyl) nicotinamide chloride and diphosphopyridine nucleotide (DPN). They were able to characterize the product of the reaction between these two analogs as being identical to 2HNA and synthesized a control of the substance for full comparison.

Using the dimethylcarbamoyl analog the mechanism of formation was deduced for 2HNA. Initial base treatment of a species featuring an oxidized nicotinamide moiety produced what is referred to as the open ring form of NAD (ONAD). The conversion from ONAD 
to 2HNA goes through a second major intermediate that is created upon hydrolysis of the Schiff base form of ONAD. This would release everything connected to what was previously the ring nitrogen of the nicotinamide, leaving 2-carboxamideglutacondialdehyde (CGDA).

Recyclization occurs upon deprotonation of CGDA which facilitates nucleophilic attack of the amide nitrogen upon carbon 5. This regenerates the pyridine structure and upon further decomposition generates 2-HNA ${ }^{109}$. The overall mechanism deduced for the generation of 2-HNA from oxidized nicotinamide species is laid out in (Figure 4.3) with key intermediates in the process highlighted. There are secondary reactions at most steps, however the concentration of base used really drives the process to the overall yield of around $95 \%$.

The work up condition specified in the original methodology paper by Lowry et al. exposed the biological sample to $8 \mathrm{~N} \mathrm{NaOH}$ in order to generate the fluorogenic species detected in the assay. With the knowledge gleamed from previous studies and now this one, it would appear that this is far more aggressive than it need be. The early work was carried out on pyridine derivatives and then transferred to the nicotinamide nucleotides as an application to biological systems. The studies by Johnson throughout the 70 s showed that the nicotinamide moieties were faster to react, and also more sensitive to base concentration to produce the ring opening derivatization ${ }^{105}$. 
Unlike the pyrimidine system which achieves maximum yields of fluorescence at $\mathrm{pH}>13$, the equivalent effects can be generated at up to four $\mathrm{pH}$ units below this with nicotinamides. In the time courses completed in this study it was shown that fluorescence can be recorded maximally when incubated at $2 \mathrm{M} \mathrm{NaOH}$. The reaction time of 2 hours is also more than enough for all $\mathrm{NAD}(\mathrm{P})^{+}$to be converted to the 2-HNA. As long as the reaction has been successfully quenched in the $150 \mathrm{mM} \mathrm{HCl}$ step, incubation in $2 \mathrm{M}$ base should still provide a significant excess of hydroxide ion concentration to fully convert to 2-HNA. Indeed, the lower base concentration may be of benefit by making the assay conditions more product stable over a prolonged time. Since the chemistry to generate 2-HNA permits going to completion at lower concentrations and is not under equilibrium, the reduced fluorescence observed at higher concentrations may be resulting from decomposition of the target molecule. This considered it may be advisable to reduce the concentration of $\mathrm{NaOH}$ used to 2-3 M to permit an increased dynamic range and stability of sample. 


\title{
Tables
}

Table 1 Sequences of tRNA used in initial thermal stability experiments. $H$. volcanii $\mathrm{Ser}^{\mathrm{CGA}}$, M. thermautotrophicus $\mathrm{Gln}^{\mathrm{UUG}}$ and E. coli $\mathrm{Gln}^{\mathrm{UUG}}$ tRNA sequences. The RNAs are transcribed from templates produced by Klenow extension of the corresponding DNA oligo pairs. The DNA primers add the T7 promoter sequence (bold) and the annealing overlap is shown underlined.

\author{
RNA sequences \\ Ser CGA (H. volcanii) \\ 5'GCCGAGGUAGCCUAGCCCGGCCAAGGCGGUAGAUUCGAAAUCUACUGUCCAUUCGGACACGUG \\ AGUUCAAAUCUCACCCUCGGCG3'
}

GIn UUG (Methanothermobacter thermautotrophicus)

5 ' AGUCCCGUGGGGUAGUGGUAAUCCUGCUGGGCUUUGGACCCGGCGACAGCGGUUCGACUCCGC UCGGGACUAUCA3'

GIn UUG (E. coli)

5 ' UGGGGUAUCGCCAAGCGGUAAGGCACCGGUUUUUGAUACCGGCAUUCCCUGGUUCGAAUCCAG GUACCCCAGCCA3'

\section{Klenow template sequences}

Ser CGA (H. volcanii)

5 ' GCAGTAATACGACTCACTATAGCCGAGGTAGCCTAGCCCGGCCAAGGCGGTAGATTCGAA3'

5' TGGCGCCGAGGGTGAGATTTGAACTCACGTGTCCGAATGGACAGTAGATTTCGAATCTAC3'

GIn UUG (Methanothermobacter thermautotrophicus)

5' GCAGTAATACGACTCACTATAAGTCCCGTGGGGTAGTGGTAATCCTGCTGGGCTTG3 '

5' TGGTAGTCCCGAGCGGAGTCGAACCGCTGTCGCCGGGTCCAAAGCCCAGC3'

GIn UUG (E. coli)

5 ' GCAGTAATACGACTCACTATAAGGGGTATCGCCAAGCGGTAAGGCACCGGTT3'

5' TGGCAGGGGTACCTGGATTCGAACCAGGGAATGCCGGTATCAAAAAACCGGTGC 3' 
Table 2 Sequences of tRNA used in TKO in vitro melting study. The RNA sequence that was used is shown first, below are the DNA oligos used to generate double stranded template for in vitro transcription.

\title{
RNA sequence
}

\section{GIn CUG (Thermococcus kodakarenisis)}

5 ' AGCCCCGUGGUGUAGCGGCCAAGCAUGCGGGACUCUGGAUCCCGCGACCGGGGUUCGAAUCCC CGCGGGGCUACCA3'

\author{
Klenow template sequences \\ 5 ' TAATACGACTCACTATAGGCCCCGTGGTGTAGCGGCCAAGCATGCGGGA3' \\ 5 'mUmGGTAGCCCCGCGGGGATTCGAACCCCGGTCGCGGGATCCAGAGTCCCGCATGC3 '
}




\section{Figures}

Figure 1.1 Structure of tRNA(a) Secondary structure of a typical tRNA shown in the cloverleaf representation. (b) The folded structure of the active tRNAPhe from $\mathrm{S}$. cerevisiae (PDB accession 1EHZ).

(a)

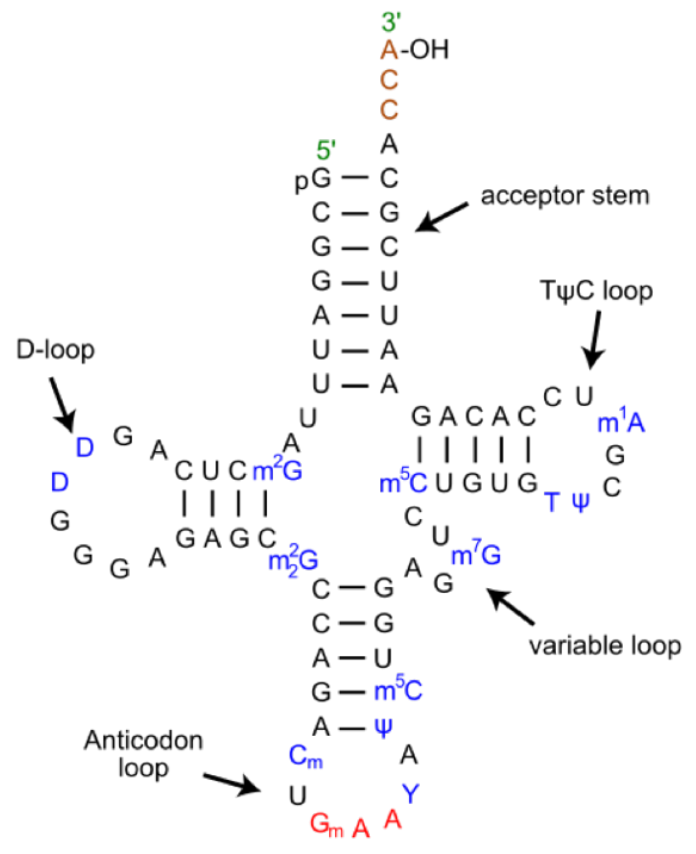

(b)

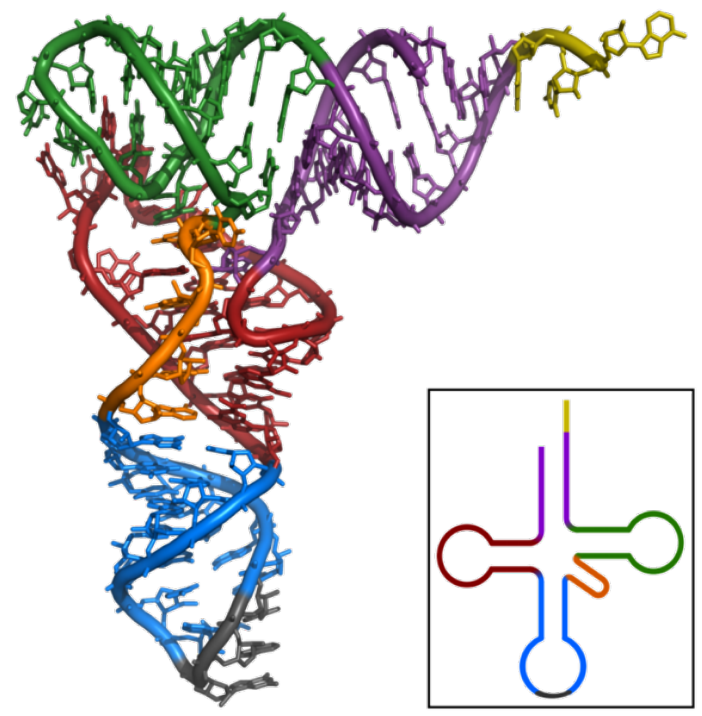


Figure 1.2 Naturally occurring modified bases. Naturally occurring modified nucleotides which are all found in tRNAs. Both queuosine and N6-threonylcarbamoyl adenine are located at the anticodon loop and maintain translation fidelity. 2'-O-methylcytidine and N7-methylguanine are involved in structural stability. Modified functional groups are shown in blue.

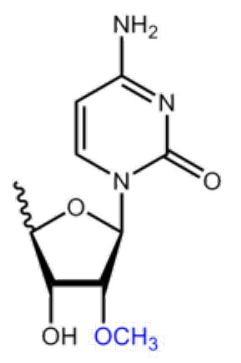

2'-O-methylcytidine<smiles>C[C@@H](O)C(NC(=O)Nc1ncnc2c1ncn2[C@@H]1O[C@H](C)C(O)[C@H]1O)C(=O)O</smiles>

N6-threonylcarbomyl adenine<smiles></smiles>

N7-methylguanine

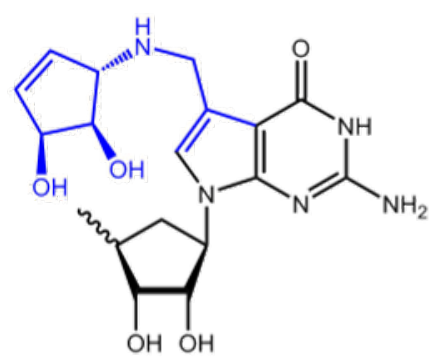

Queuosine 
Figure 1.3 Biosynthesis of $\mathrm{pre}_{0}$ nucleobase. The first steps that are common to the archaeosine and queuosine pathway is the formation of $\mathrm{preQ}_{0}$ from GTP. Figure modified from Biochemistry 2009, 48, 3847-3852.
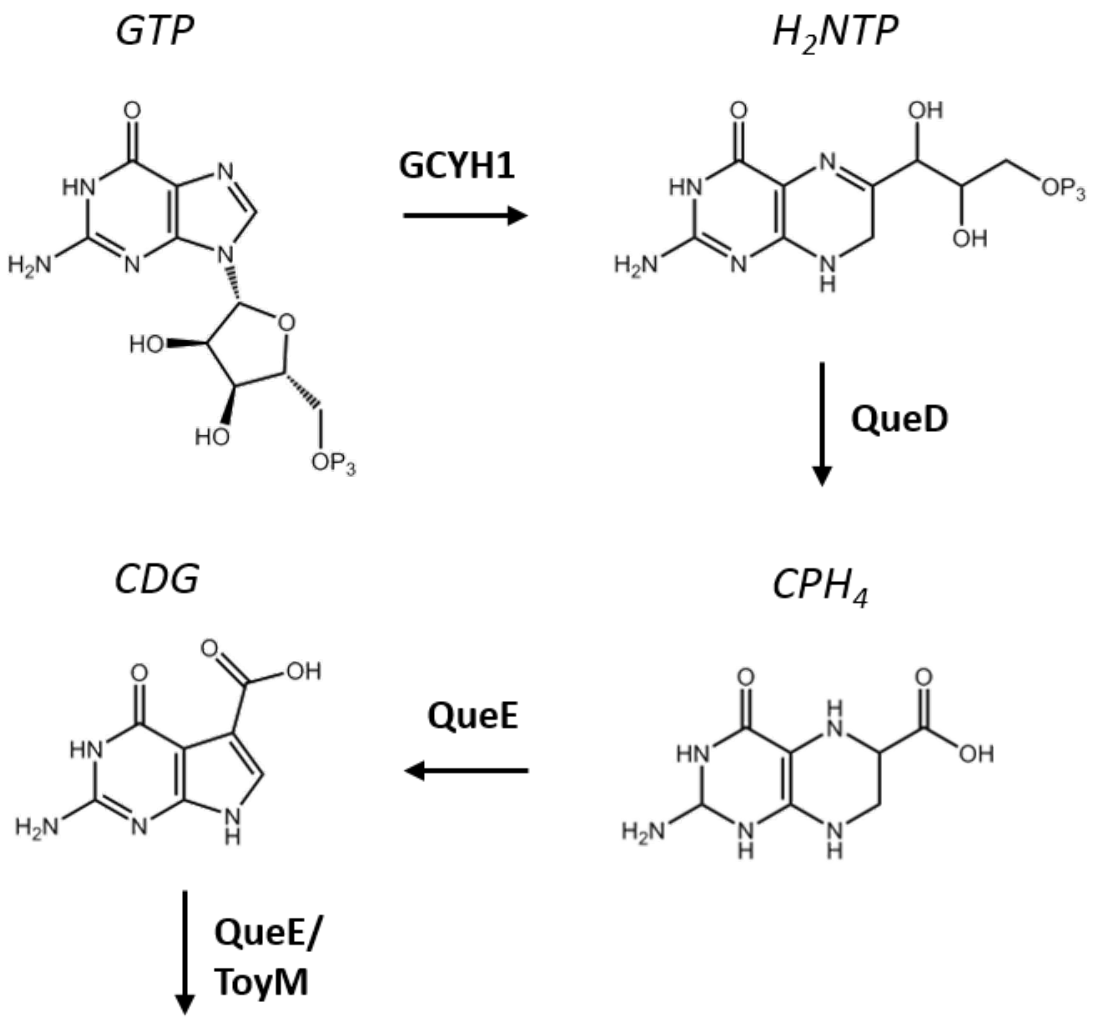<smiles>N#Cc1c[nH]c2nc(N)[nH]c(=O)c12</smiles> 
Figure 1.4 Queuosine biosynthesis. The fate of $\mathrm{preQ}_{0}$ in bacteria is to be converted to preQ $_{1}$ before being inserted in to tRNA by bacTGT. Figure modified from NAR. 2016, 44(20): 9965-9976
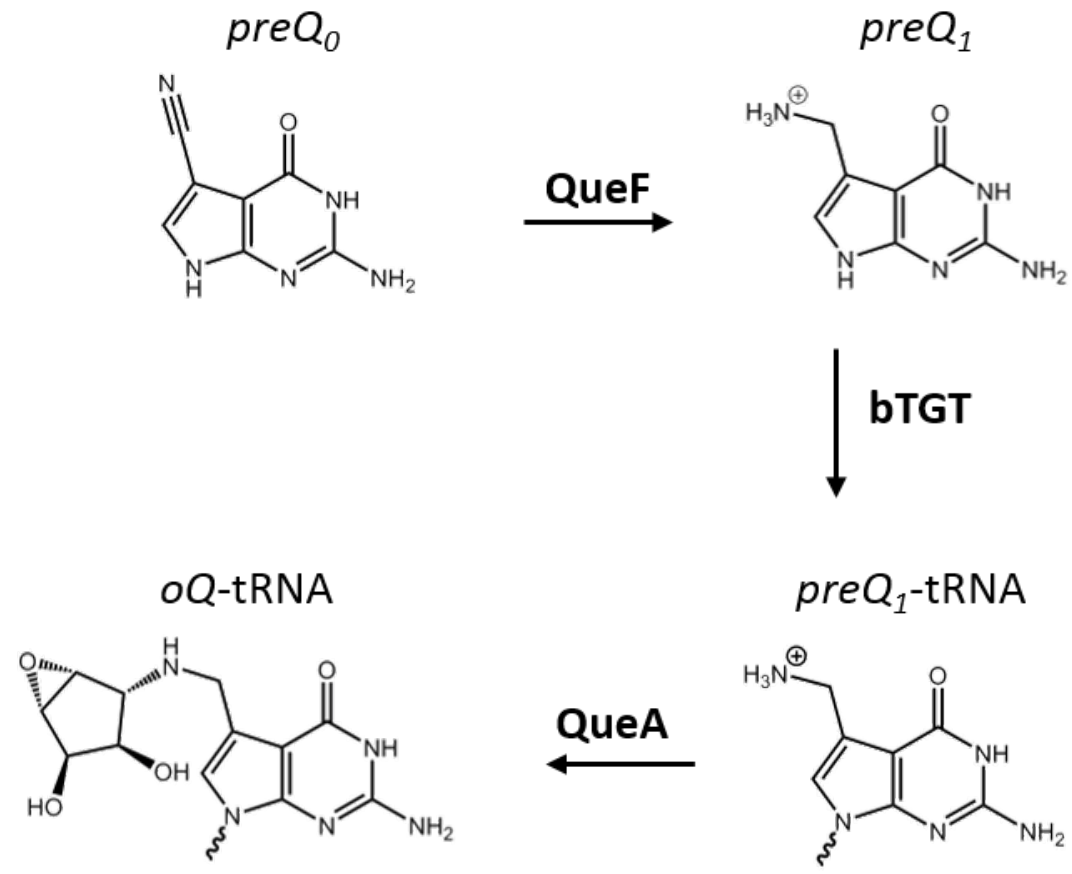

\section{QueA}

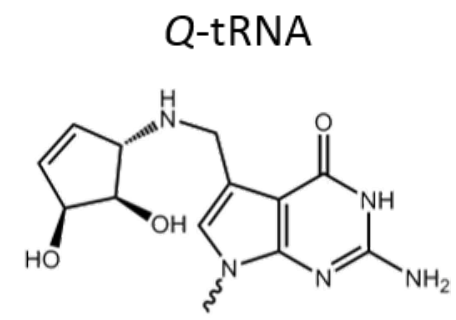


Figure 1.5 Archaeosine $\left(\mathrm{G}^{+}\right)$biosynthesis. After insertion in to substrate tRNA at position 15 , preQ ${ }_{0}$-tRNA is further modified by either $\operatorname{ArcS}(\mathrm{A})$, QueF-like (Q) or Gat-QueC (G). (ACS Chem Biol. 2012; 7(2): 300-305)
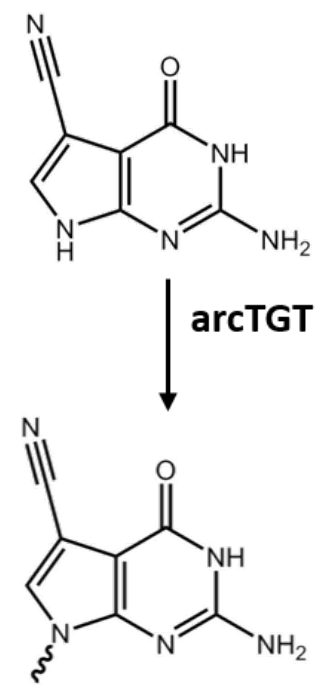

A/Q/G

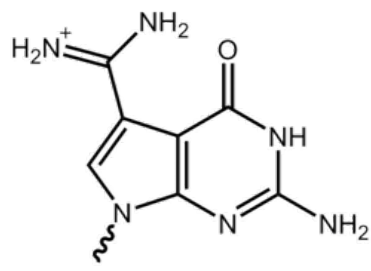


Figure 1.6 Electron density computed for Guanine and modeled $\mathrm{G}^{+}$. The model proposes a substitution of a coordinated magnesium ion in unmodified tRNA for the positively charged formamidino group of $\mathrm{G}^{+}(R N A .2007 \mathrm{Sep} ; 13(9)$ : 1427-1436).
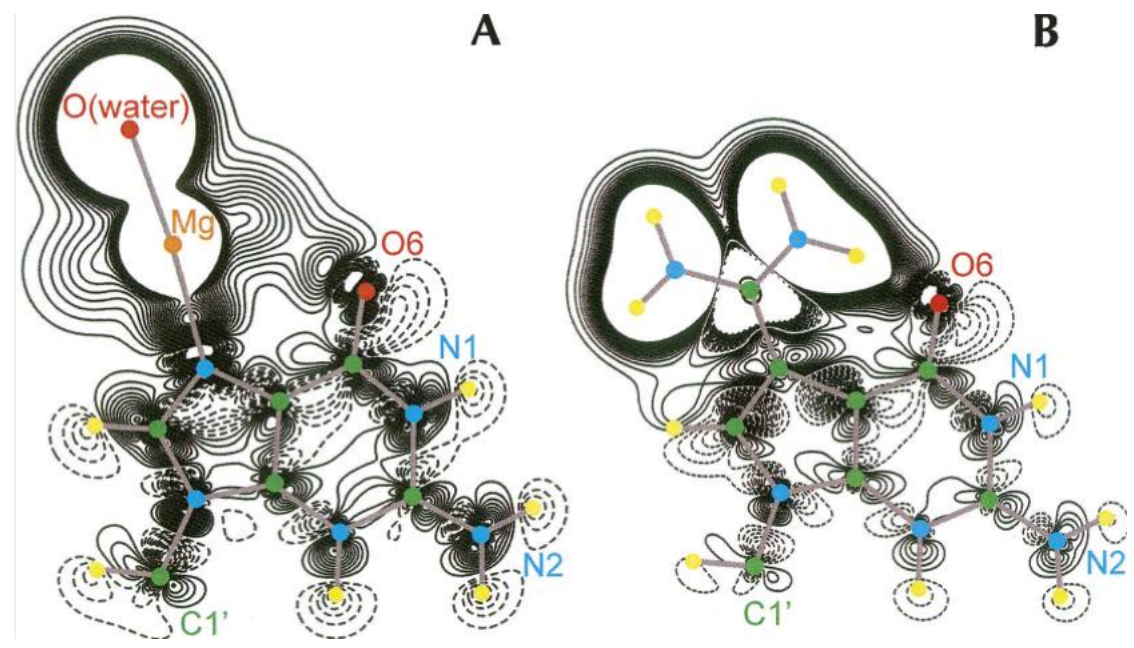
Figure 1.7 The positioning of $\mathrm{Mg}^{2+}$ and $\mathrm{Mn}^{2+}$ in the proximity of $\mathrm{N} 7$ in guanine 15 . The crystal structure of tRNAPhe from $S$. cerevisiae showing the unmodified Levit base pair (G15-C48) in stick mode. The neighboring nucleotides are shown in surface render indicating negatively charged phosphates (orange and red) surrounding the manganese ion (purple sphere).

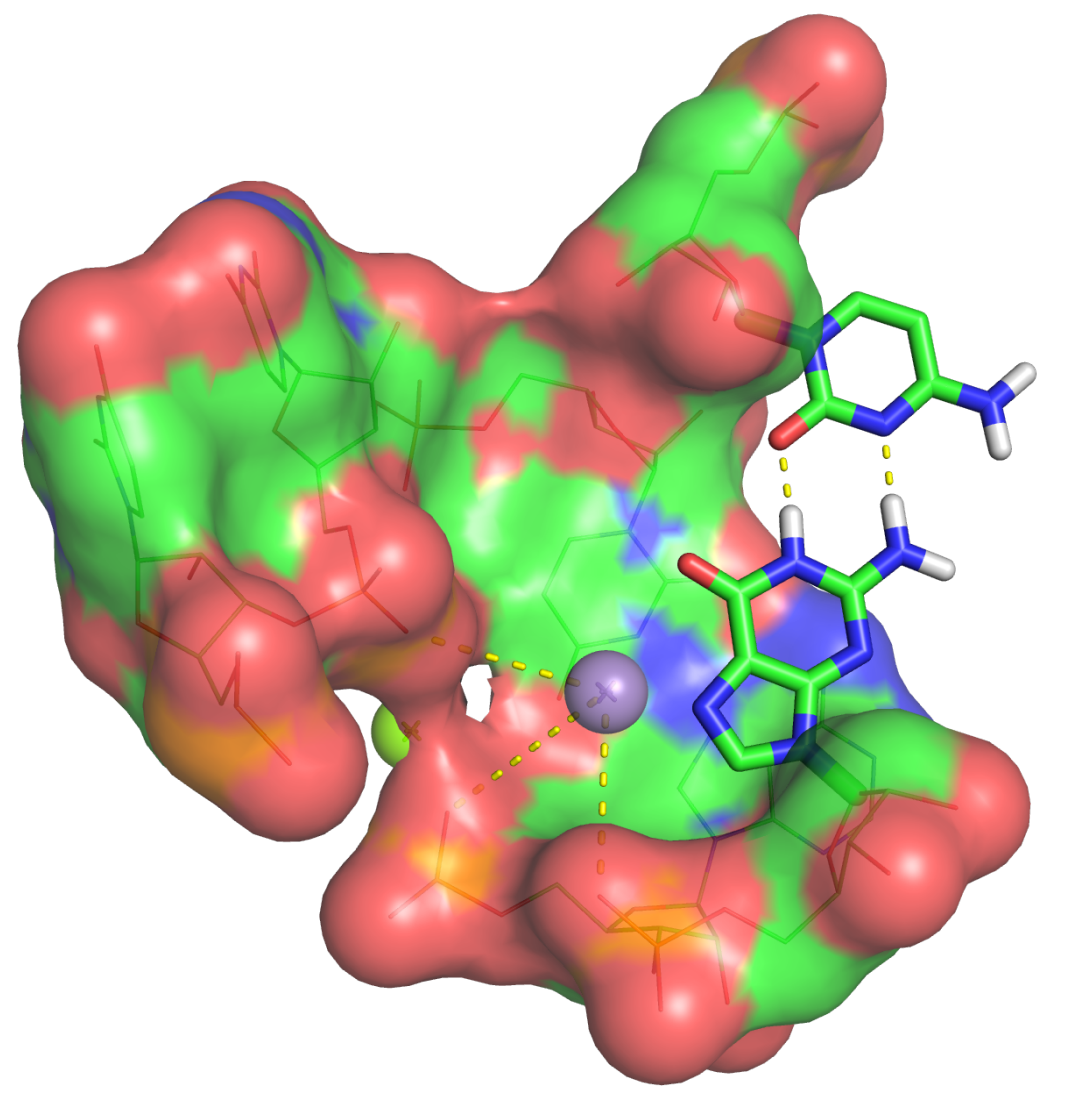


Figure 1.8 Thermal melting of tRNA structure. Using the hyperchromic effect of UV absorbance during thermal denaturation of tRNA it is possible to detect the unfolding events as subpopulations in the melting profile (first differential plot of dAbs vs T). (a) the melting of in vitro and in vivo tRNAPhe in EDTA (dotted), $100 \mu \mathrm{M} \mathrm{MgCl}_{2}$ (solid) and $4 \mathrm{mM} \mathrm{MgCl}_{2}$ (dashed) (NAR 1998 Jun 1; 26(11): 2723-2728). Subpopulations shown as peaks I or II have been previously deconvoluted by NMR studies to represent individual structures falling apart. (b) the subpopulations are sensitive to the concentration of magnesium ions and at biologically relevant concentrations the melting of tRNA collapses into a single melting event dictated by the breaking of the D-stem/T-stem contacts. (Trends Biochem Sci. 1996 Apr;21(4):145-9).

(a)

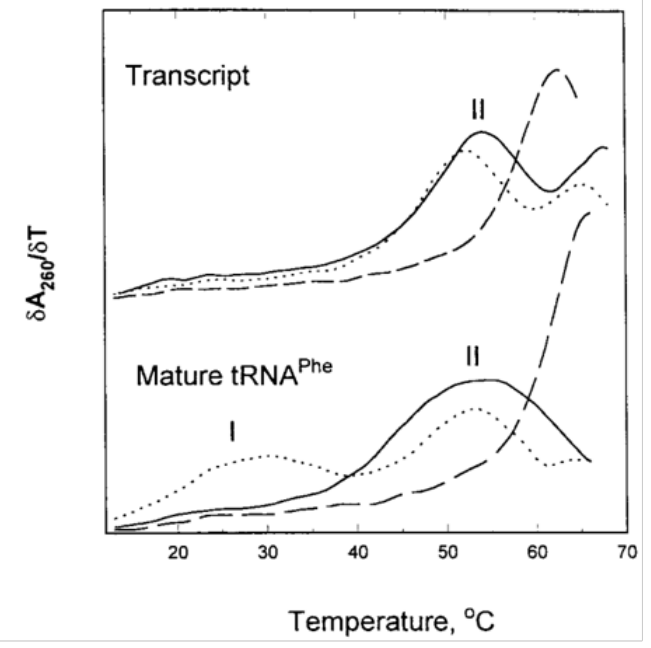

(b)

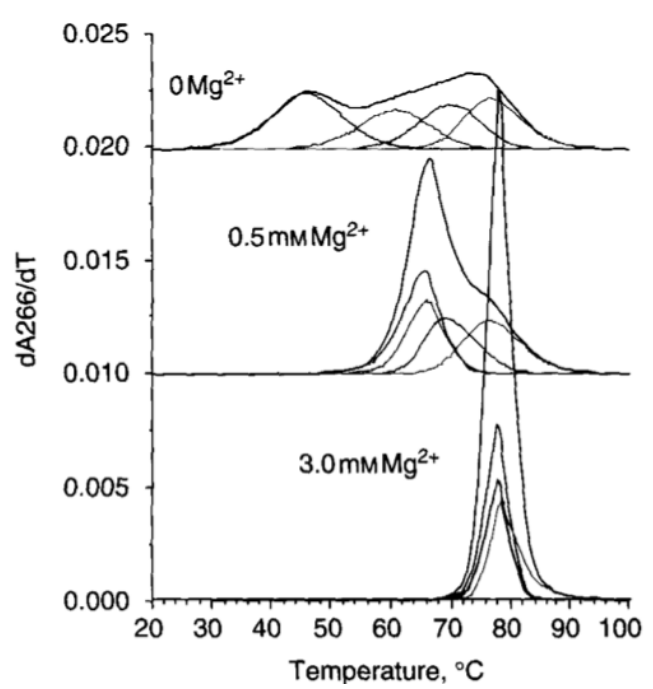


Figure 1.9 The de novo synthesis and salvage pathways of NADH. Schematic for the biosynthetic pathway of both NAD and ultimately NADP cofactors. (FEBS Journal, 2012, 279, 3355-3363)

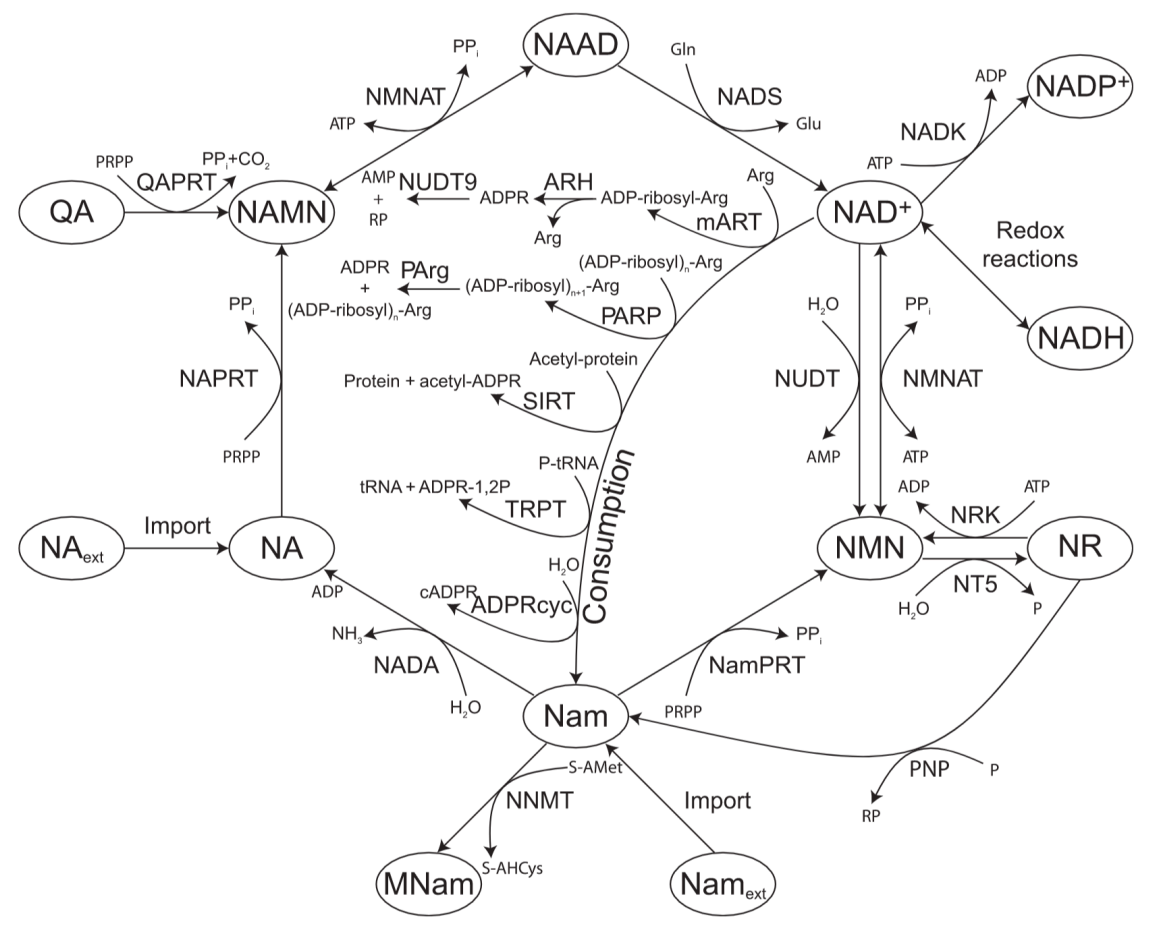


Figure 3.1 SDS PAGE analysis of arcTGT purification. CFE is the total soluble protein fraction and RT is the run through fraction that does not interact with the resin. Unbound and non-specifically bound proteins are eluted at 0 and $10 \mathrm{mM}$ imidazole respectively. The target 6 His fusion protein is eluted at $50 \mathrm{mM}$ imidazole.

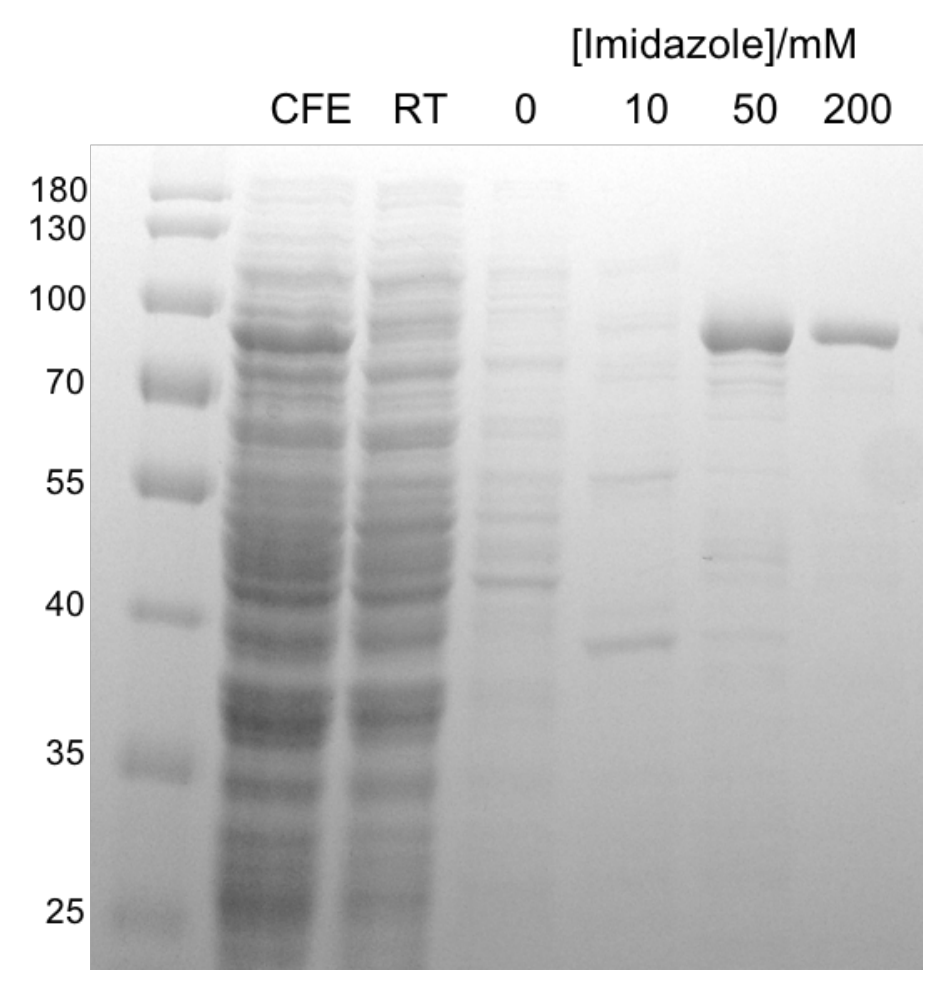


Figure 3.2 SDS PAGE analysis of ArcS purification. SN is the total soluble protein fraction obtained following lysis and RT is the run through fraction that does not interact with the resin. A stepwise gradient of imidazole concentration was applied and the target ArcS was eluted at 50mM imidazole.

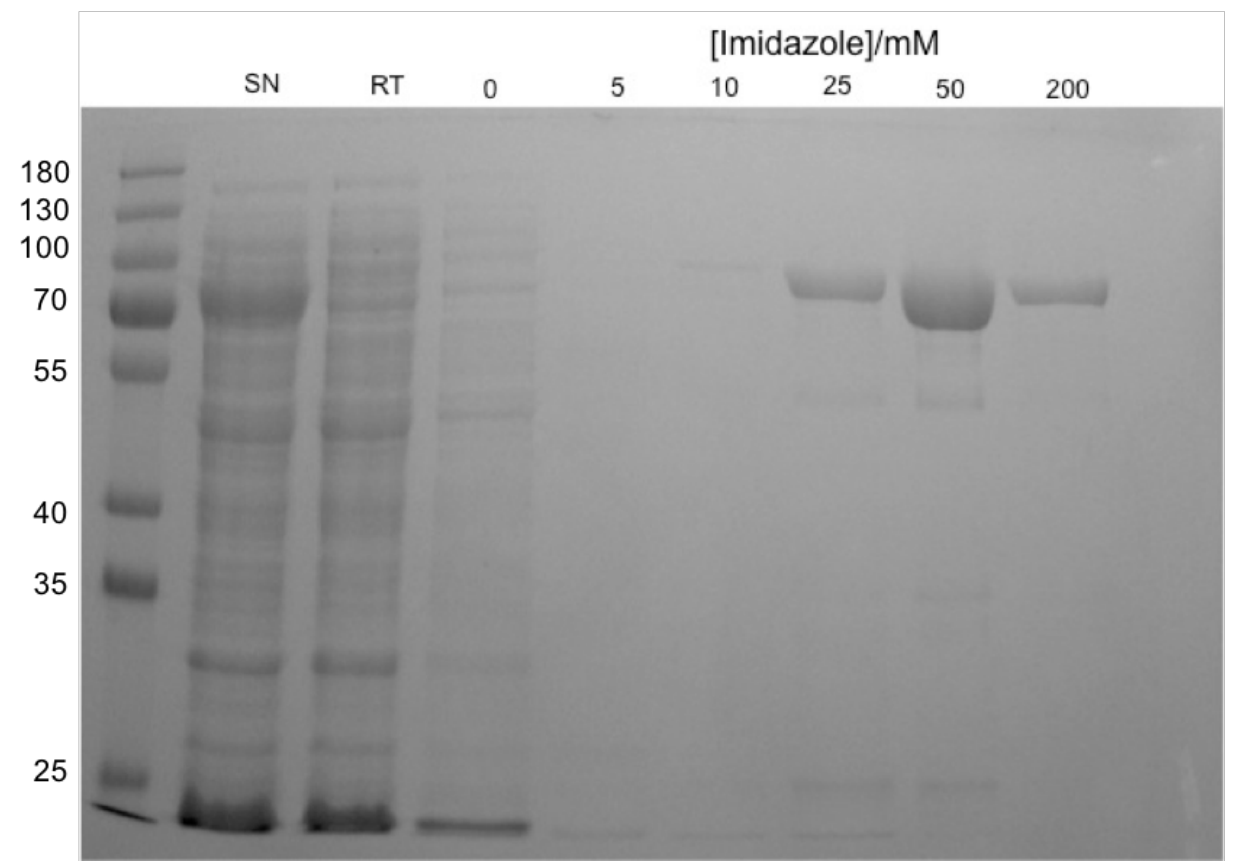


Figure 3.3 Modification of the in vitro prepared tRNA. (a) shows the $\left[8{ }^{14} \mathrm{C}\right.$-guanine] incorporation into substrate tRNA to assay arcTGT activity. (b) HPLC separation of total nucleoside digest of $\mathrm{preQ}_{0}$ modified tRNA, with the modified nucleoside eluting at approximately 21.5 minutes. (c) transformation of preQ $_{0}$ (black) in to $\mathrm{G}^{+}$(gray) by the activity of ArcS, again showing total nucleoside digest analysis by RP-HPLC.

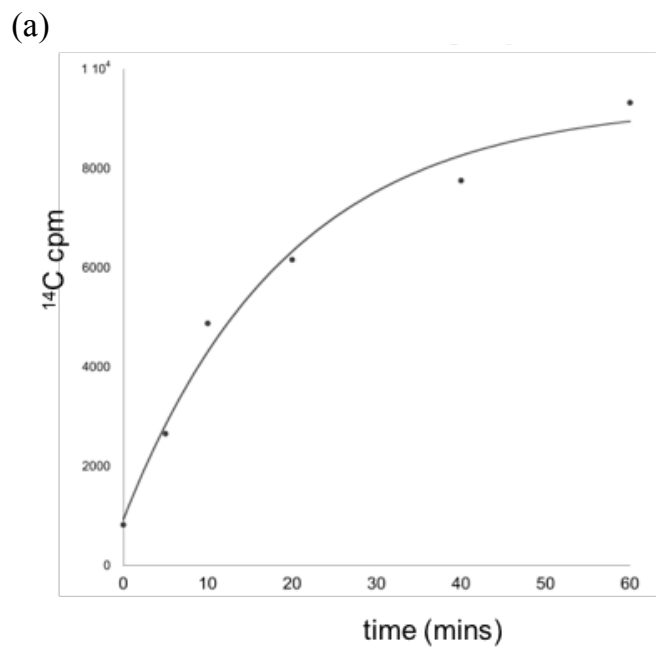

(b)

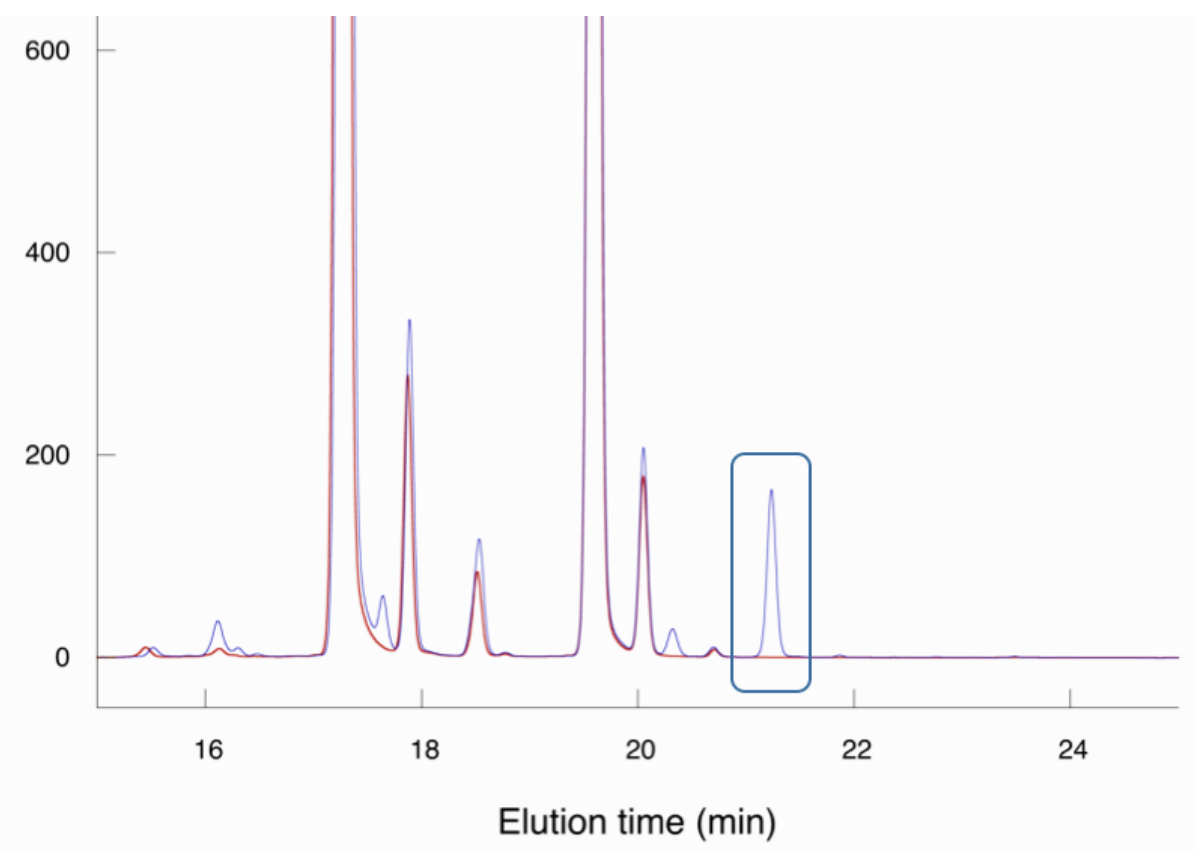


(c)

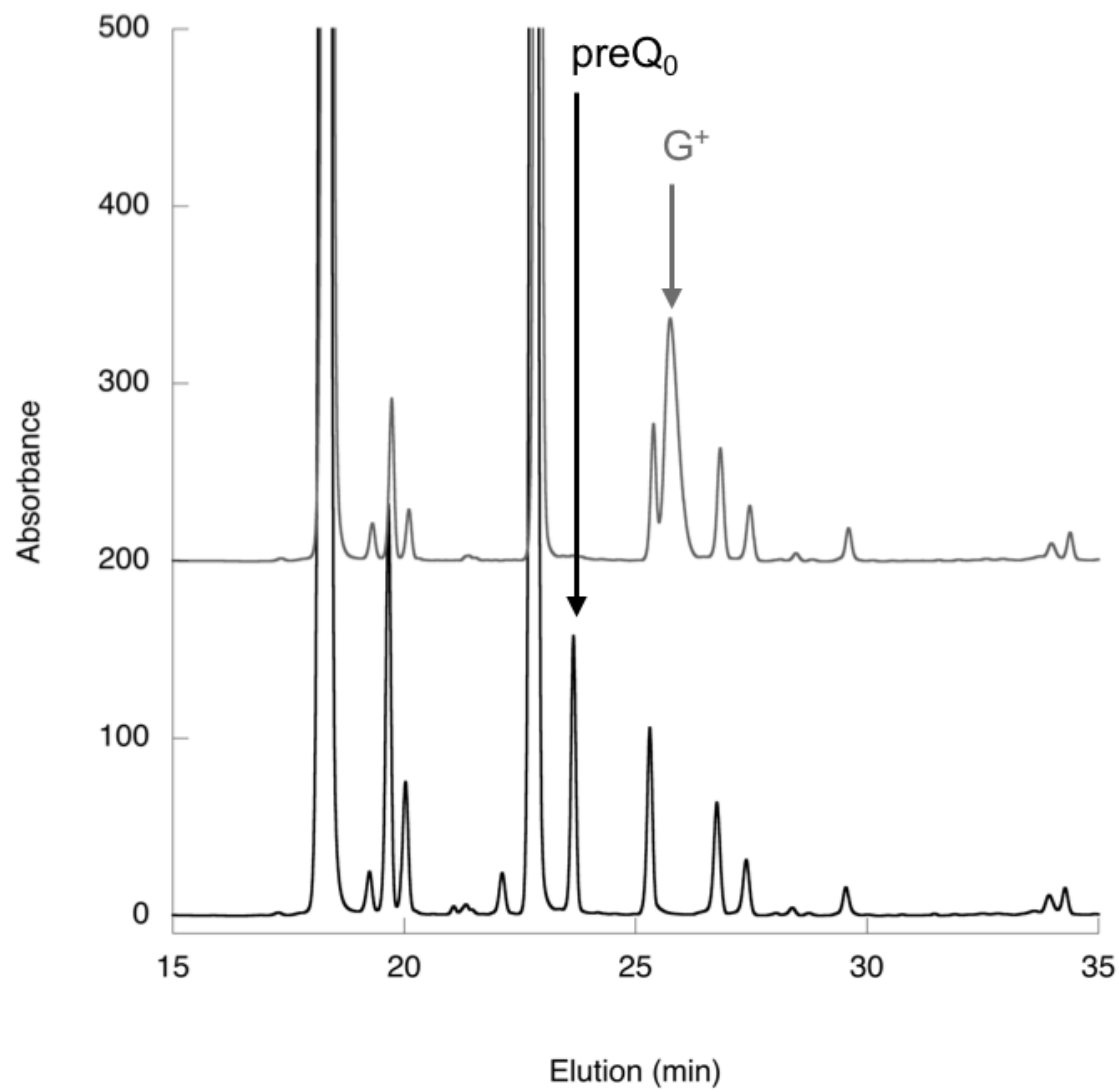


Figure 3.4 Magnesium dependence of thermal stability of tRNA. The in vitro transcribed tRNA for (a) H. volcanii, (b) M. thermautotrophicus and (c) E. coli have been modified to feature preQ $\mathrm{Q}_{0}$ or $\mathrm{G}^{+}$. The RNA is melted under increasing concentrations of $\mathrm{Mg}^{2+}$ ions in a background of $100 \mathrm{mM} \mathrm{NaCl}$. The isotherms are fitted to a two-state model to obtain minimal and maximal melting temperatures.

(a)

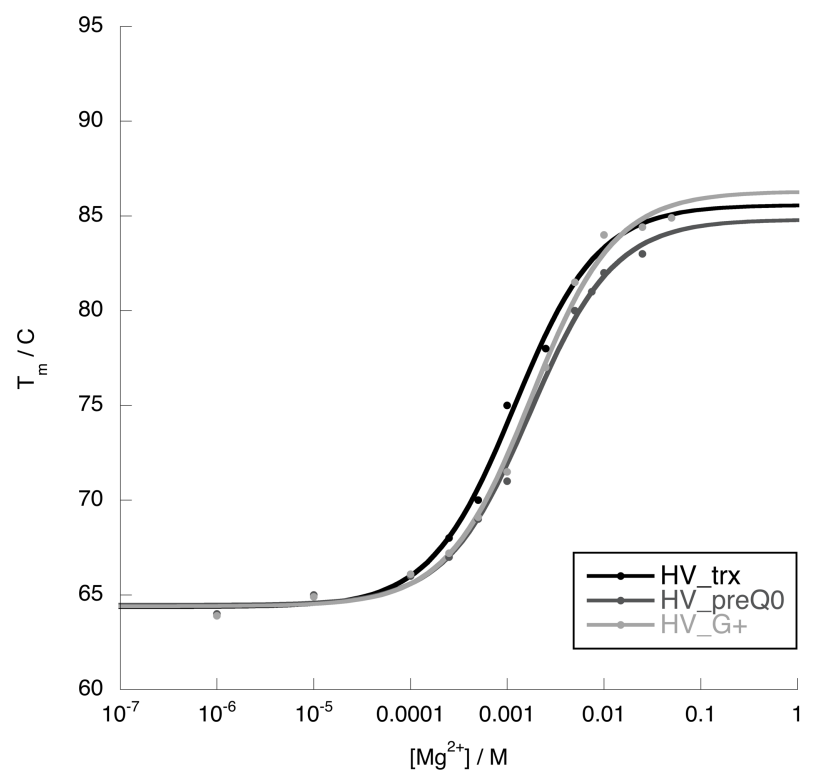

(b)

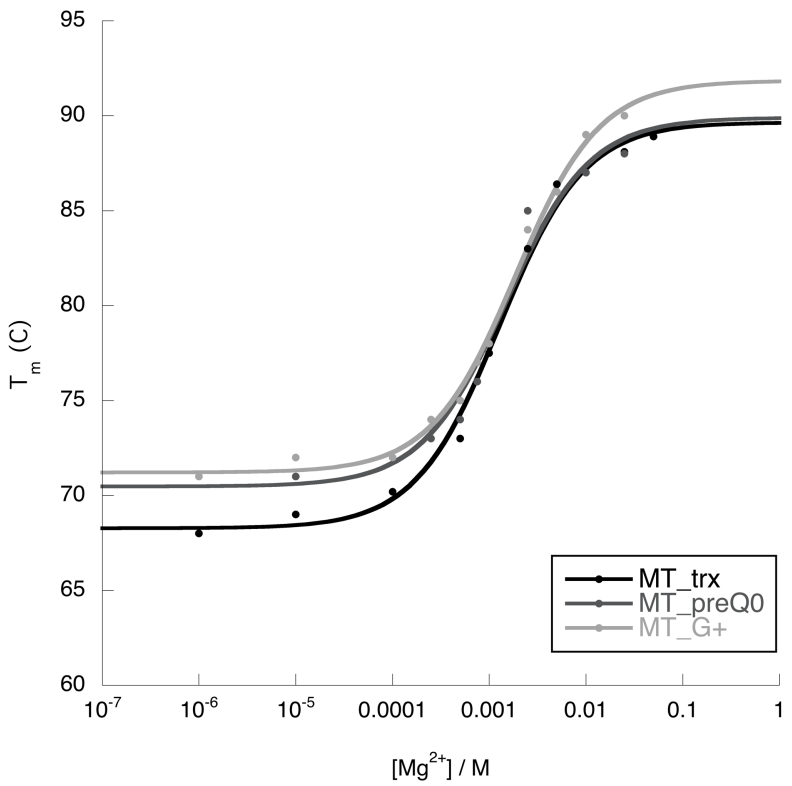


(c)

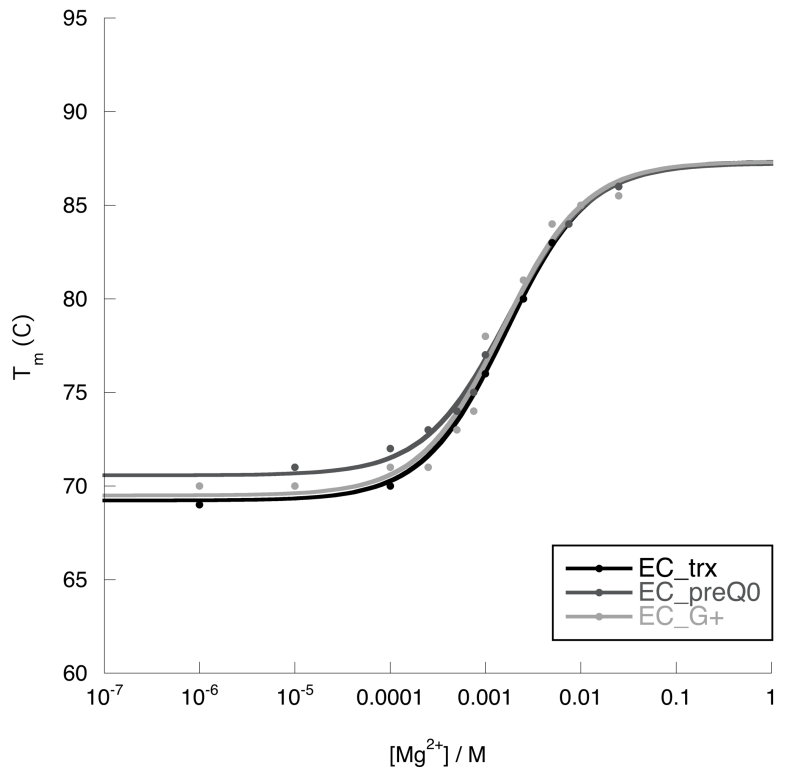


Figure 3.5 Magnesium dependence of thermal stability of tRNA. The extracted values for the isotherm fits of magnesium dependence on $T_{m}$. For each RNA species and modification state there is a minimum and maximum $\mathrm{T}_{\mathrm{m}}$ and the transition midpoint for the response.

\begin{tabular}{|l|l|l|l|}
\hline HV CGA & trx & preQ $_{\mathbf{0}}$ & $\mathbf{G}^{+}$ \\
\hline $\min$ & 64.3 & 64.5 & 64.4 \\
\hline $\max$ & 85.5 & 84.8 & 86.2 \\
\hline$\left[\mathrm{Mg}^{2+}\right]_{1 / 2}$ & $1.2 \mathrm{mM}$ & $1.7 \mathrm{mM}$ & $1.8 \mathrm{mM}$ \\
\hline $\mathrm{MT}$ UUG & trx & preQ & $\mathrm{G}^{+}$ \\
\hline $\min$ & 68.3 & 70.5 & 71.2 \\
\hline $\max$ & 89.7 & 89.9 & 91.8 \\
\hline$\left[\mathrm{Mg}^{2+}\right]_{1 / 2}$ & $1.2 \mathrm{mM}$ & $1.5 \mathrm{mM}$ & $1.9 \mathrm{mM}$ \\
\hline $\mathrm{EC} \mathrm{Gln}^{+}$ & trx & preQ & $\mathrm{G}^{+}$ \\
\hline $\min$ & 69.2 & 70.5 & 69.5 \\
\hline $\max$ & 87.3 & 87.4 & 87.3 \\
\hline$\left[\mathrm{Mg}^{2+}\right]_{1 / 2}$ & $1.6 \mathrm{mM}$ & $1.7 \mathrm{mM}$ & $1.5 \mathrm{mM}$ \\
\hline
\end{tabular}


Figure 3.6 Magnesium binding by fluorescence of HQS. (a) Preparation of the demetallated HQS reagent by recrystalization gives a magnesium responsive fluorophore whose absorbance spectra have well defined isosbestic points. (b) Binding of magnesium in the absence (red) and presence of trx (dark blue) and $\mathrm{G}^{+}$(light blue) tRNA gives an observed shift in the affinity of magnesium for the dye. (c) The difference between the control titration (HQS alone) and the RNA titration is used to deduce the preferential binding coefficient (colored as previous figure).

(a)
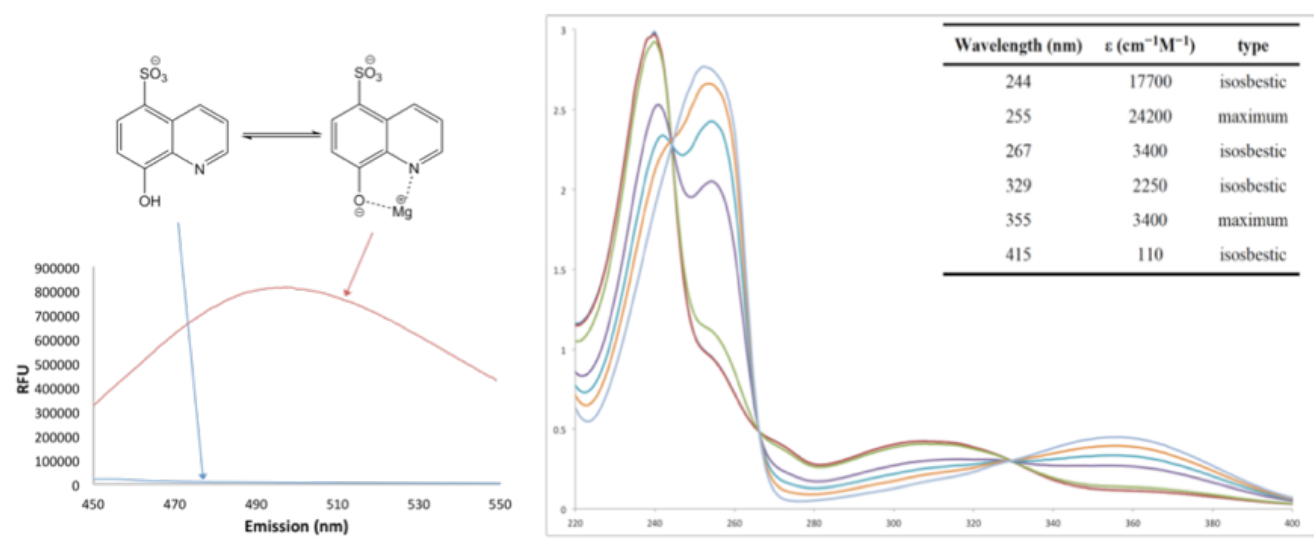

(b)

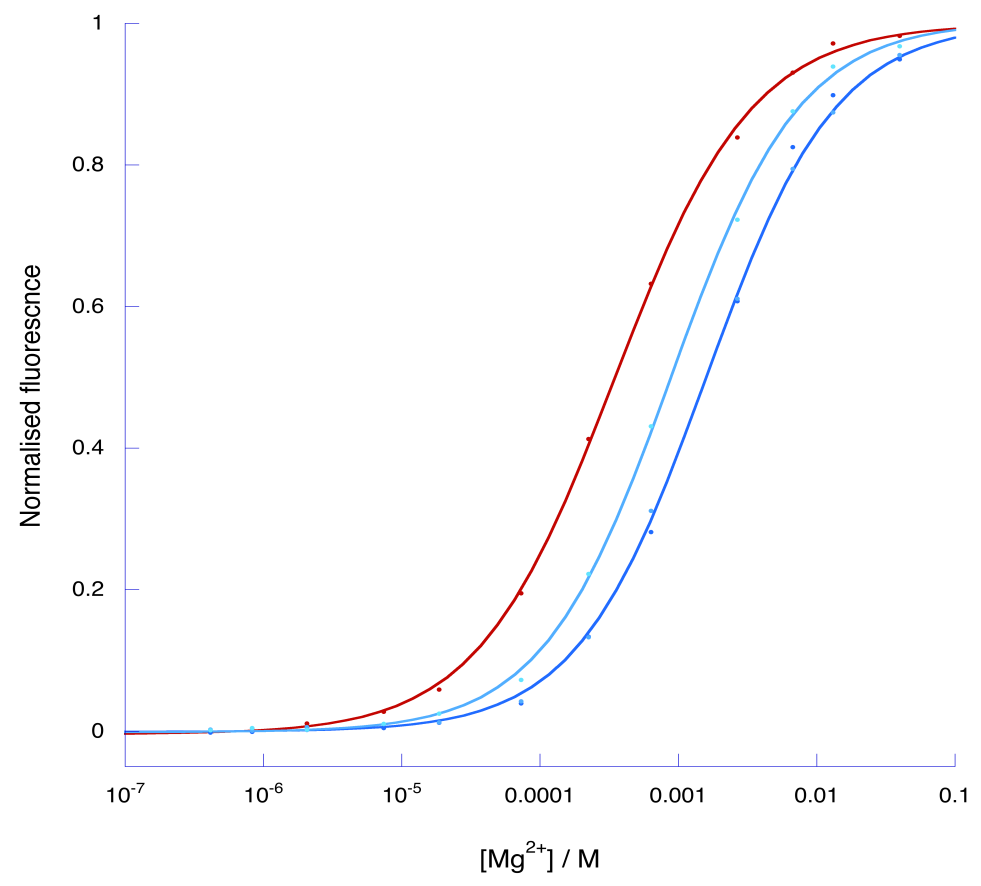


(c)

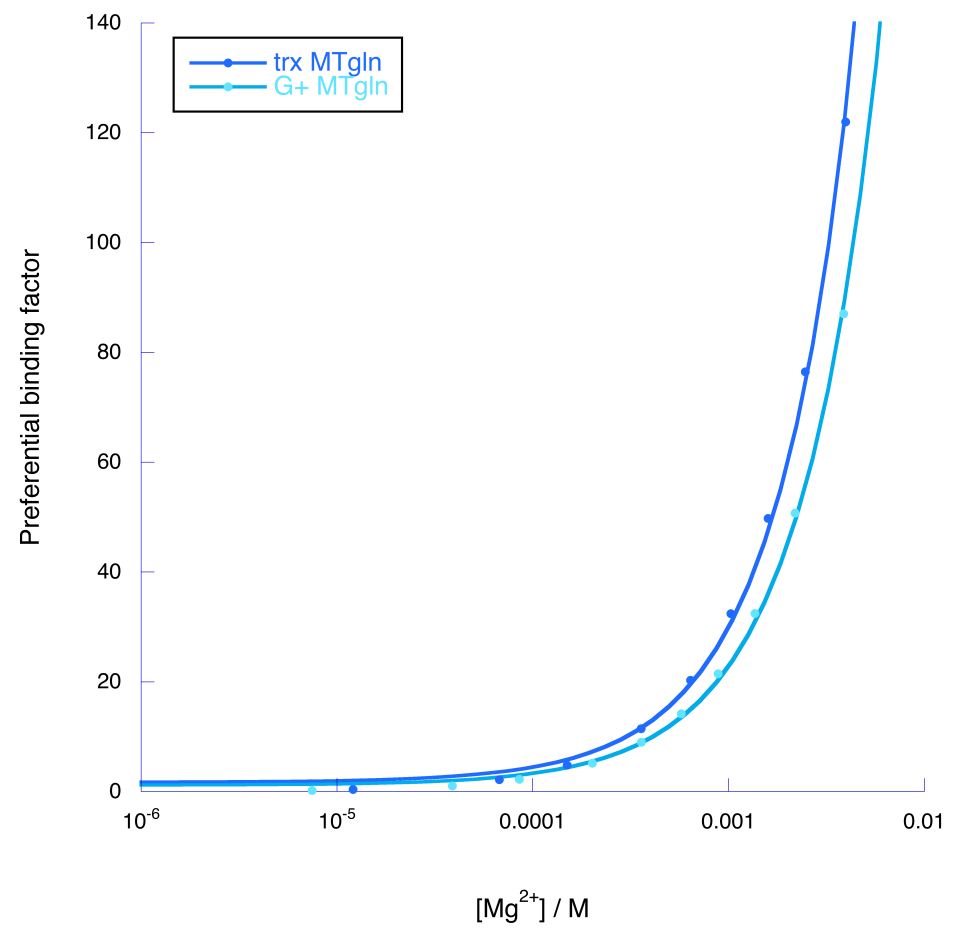


Figure 3.7 Scheme for the generation of arcTGT (TK0760). The addition of the TK0149 to the knockout cassette permits temporary prototrophism to be established in the normally agmatine auxotrophic TKO strain. The gene for 6-methylpurine (6MP) acts as a counter selective agent to drive the looping out of the cassette to produce the final stable TK0760 cell line.

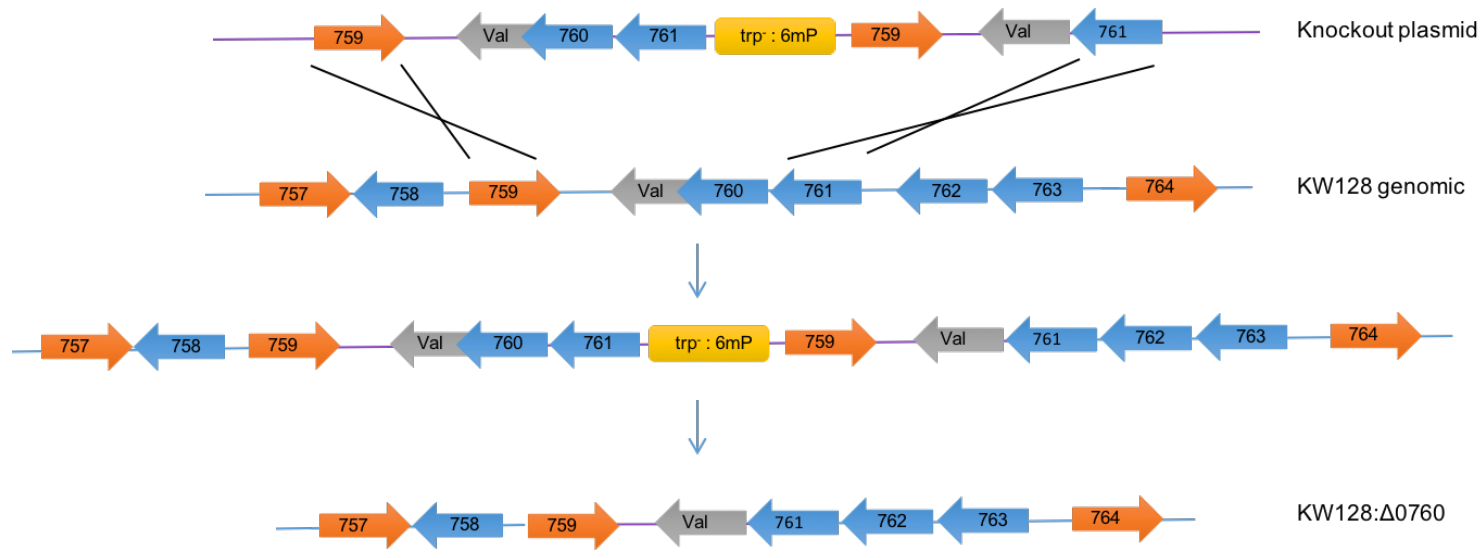


Figure 3.8 Confirmation of knockout in TKO cell line by PCR. Genomic material was recovered from each cell line and amplified by PCR, targeting either the TGT gene cassette (lanes 1, 2 and 3) or the ArcS gene cassette (lanes 4, 5 and 6). Lanes 1 and 4 confirm WT maintains both genes. Lanes 2 and 6 confirm the TGT and ArcS, respectively, have been successfully knockdown with truncation of the cassette. ArcS is still present in the $\Delta t g t$ cells and TGT is still present in $\triangle \operatorname{arc} S$.

1. 2 3. 4. 5. 6 .

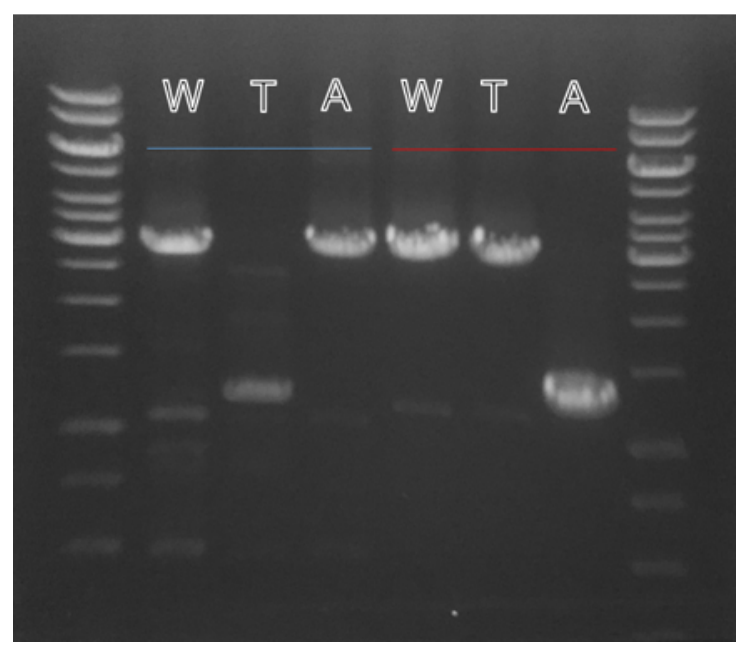


Figure 3.9 Analysis of purified total in vivo tRNA. (a) Denaturing PAGE separation of the tRNA pool extracted from the three cells lines. $1 \& 2$ are $\mathrm{WT} \mathrm{LiCl} \mathrm{precipitation} \mathrm{products,}$ $3 \& 4 \Delta \operatorname{tgt}$ and $5 \& 6$ are $\Delta \operatorname{arcS}$. (b) Total nucleoside digest of the samples analyzed by RPHPLC. PreQ ${ }_{0}$ appears at 26 minutes and is absent from the WT and $\triangle \operatorname{arcS}$ samples. G ${ }^{+}$ elutes at 30 minutes and is present in the wild type sample only.

(a)

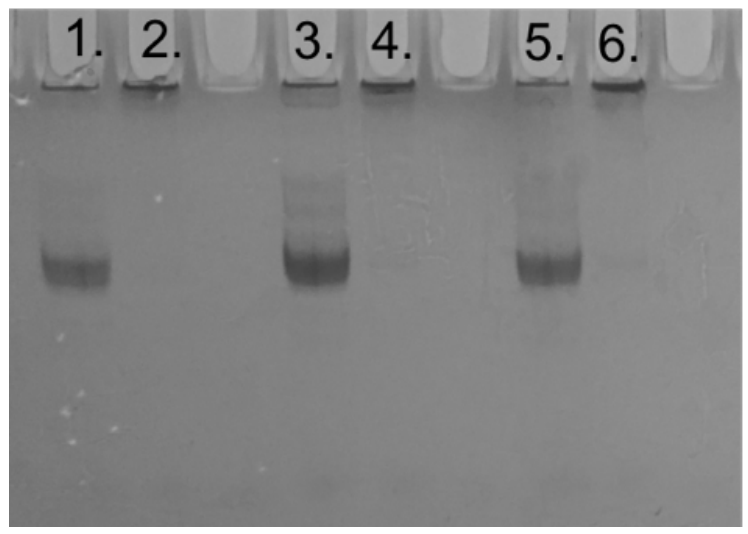

rRNA

tRNA

(b)
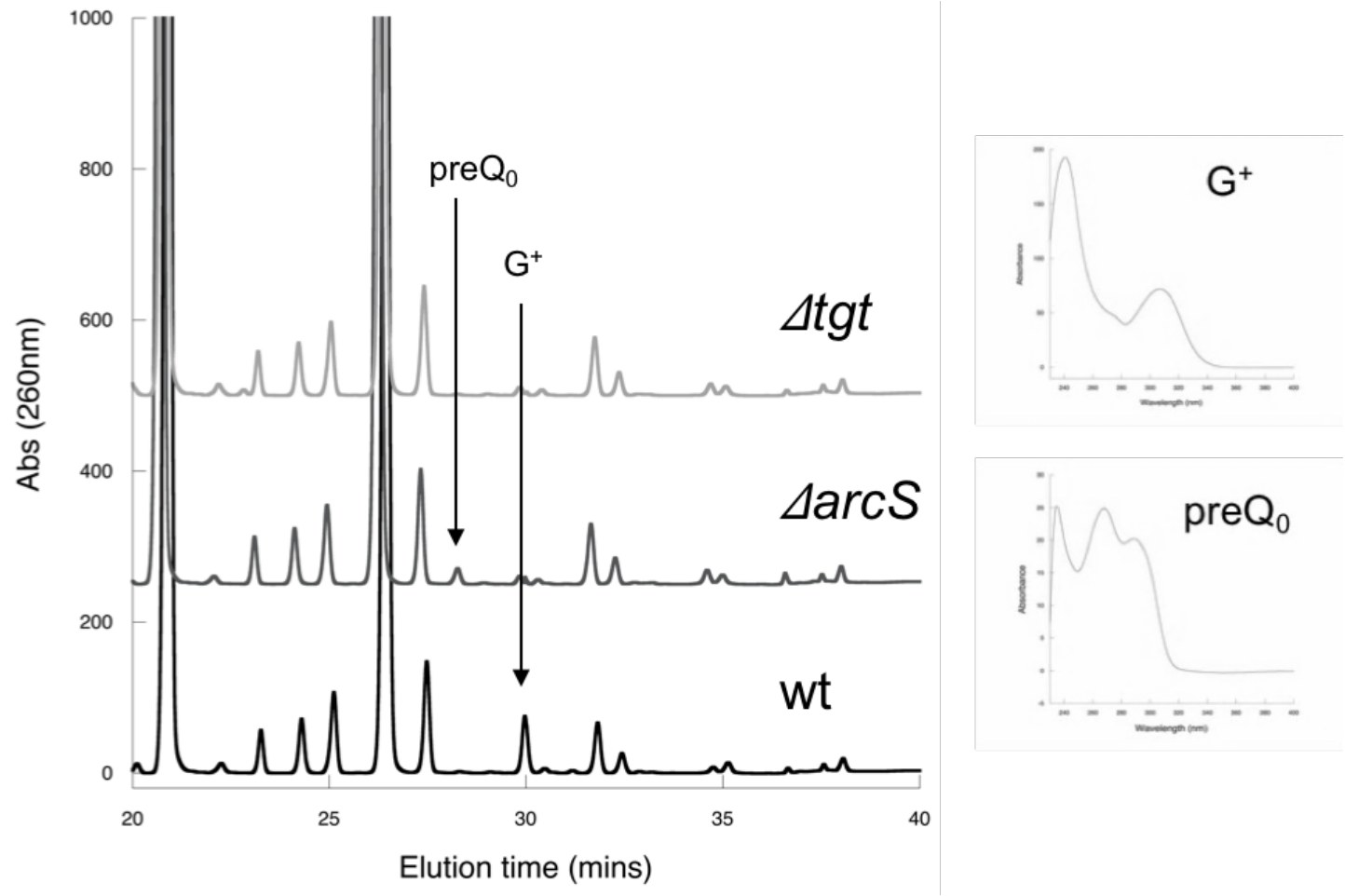
Figure 3.10 Mass spectrometry of the in vivo modified tRNA. The extracted chromatogram for $\mathrm{G}^{+}\left(324+\mathrm{H}^{+}\right)$are shown for each cell line tRNA sample. (a) The WT shows a strong peak at 29 minutes corresponding to the $\mathrm{G}^{+}$nucleoside. (b) In the TGT knockout, no peak is seen for this mass confirming the expected effect. (c) In the Arcs knockout, there is a peak at approximately $1.6 \%$ of the WT intensity seen.

(a)

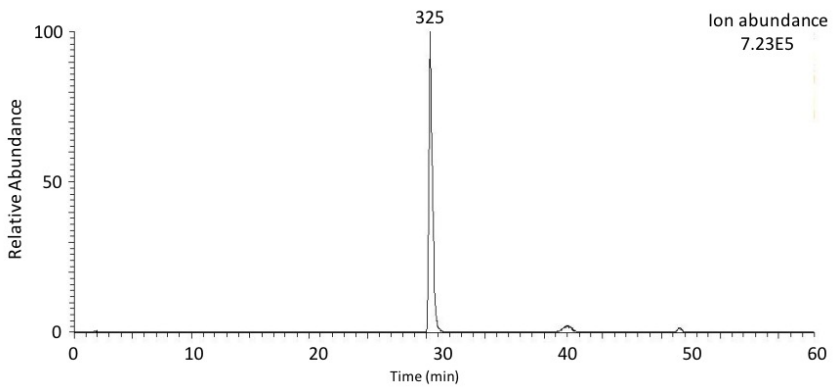

(b)

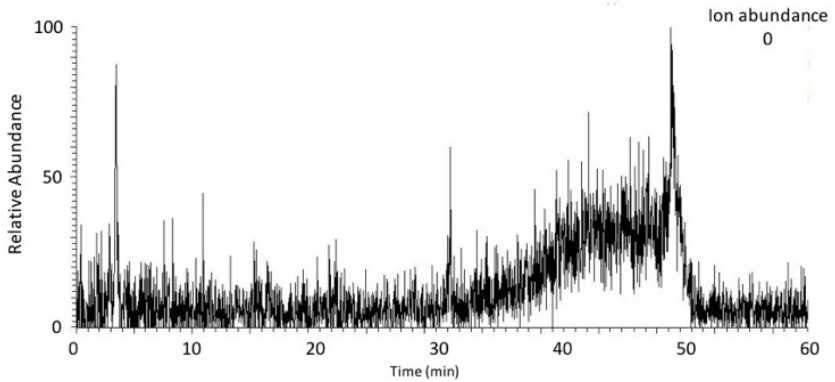

(c)

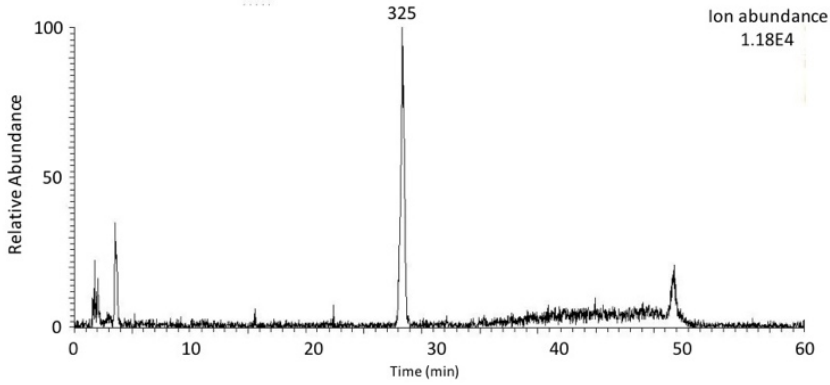


Figure 3.11 Affinity tag for isolation of GlnX isoacceptor from TKO. (a) The target sequences of the GlnX gene that were used to derive affinity oligos (the reverse compliment of sequence shown). (b) Native PAGE analysis of the complexes formed between the four candidate oligos and the transcribed tRNA ${ }^{\mathrm{CUG}}$.

(a)

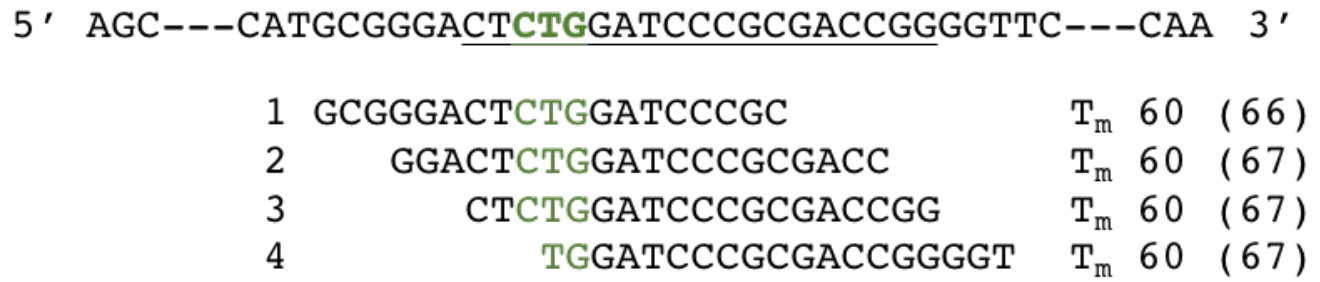

(b)

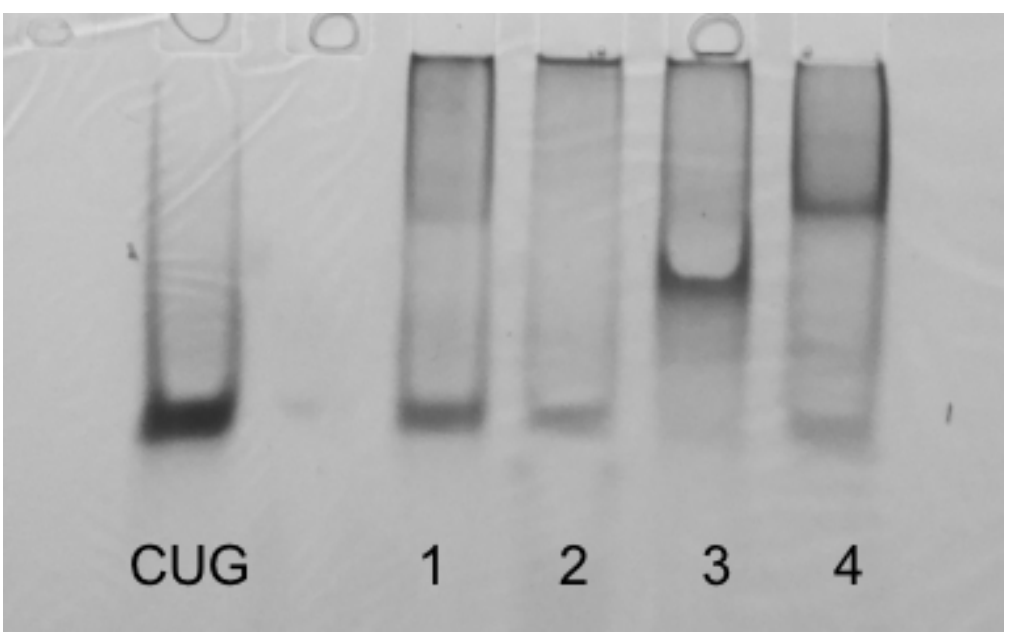


Figure 3.12 Purification of the GlnX isoacceptors. Total tRNA from the three cell lines was incubated with streptavidin sepharose which had been coupled with the biotinylated Aff3 oligo. The RNA (in $10 \mathrm{mM}$ Tris. $\mathrm{HCl} \mathrm{pH} 7.0,900 \mathrm{mM} \mathrm{NaCl}$ and $1 \mathrm{mM}$ EDTA) was heated to $95^{\circ} \mathrm{C}$ and mixed with pre-equilibrated resin. The suspension was slow cooled to allow the Aff3 to anneal to the tRNA. The wash fractions (W) of annealing buffer were continued until the $\mathrm{OD}_{260}$ was below 0.001 units. The RNA was eluted at both 45 and $75^{\circ} \mathrm{C}$ in $10 \mathrm{mM}$ Tris. $\mathrm{HCl} \mathrm{pH} 7$ and $100 \mathrm{mM} \mathrm{NaCl}$.
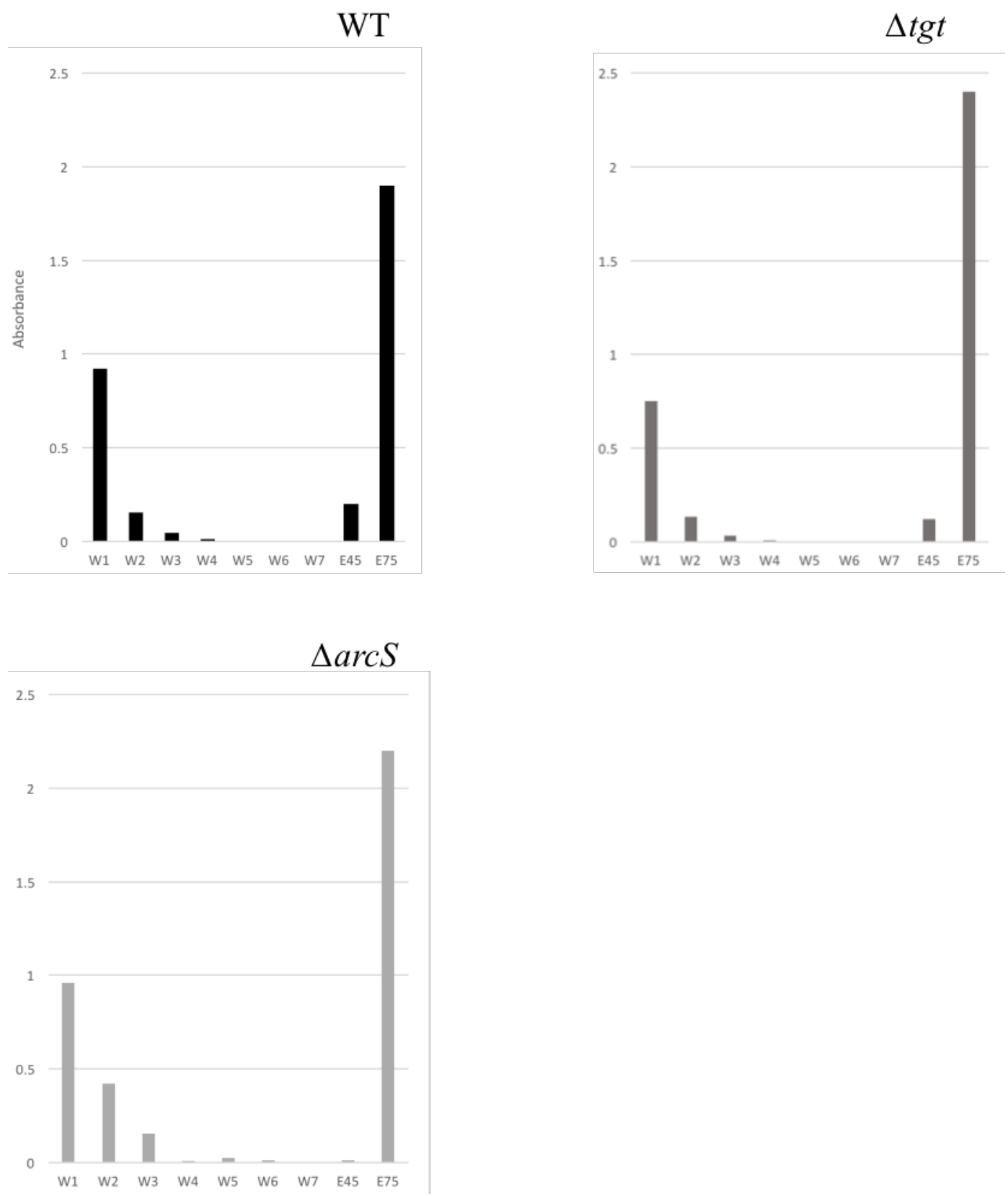
Figure 3.13 Confirmation of in vivo isoacceptor purity. The isoacceptors were slow cooled according the melt experiment prep and then run through either a 10\% denaturing PAGE (a) or an $8 \%$ native gel (b). Lane 1: mixture of tRNA ${ }^{\mathrm{CUG}}$ (76mer) and a DNA oligo at 49 bases (d49) and 19 bases (d19) in length. Lane 2: WT, lane 3: $\Delta \operatorname{tgt}$ and lane 4: $\Delta \operatorname{arcS}$. Xylene cyanol (XC) and bromophenol blue (BB) are shown for electrophoretic progress.

(a)

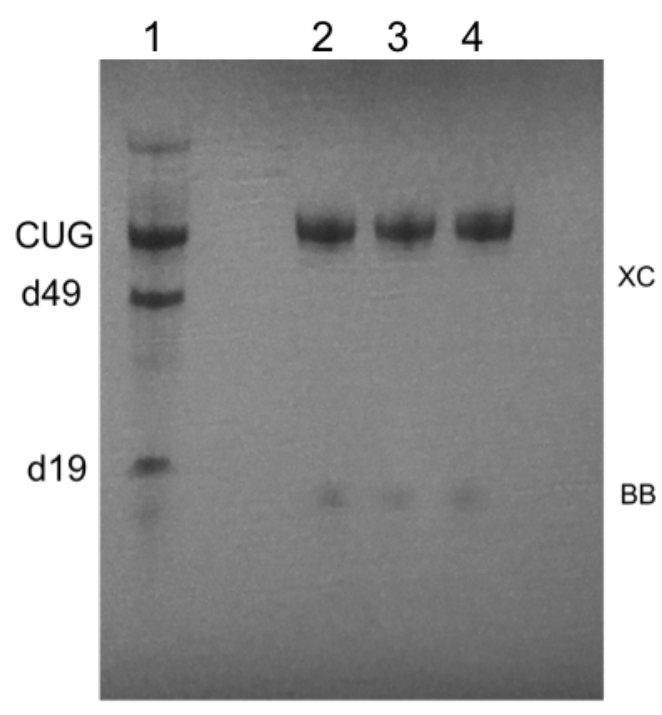

(b)

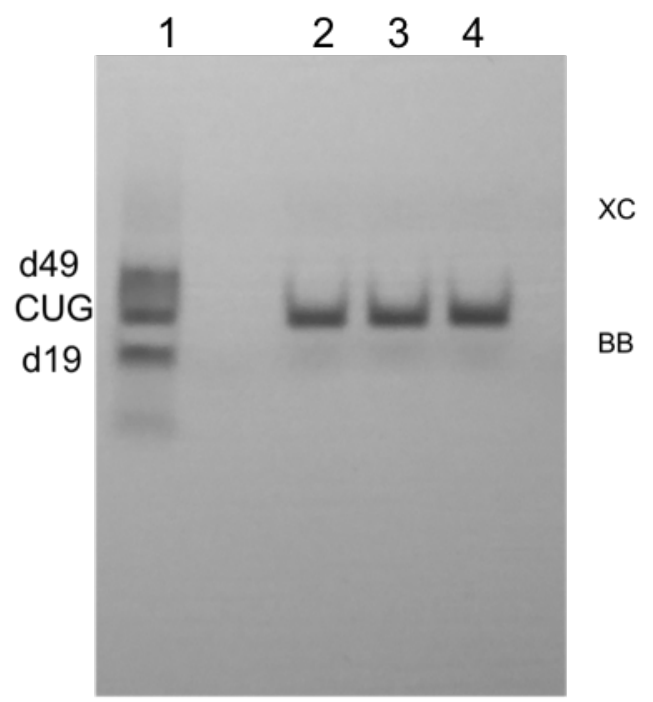


Figure 3.14 Melting profiles of in vitro produced TKO Gln ${ }^{\mathrm{CUG}}$. The Gln ${ }^{\mathrm{CUG}}$ sequence was used for comparison to the in vivo material extracted from $T$. kodakarensis. The RNA was modified in vitro to produce $\mathrm{G}$ (black), preQ $_{0}$ (dashed) or $\mathrm{G}^{+}$(gray) at position 15 . The melting profiles were recorded at (a) $100 \mathrm{mM} \mathrm{NaCl}$ (b) $1 \mu \mathrm{M} \mathrm{MgCl}_{2}$ (c) $100 \mu \mathrm{M} \mathrm{MgCl}_{2}$ and (d) $10 \mathrm{mM} \mathrm{MgC1} 1_{2}$.

(a)

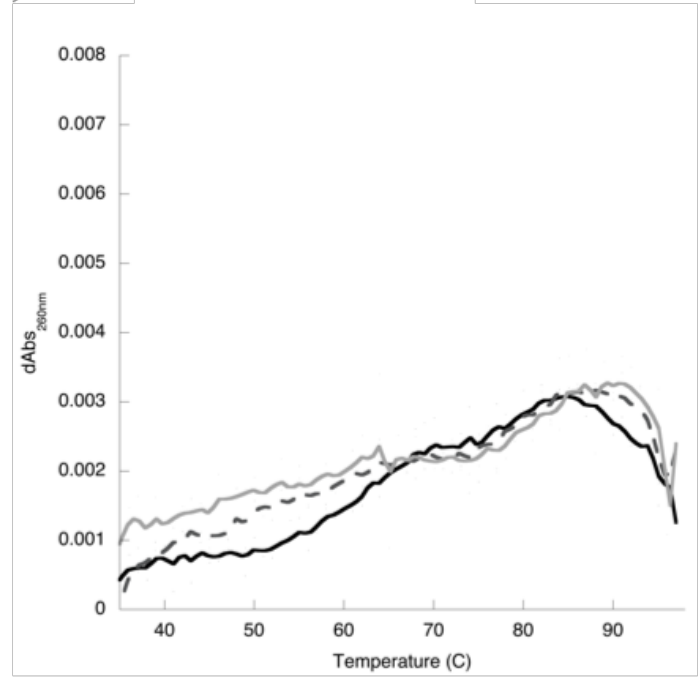

(c)

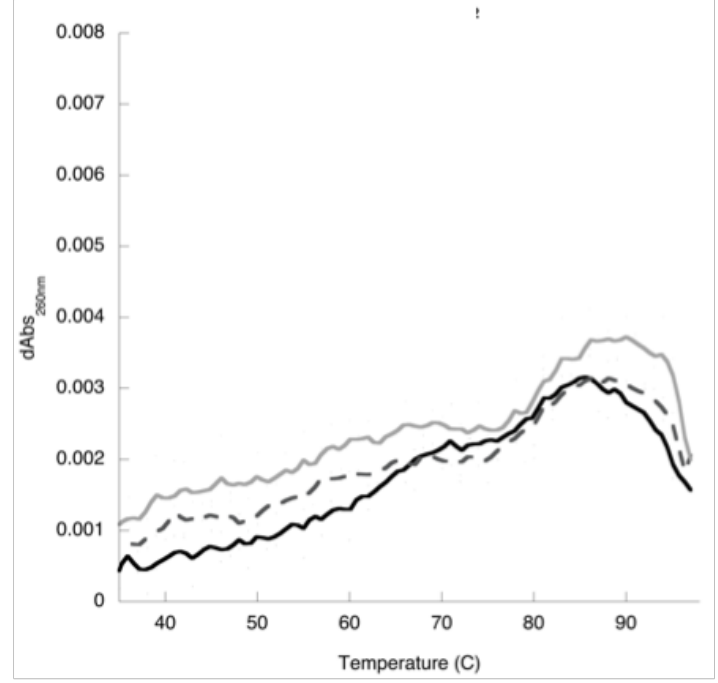

(b)

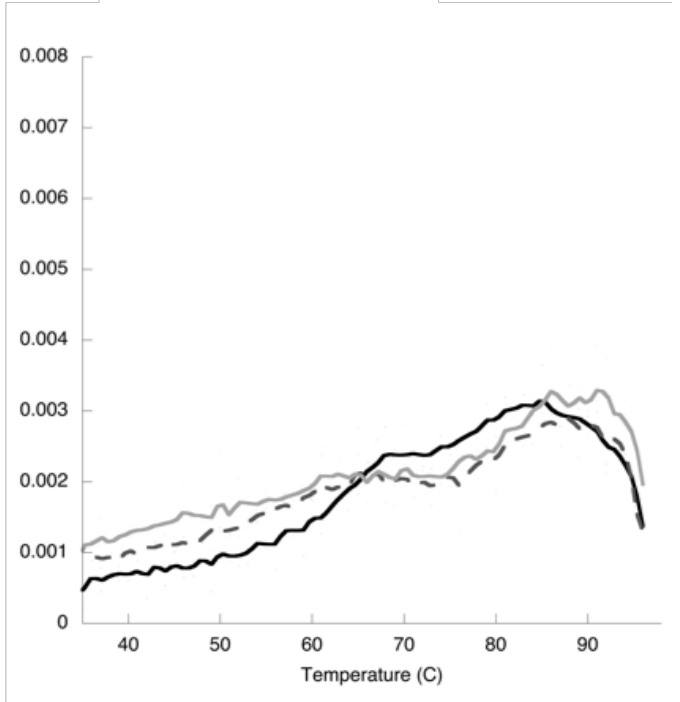

(d)

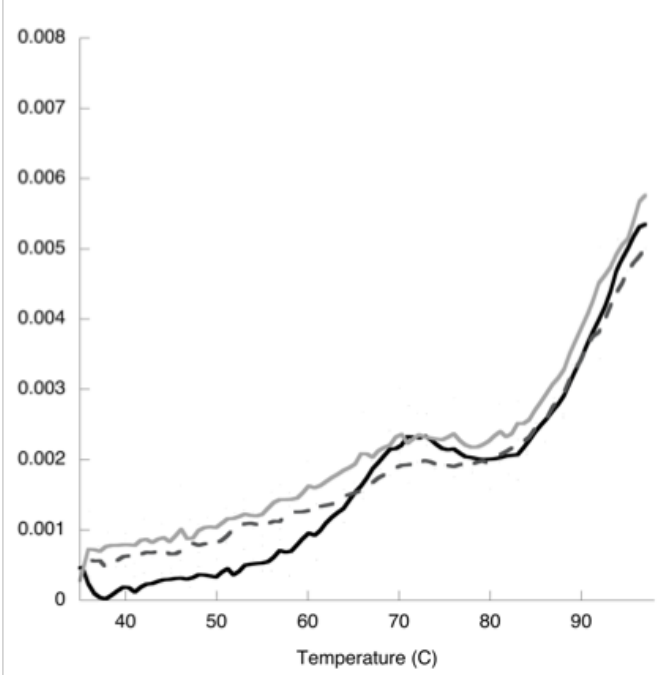


Figure 3.15 Melt profiles of in vivo TKO GlnX isoacceptor tRNA. The purified isoacceptor tRNA from $W T$ (black), $\Delta$ tgt (dashed) and $\triangle \operatorname{arcS}$ (gray) are melted in the presence of increasing $\mathrm{Mg}^{2+}$ concentrations; (a) $100 \mathrm{mM} \mathrm{NaCl}$, (b) $10 \mu \mathrm{M} \mathrm{MgCl}_{2}$ (c) $100 \mu \mathrm{M} \mathrm{MgCl}_{2}$ (d) $1 \mathrm{mM} \mathrm{MgCl} 2$ (e) $10 \mathrm{mM} \mathrm{MgCl}$.

(a)

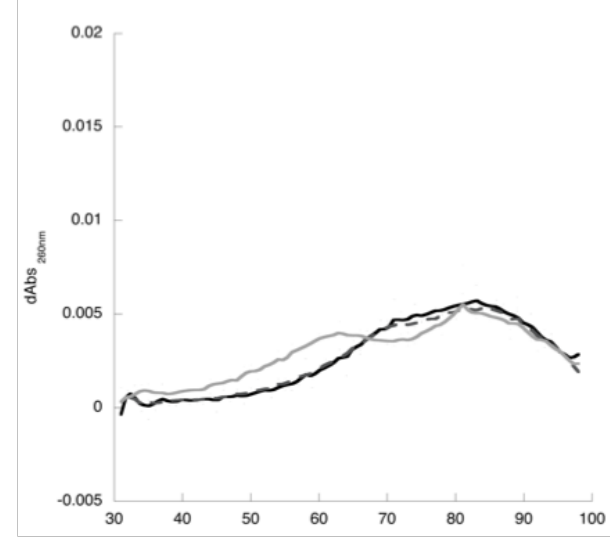

(c)

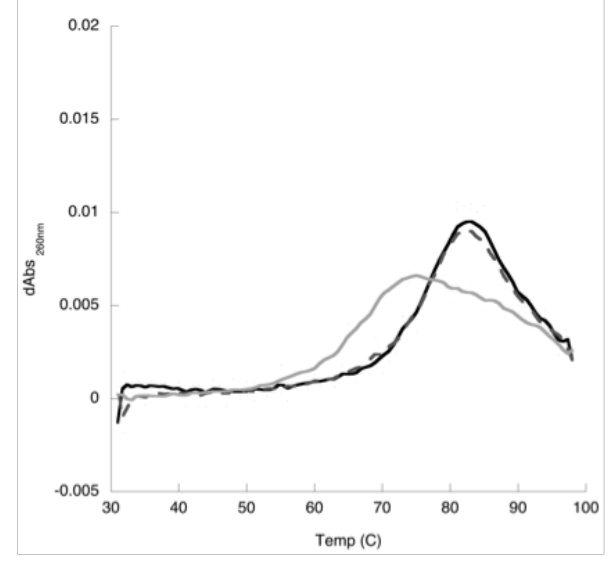

(e)

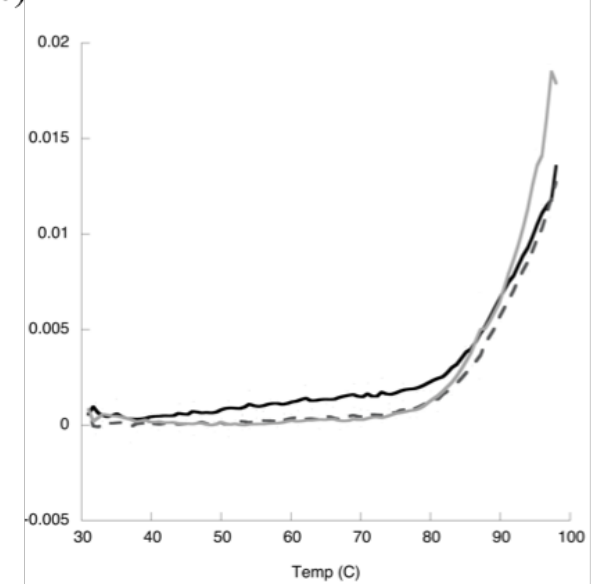

(b)

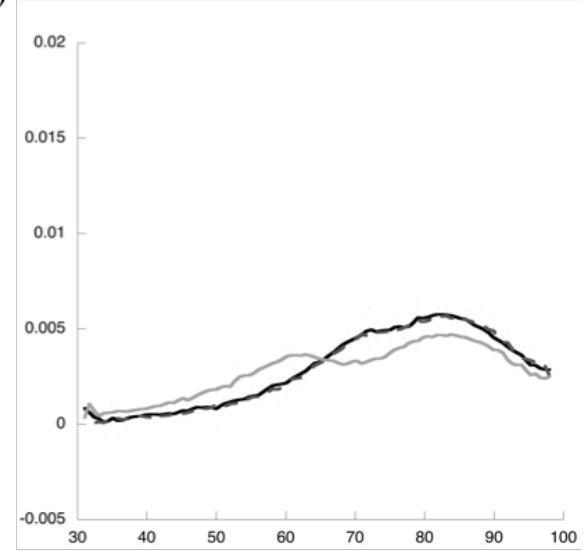

(d)

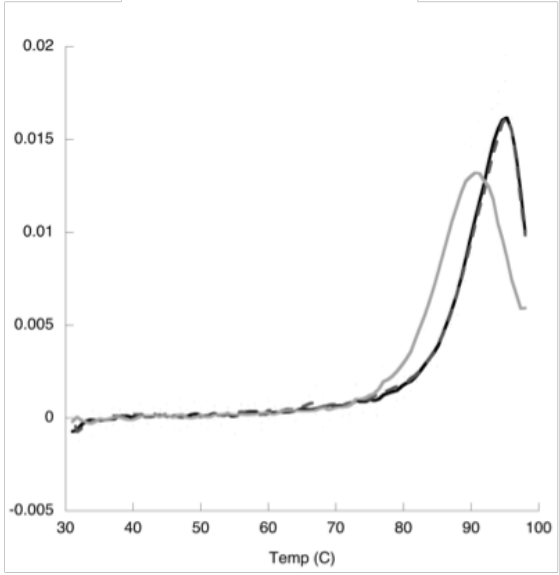


Figure 3.16 The products of acid treatment of reduced NADPH. (a) HPLC separation of NAPDH in water (red) and following treatment with $150 \mathrm{mM} \mathrm{HCl}$ (blue). HPLC was carried out using an isocratic mobile phase of $100 \mathrm{mM} \mathrm{NH}_{4} \mathrm{OAc}(\mathrm{pH} 6.8)$. (b) The extracted absorbance spectrum (red) for the peak at 3.3 minutes of the untreated NADPH separation. The product peaks for the adenosyl moiety (dashed blue) and nicotinamide moiety (solid blue) eluting at around 0.5 and 6.5 minutes respectively.

(a)

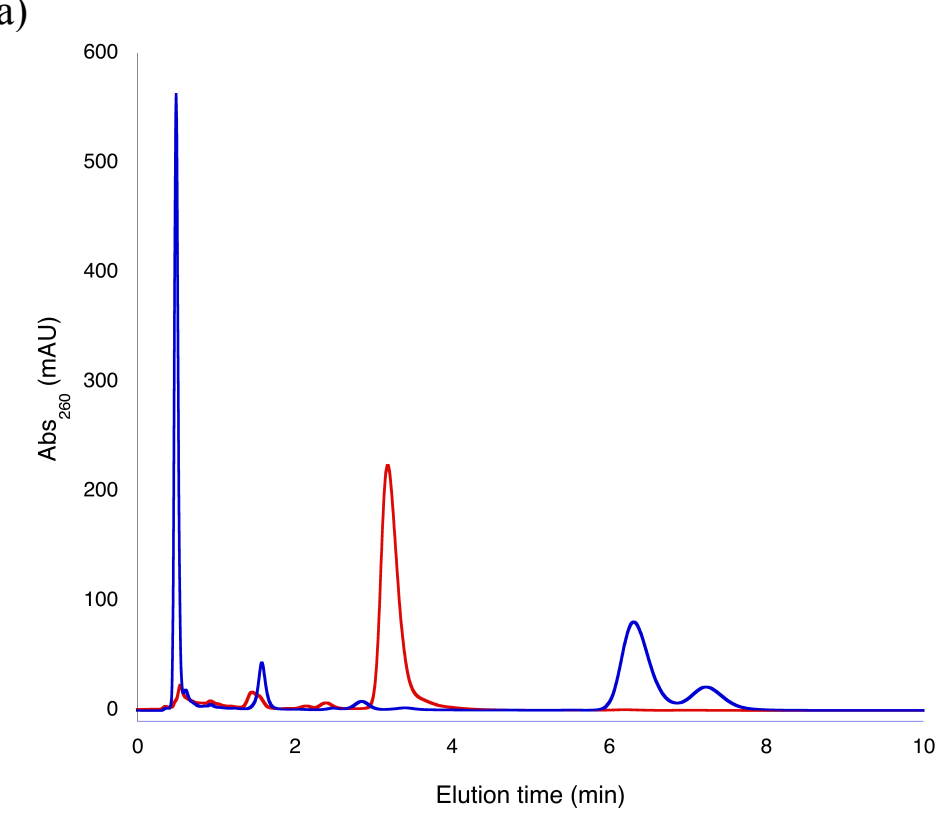

(b)

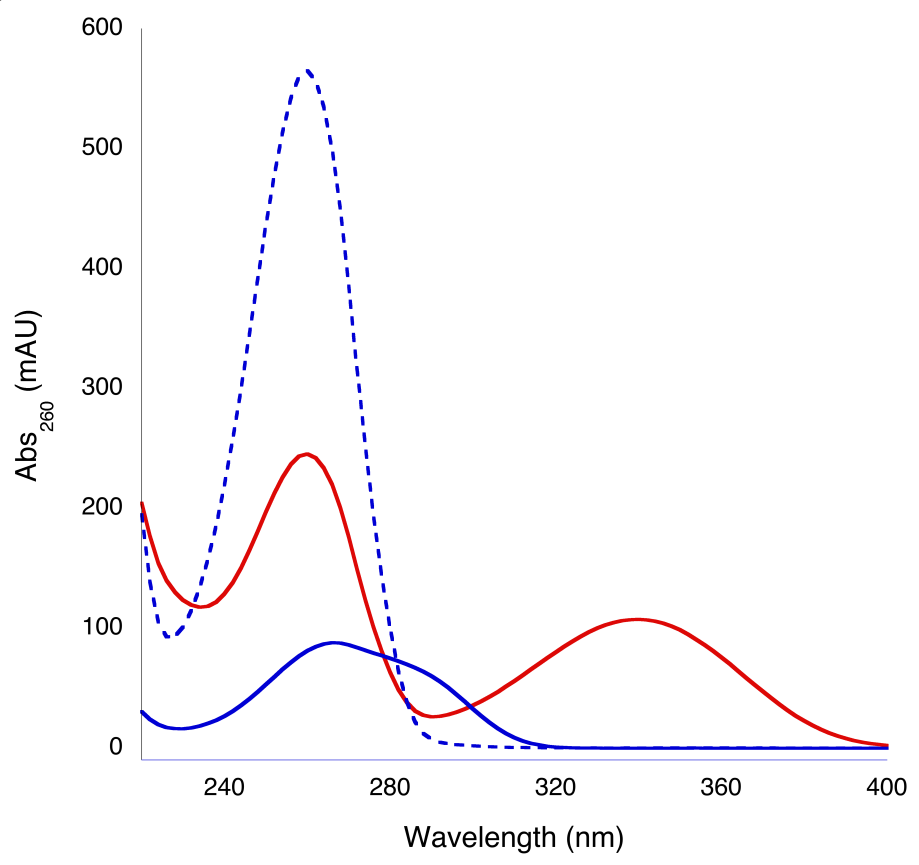


Figure 3.17 Time dependence of fluorophore yield. (a) Fluorescence intensity of a solution of $\mathrm{NADP}^{+}$and increasing concentration of $\mathrm{NaOH}$. Immediate quantitation of fluorescence is in red, the blue data points reflect an $18 \mathrm{hr}$ incubation at each concentration. (b) HPLC separation of the base treatment of $\mathrm{NADP}^{+}$at $2 \mathrm{M} \mathrm{NaOH}$. The NADP ${ }^{+}$is shown in red. Immediate quenching with $\mathrm{HCl}$ produced the products for 0 mins (blue dash), 60 minutes (blue dotted) and 120 minutes (solid blue). The loss of $\mathrm{NADP}^{+} 260 \mathrm{~nm}$ absorbance is shown inset.

(a)

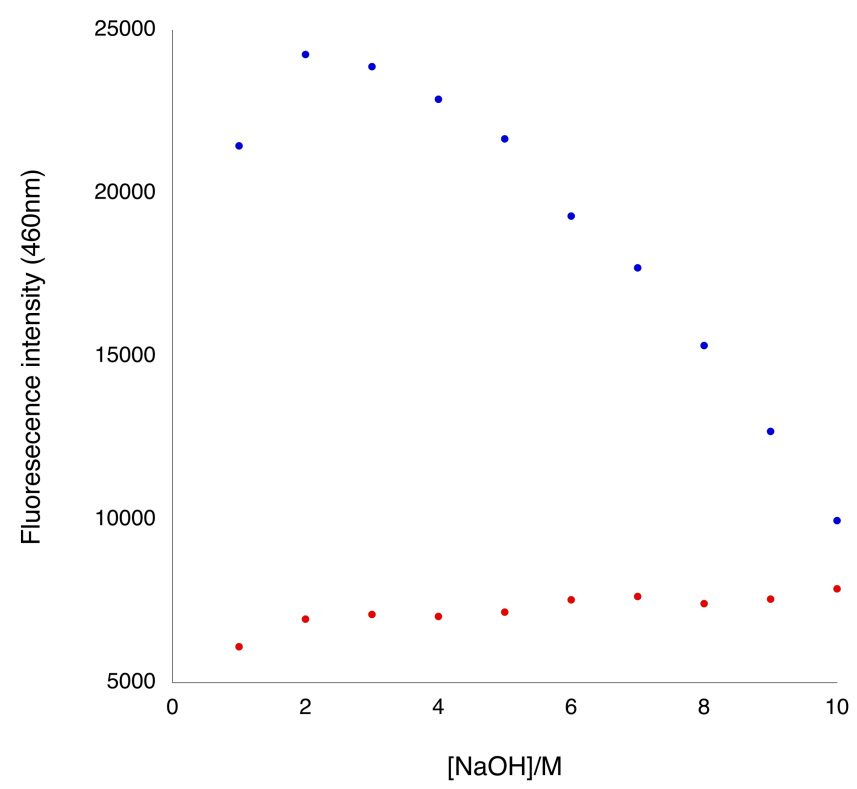

(b)

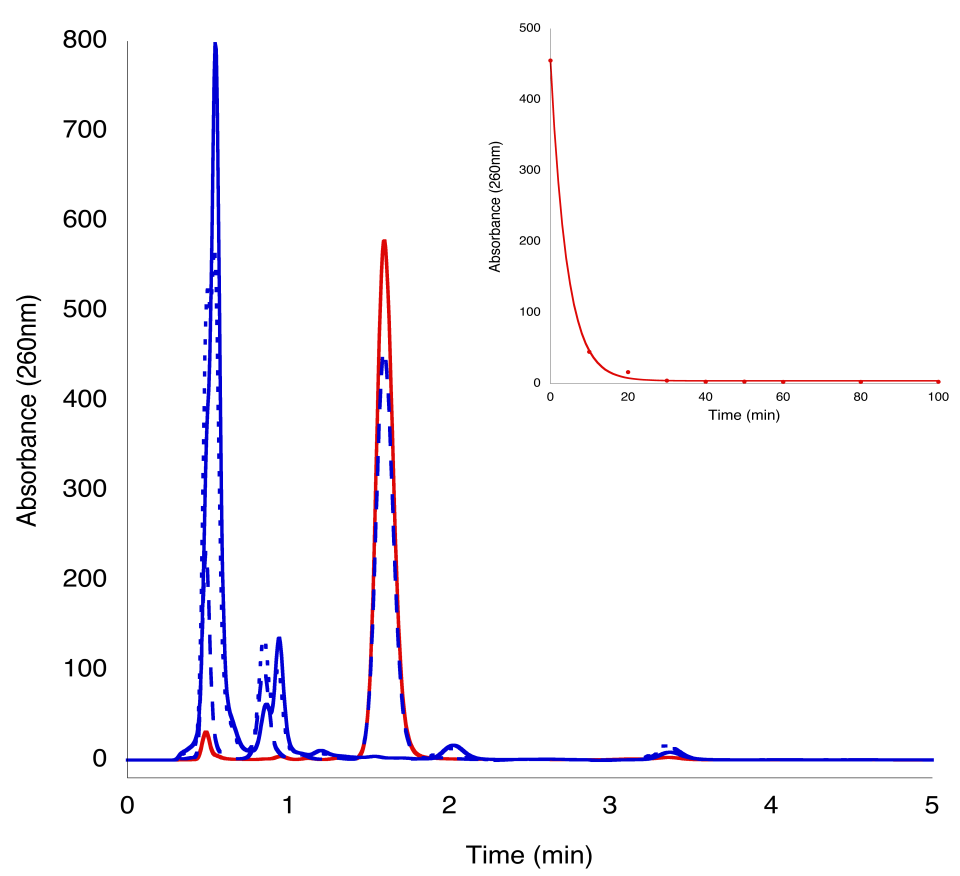


Figure 3.18 UV spectra of NADPH, NADP ${ }^{+}$and NMN derivatives. (a) NADPH in water (dark blue), treated with base in $0.5 \mathrm{M} \mathrm{NaOH}$ (medium blue) and in water (light blue). (b) $\mathrm{NADP}^{+}$in water (purple), treated with base in $0.5 \mathrm{M} \mathrm{NaOH}$ (lilac) and in water (magenta). (c) NMN in water (red), treated with base in $0.5 \mathrm{M} \mathrm{NaOH}$ (yellow) and in water (orange). Base treatment in each case was $2 \mathrm{hr}$ in $2 \mathrm{M} \mathrm{NaOH}$ before being neutralized with $\mathrm{HCl}$.

(a)

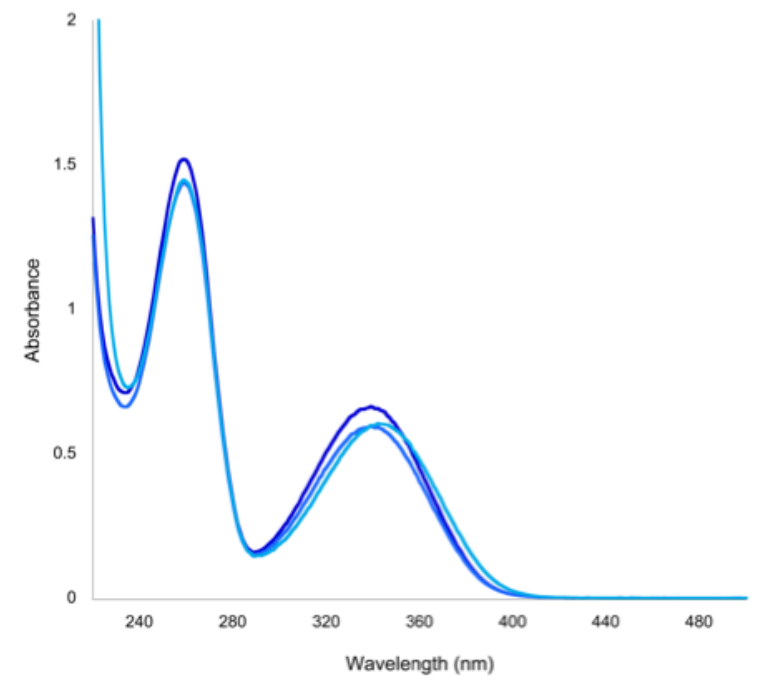

(b)

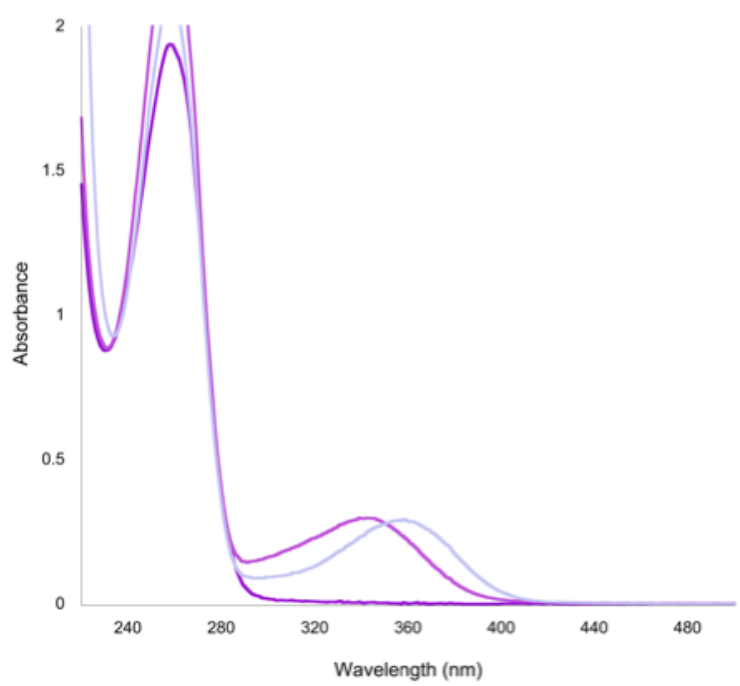

(c)

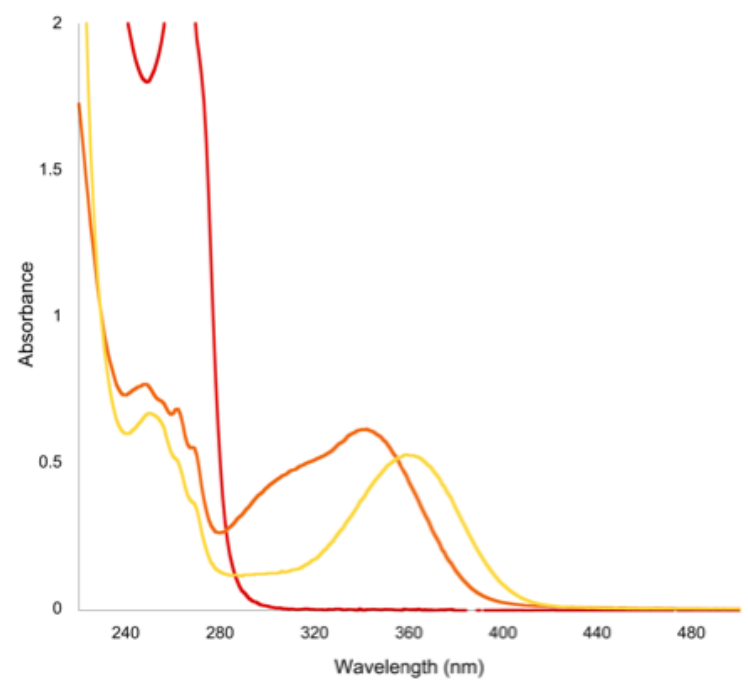


Figure 3.19 UV absorbance and fluorescence of isolated fluorophore product. The absorbance spectrum of the product was measured between 250 and $500 \mathrm{~nm}$, in both neutral conditions in water (red) and $0.5 \mathrm{M} \mathrm{NaOH}$ (blue). The fluorescence is measured from 400 to $600 \mathrm{~nm}$ with excitation at $360 \mathrm{~nm}$ (dashed lines, colors represent the same conditions as absorbance).

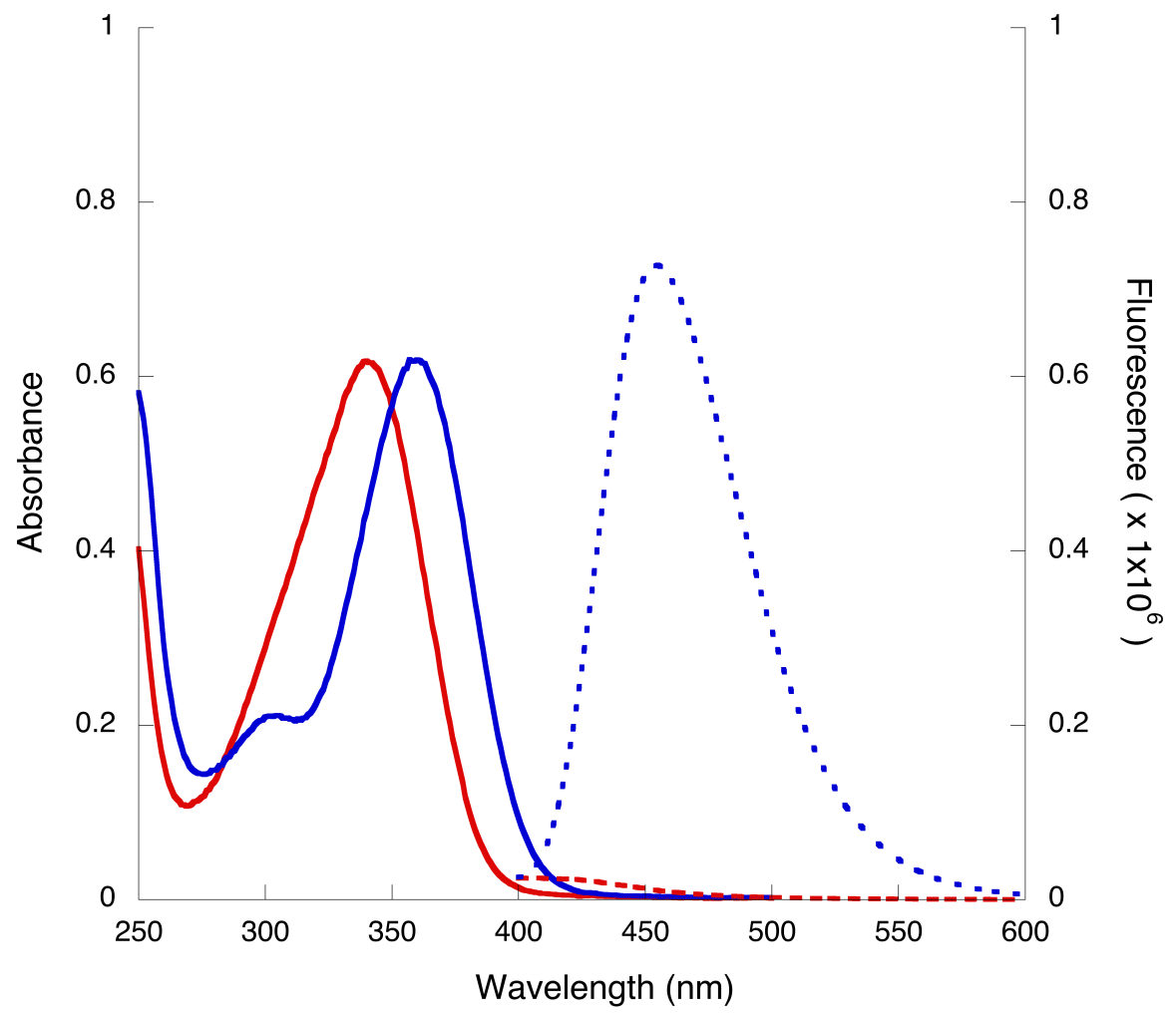


Figure 3.20 Determination of quantum yield for the base product. The fluorescence spectra of a quinine sulfate standard (red) in $0.5 \mathrm{M} \mathrm{H} 2 \mathrm{~S} 04$ and the base product (blue) in $0.5 \mathrm{M}$ $\mathrm{NaOH}$. The area between 400 and $600 \mathrm{~nm}$ was integrated and plotted against the corresponding absorbance value at $350 \mathrm{~nm}$.

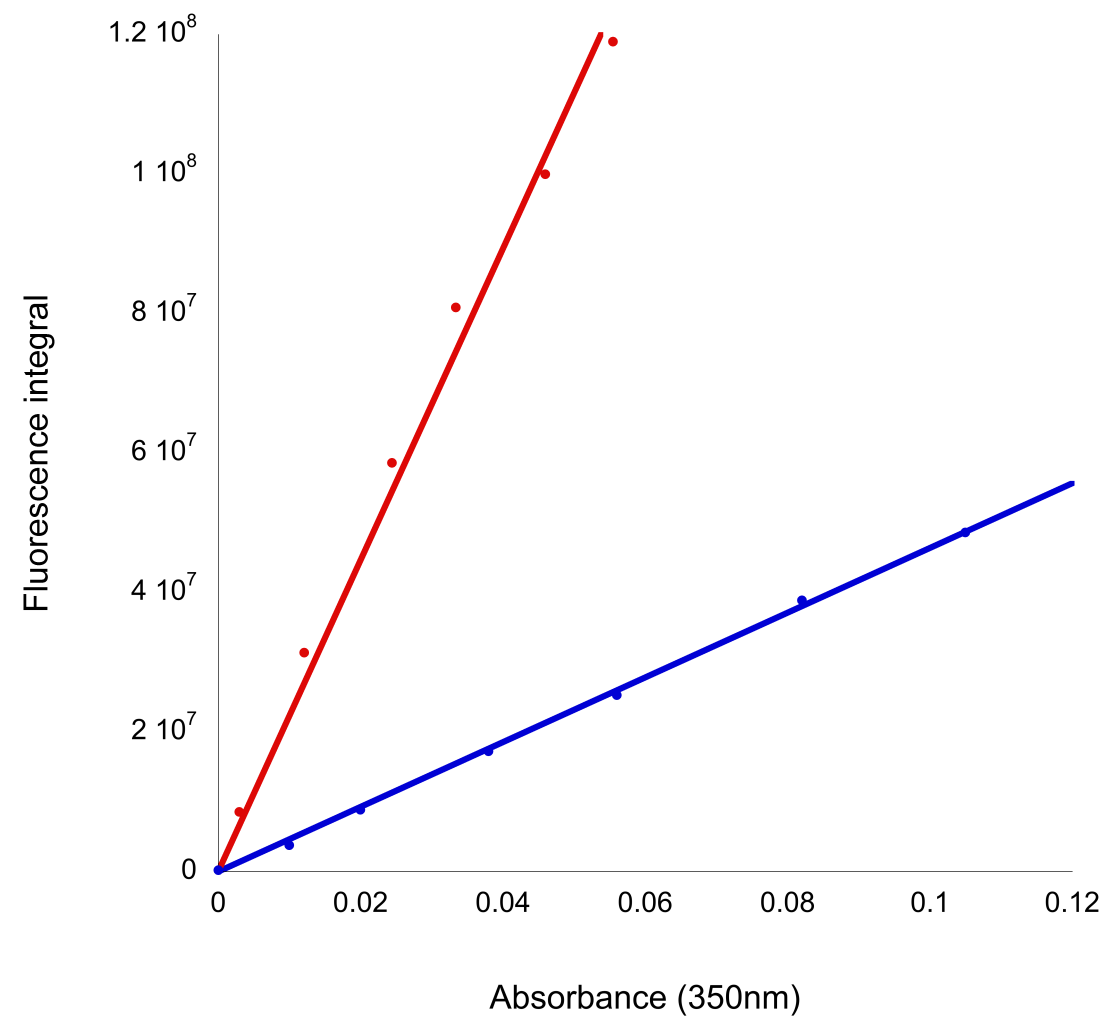


Figure 3.21 Accurate mass determination. Freshly prepared and purified fluorophore in DI water is mixed with an equal volume of methanol before being analyzed by electrospray MS. In positive mode the two main peaks have $\mathrm{m} / \mathrm{z}$ of 124.03948 and 146.02178. This corresponds to a molecular weight of $123.0315 \mathrm{gmol}^{-1}$.
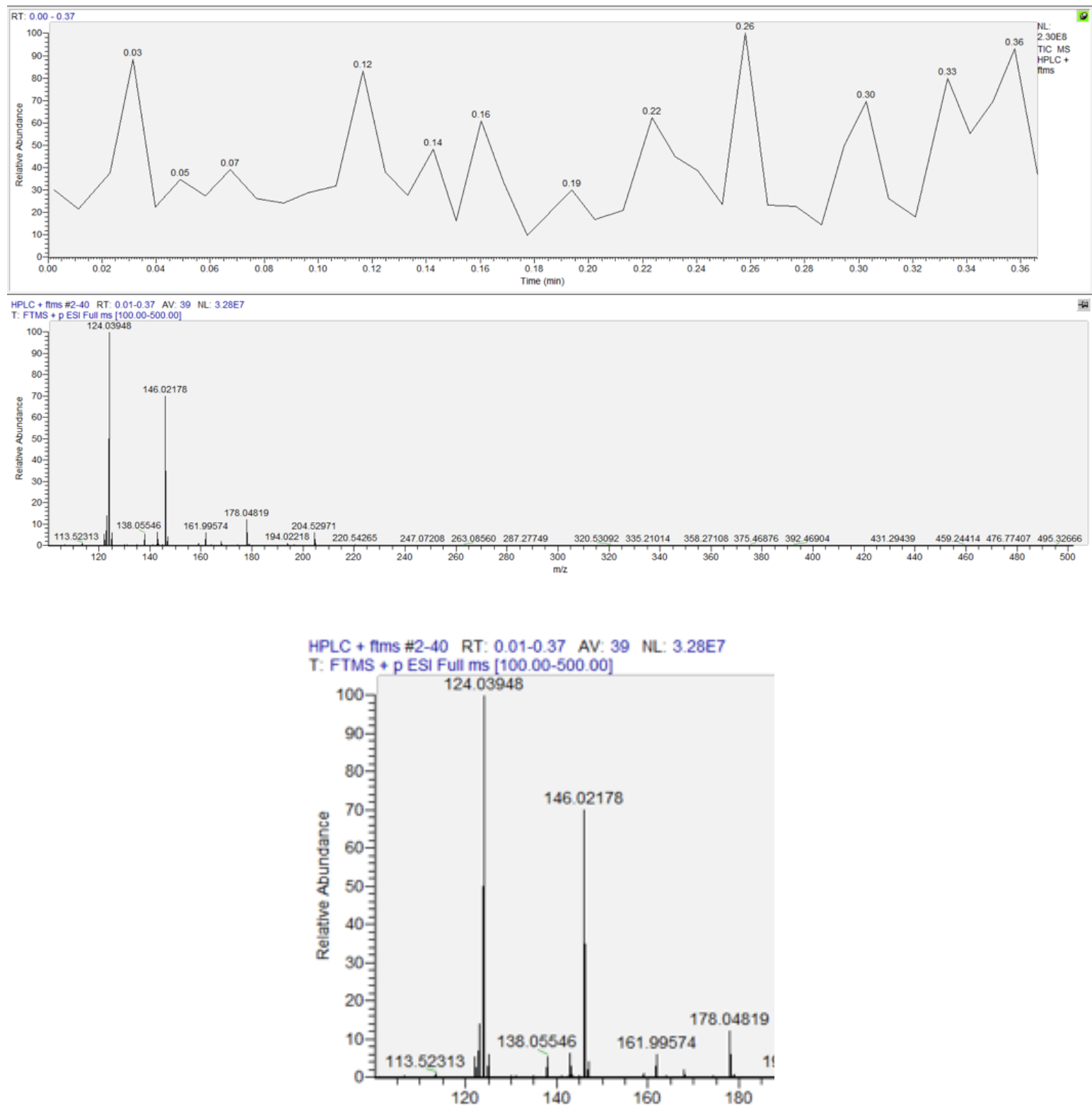
Figure 3.22 ${ }^{1} \mathrm{H}$ NMR of the isolated fluorescent product. Water suppression ${ }^{1} \mathrm{H}$ spectrum of the HPLC purified product shows four resonances: $9.88(\mathrm{~s}), 8.18(\mathrm{~d}, \mathrm{~d}), 7.81(\mathrm{~d})$ and 6.63 (t) (expanded in lower panels). Spectrum collected in $10 \% \mathrm{D}_{2} \mathrm{O}$.
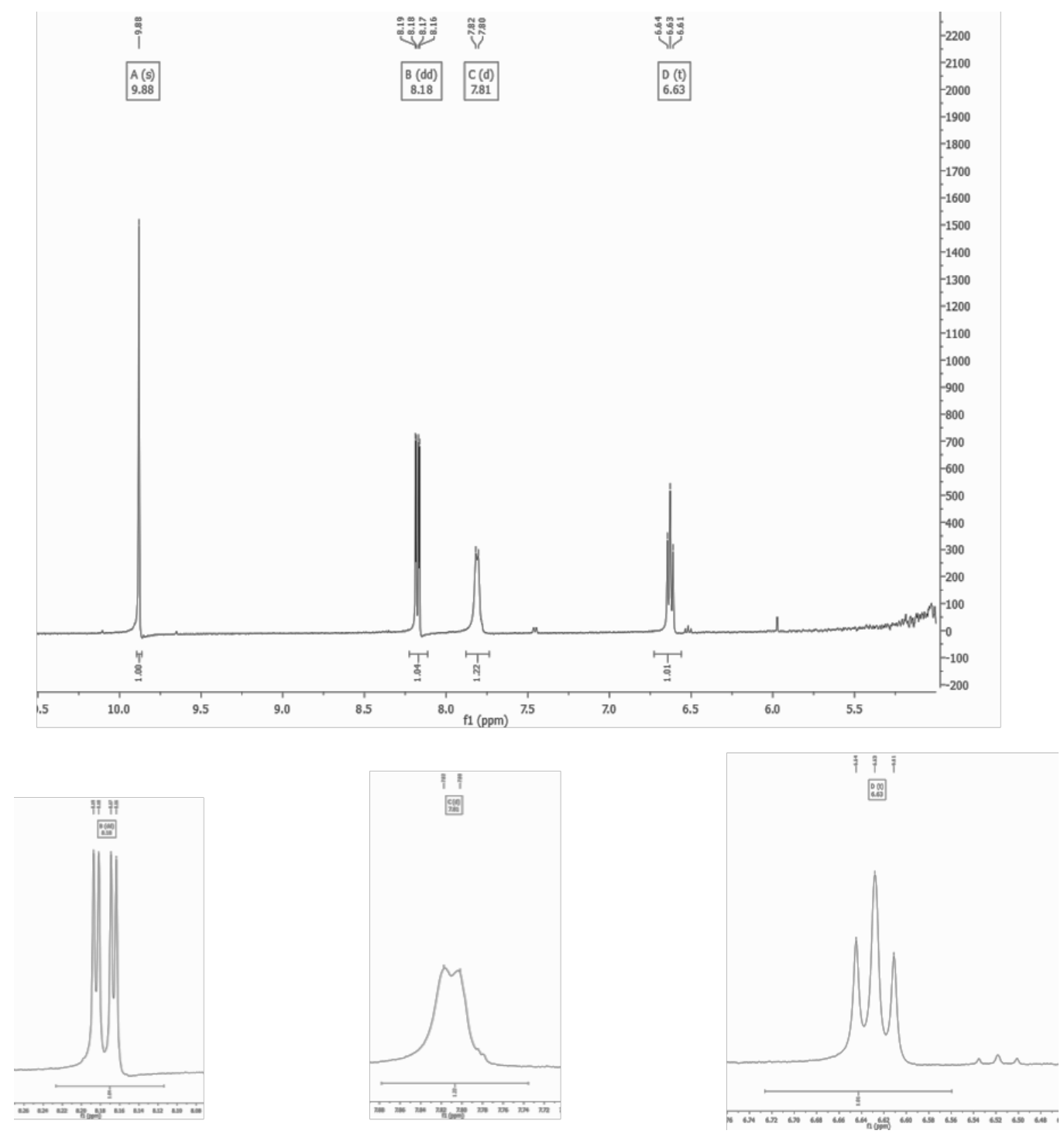
Figure 3.23 ${ }^{1} \mathrm{H}$ NMR of the isolated fluorescent product in basic conditions. Water suppression ${ }^{1} \mathrm{H}$ spectraum of the HPLC purified product shows four resonances: $9.87(\mathrm{~s})$, $8.08(\mathrm{~d}, \mathrm{~d}), 7.83(\mathrm{~d}, \mathrm{~d})$ and $6.50(\mathrm{~d}, \mathrm{~d})$ (expanded in lower panels). Spectrum collected in $1 \mathrm{M}$ NaOD.

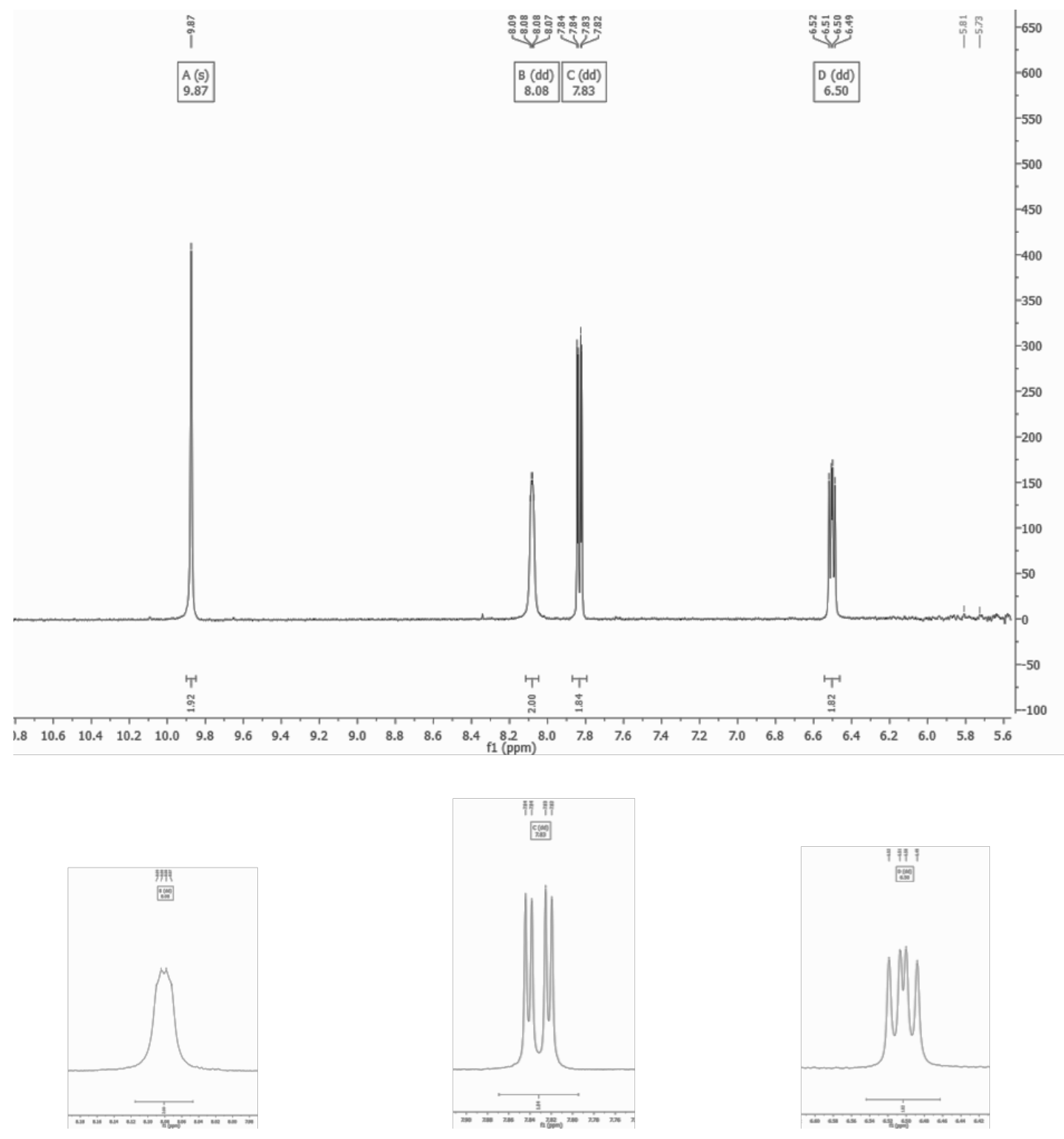


Figure 3.24 ${ }^{13} \mathrm{C}$ NMR of the isolated fluorescent product. Carbon spectrum of the HPLC purified product shows seven resonances: 192.09 (s), 180.98 (s), 148.07 (s), 142.77 (s), 124.25 (s) and 108.47 (s) relate to the compound being studied. The resonance at 22.95 $\mathrm{ppm}$ is from the acetate carried over from the purification.

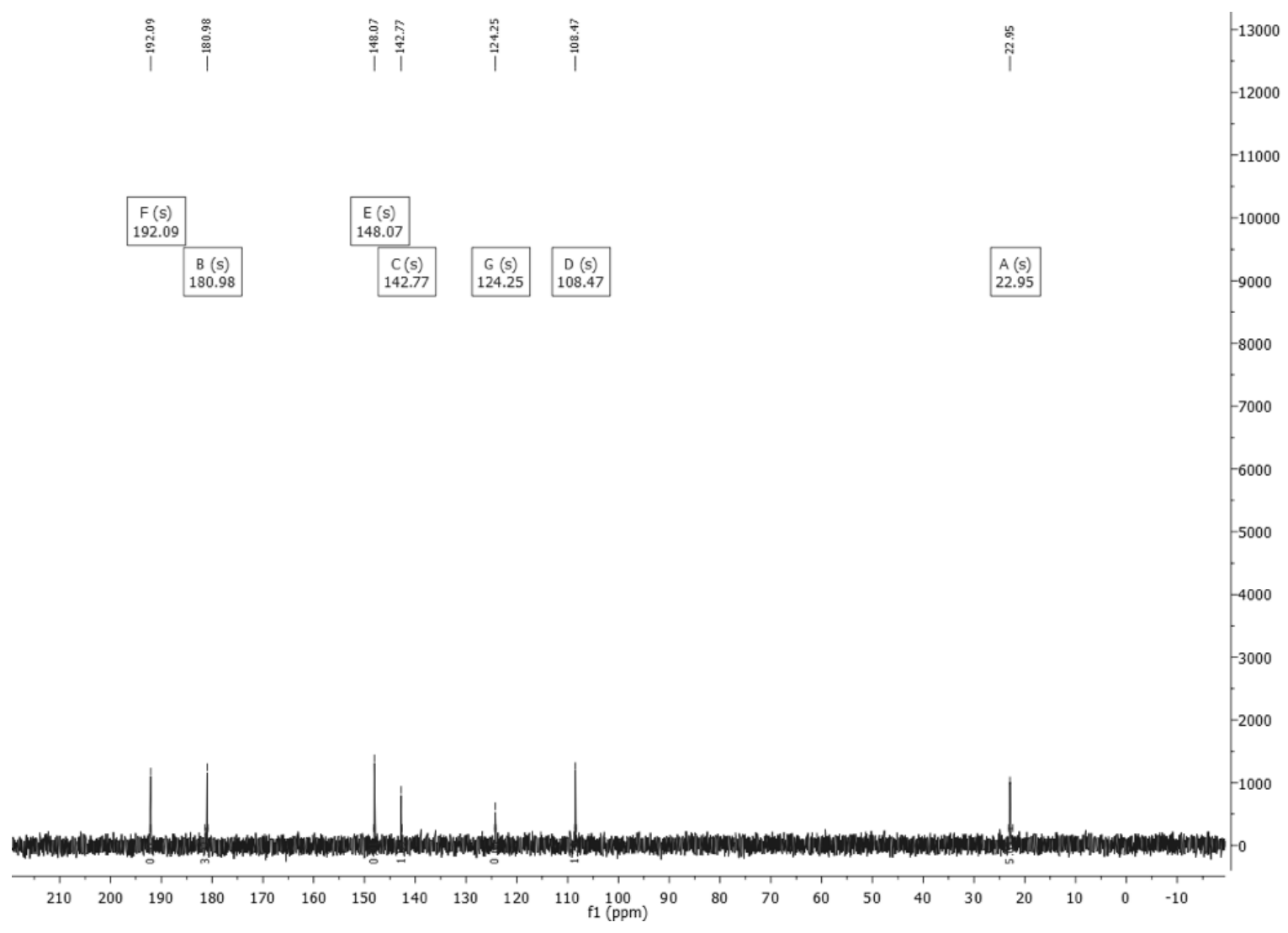


Figure 3.26 IR spectrum of the isolated fluorophore. The sample was extracted from the MQ water with ethyl acetate and concentrated under nitrogen.

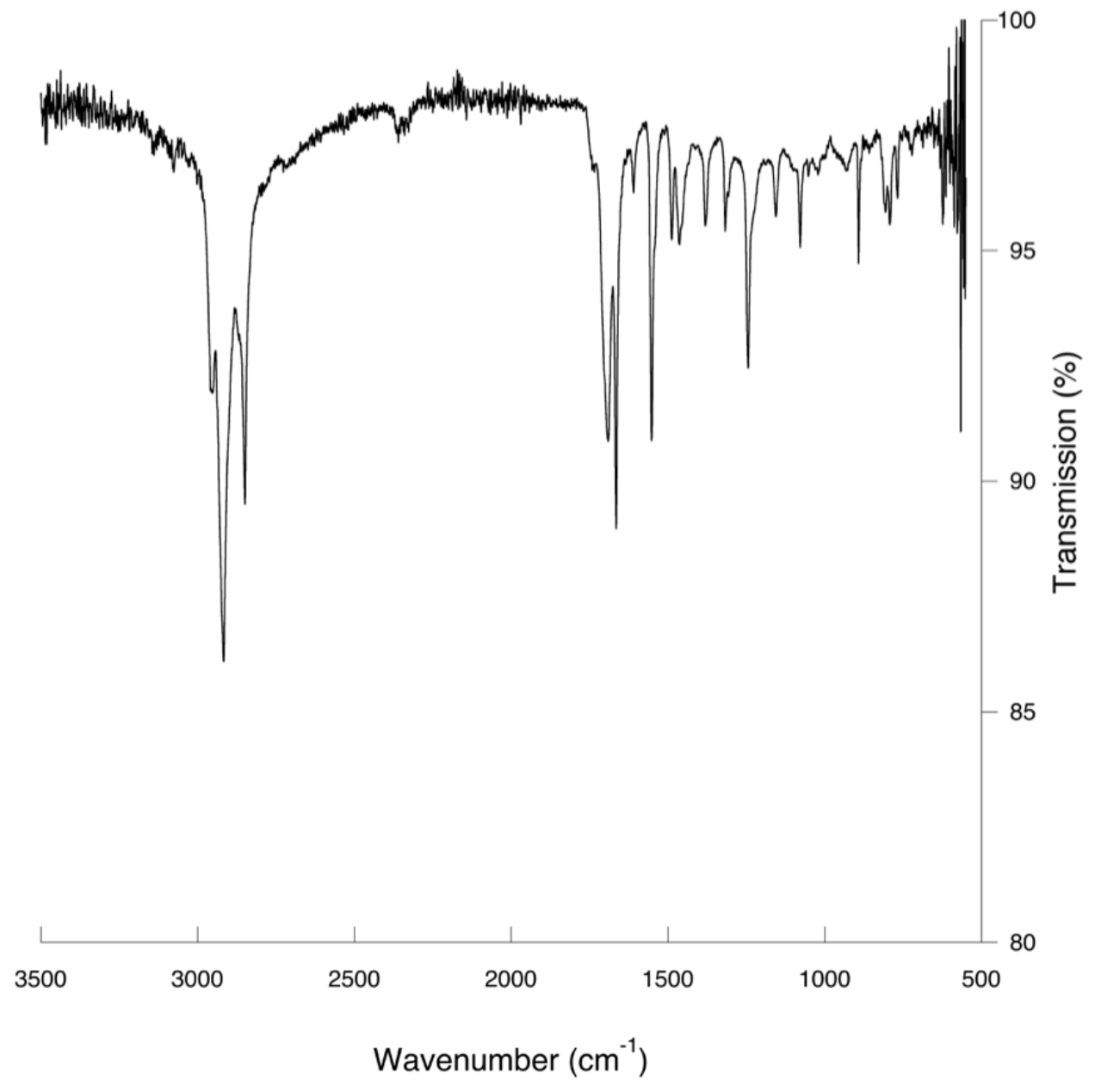


Figure 4.1 Growth phenotype of the T. kodakarensis mutants. Both the $\Delta \operatorname{tgt}(\mathrm{TK} 0760)$ and $\Delta \operatorname{arcS}$ (TK2156) mutants show greatly reduced growth at $95^{\circ}$ where the wild type is still showing rigorous growth.

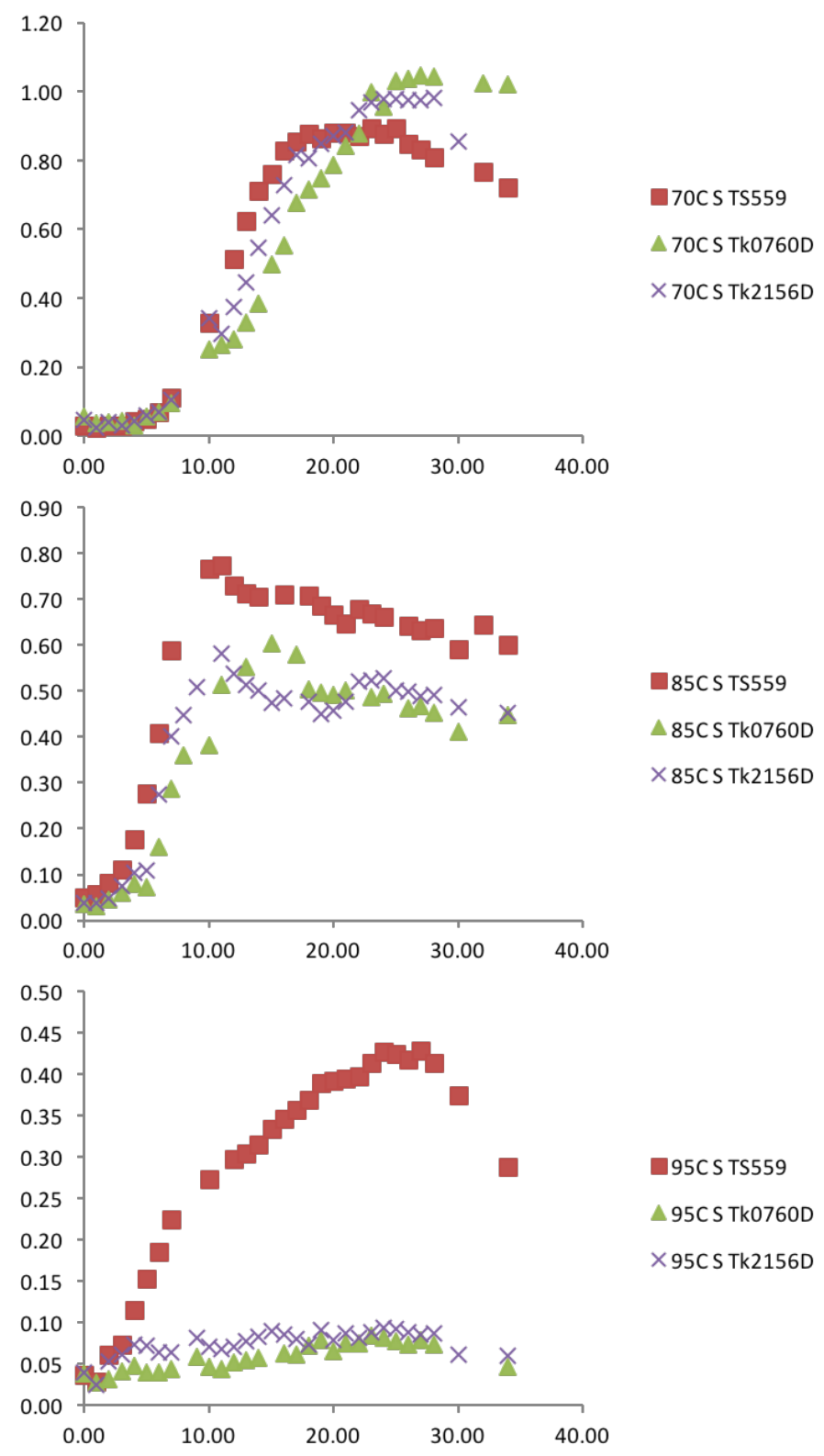


Figure 4.2 Location of base modifications in the core of tRNA. Shown is a schematic of the tRNA form $H$. volcanii, showing type and location of modifications that are specific to Archaea and facilitate the formation of the folded core (bases in the blue box). (figure modified from BMC Genomics, 2008, 9:470).

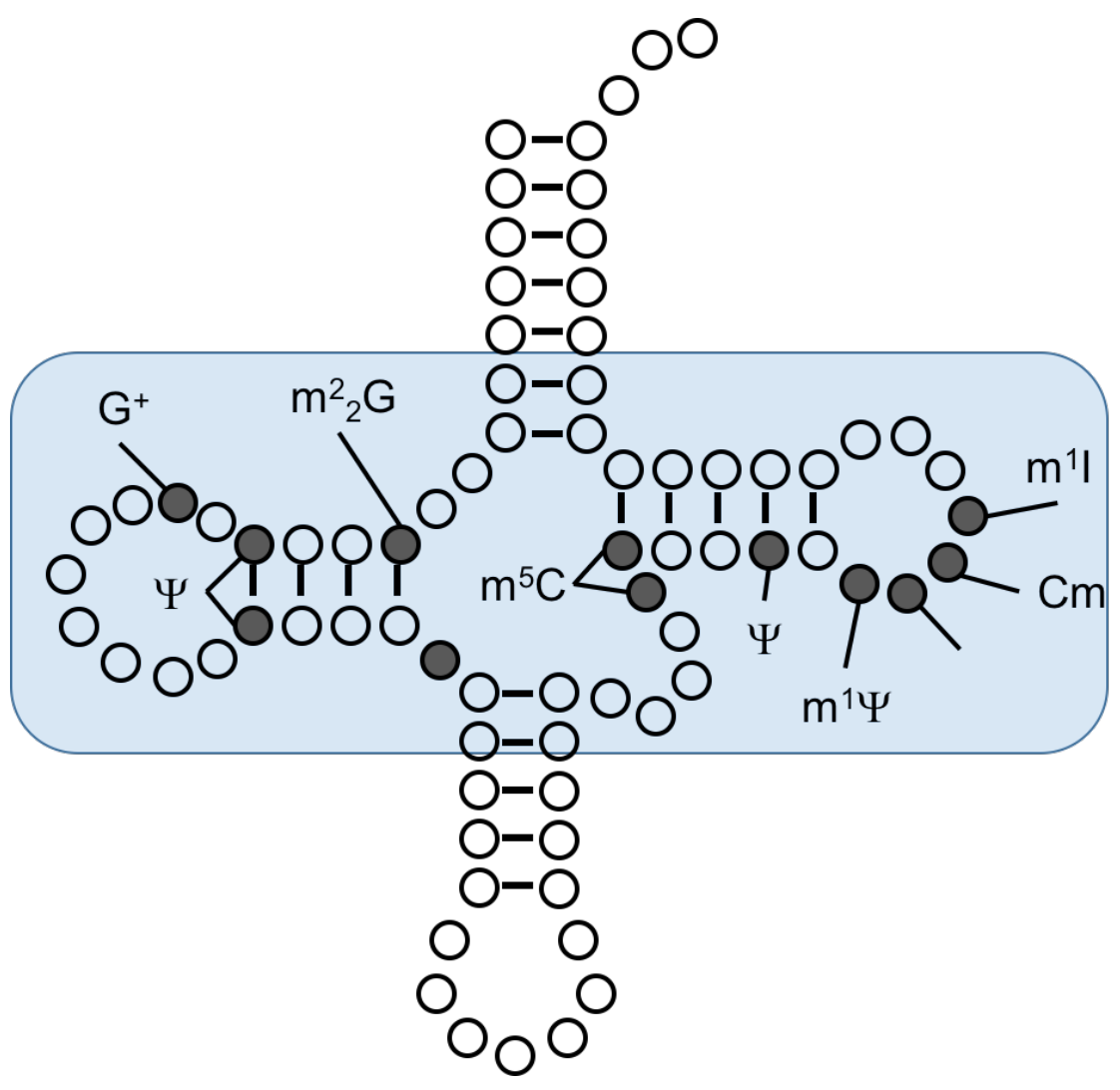


Figure 4.3 Mechanism of base reaction to yield 2-hydroxynicotinaldehyde. The first step in producing 2HNA is the nucleophilic attack of hydroxide at position 2 of a reduced nicotinamide species $(i)$. This yields (ii) which upon further supply of hydroxide ions irreversibly is converted to the ring open form of $\mathrm{NAD}^{+}$or ONAD (iii). This decomposes to generate 2-carboxamideglutacondialdehyde (CGDA) (iv) with loss of what was the ring nitrogen of the starting material. Intramolecular re-cyclization results in the formation of the fluorescent product $(v)$ which is in equilibrium with the inactive protonated form $(v i)$.

(i)<smiles></smiles>

(iv)<smiles>NC(=O)C(C=O)=CC=C[O-]</smiles>

$(v)$<smiles>O=Cc1cccnc1[O-]</smiles><smiles>C=C</smiles><smiles>NC(O)C1C=CCN2CCCC12[O-]</smiles>

(ii)

(iii)<smiles>CCC(C=CC=NC)=CO</smiles><smiles>C=C</smiles><smiles>O=Cc1cccnc1O</smiles>

$(v i)$ 


\section{Bibliography}

[1] Leontis, N. B., Stombaugh, J., and Westhof, E. (2002) Motif prediction in ribosomal RNAs Lessons and prospects for automated motif prediction in homologous RNA molecules, Biochimie 84, 961-973.

[2] Leontis, N. B., Stombaugh, J., and Westhof, E. (2002) The non-Watson-Crick base pairs and their associated isostericity matrices, Nucleic Acids Res 30, 3497-3531.

[3] Leontis, N. B., Lescoute, A., and Westhof, E. (2006) The building blocks and motifs of RNA architecture, Curr Opin Struct Biol 16, 279-287.

[4] Laing, C., and Schlick, T. (2009) Analysis of four-way junctions in RNA structures, $J$ Mol Biol 390, 547-559.

[5] Butcher, S. E., and Pyle, A. M. (2011) The molecular interactions that stabilize RNA tertiary structure: RNA motifs, patterns, and networks, Acc Chem Res 44, 13021311.

[6] Lowe, T. M., and Eddy, S. R. (1997) tRNAscan-SE: a program for improved detection of transfer RNA genes in genomic sequence, Nucleic Acids Res 25, 955-964.

[7] Sprinzl, M., and Vassilenko, K. S. (2005) Compilation of tRNA sequences and sequences of tRNA genes, Nucleic Acids Res 33, D139-140.

[8] Green, N. J., Grundy, F. J., and Henkin, T. M. (2010) The T box mechanism: tRNA as a regulatory molecule, FEBS Lett 584, 318-324.

[9] Janssen, B. D., and Hayes, C. S. (2012) The tmRNA ribosome-rescue system, $A d v$ Protein Chem Struct Biol 86, 151-191.

[10] Thompson, D. M., and Parker, R. (2009) Stressing out over tRNA cleavage, Cell 138, 215-219.

[11] Lee, Y. S., Shibata, Y., Malhotra, A., and Dutta, A. (2009) A novel class of small RNAs: tRNA-derived RNA fragments (tRFs), Genes Dev 23, 2639-2649.

[12] Arendt, W., Hebecker, S., Jäger, S., Nimtz, M., and Moser, J. (2012) Resistance phenotypes mediated by aminoacyl-phosphatidylglycerol synthases, J Bacteriol 194, 1401-1416.

[13] RajBhandary, U. L., and Söll, D. (2008) Aminoacyl-tRNAs, the bacterial cell envelope, and antibiotics, Proc Natl Acad Sci U S A 105, 5285-5286.

[14] Machnicka, M. A., Milanowska, K., Osman Oglou, O., Purta, E., Kurkowska, M., Olchowik, A., Januszewski, W., Kalinowski, S., Dunin-Horkawicz, S., Rother, K. M., Helm, M., Bujnicki, J. M., and Grosjean, H. (2013) MODOMICS: a database of RNA modification pathways--2013 update, Nucleic Acids Res 41, D262-267.

[15] Crain, P. F., and McCloskey, J. A. (1997) The RNA modification database, Nucleic Acids Res 25, 126-127.

[16] Hamma, T., and Ferré-D'Amaré, A. R. (2006) Pseudouridine synthases, Chem Biol $13,1125-1135$.

[17] Clouet-d'Orval, B., Gaspin, C., and Mougin, A. (2005) Two different mechanisms for tRNA ribose methylation in Archaea: a short survey, Biochimie 87, 889-895.

[18] Schweizer, M. P., Chheda, G. B., Baczynskyj, L., and Hall, R. H. (1969) Aminoacyl nucleosides. VII. N-(Purin-6-ylcarbamoyl)threonine. A new component of transfer ribonucleic acid, Biochemistry 8, 3283-3289. 
[19] Deutsch, C., El Yacoubi, B., de Crécy-Lagard, V., and Iwata-Reuyl, D. (2012) Biosynthesis of threonylcarbamoyl adenosine (t6A), a universal tRNA nucleoside, J Biol Chem 287, 13666-13673.

[20] Vold, B. S., Keith, D. E., Buck, M., McCloskey, J. A., and Pang, H. (1982) Lysine tRNAs from Bacillus subtilis 168: structural analysis, Nucleic Acids Res 10, 31253132.

[21] Bajji, A. C., and Davis, D. R. (2002) Synthesis of the tRNA(Lys,3) anticodon stemloop domain containing the hypermodified ms2t6A nucleoside, J Org Chem 67, 5352-5358.

[22] Kang, B. I., Miyauchi, K., Matuszewski, M., D'Almeida, G. S., Rubio, M. A., Alfonzo, J. D., Inoue, K., Sakaguchi, Y., Suzuki, T., and Sochacka, E. (2016) Identification of 2-methylthio cyclic N6-threonylcarbamoyladenosine (ms2ct6A) as a novel RNA modification at position 37 of tRNAs, Nucleic Acids Res.

[23] Perrochia, L., Crozat, E., Hecker, A., Zhang, W., Bareille, J., Collinet, B., van Tilbeurgh, H., Forterre, P., and Basta, T. (2013) In vitro biosynthesis of a universal t6A tRNA modification in Archaea and Eukarya, Nucleic Acids Res 41, 1953-1964.

[24] Thiaville, P. C., Iwata-Reuyl, D., and de Crécy-Lagard, V. (2014) Diversity of the biosynthesis pathway for threonylcarbamoyladenosine $(\mathrm{t}(6) \mathrm{A})$, a universal modification of tRNA, RNA Biol 11, 1529-1539.

[25] Murphy, F. V., Ramakrishnan, V., Malkiewicz, A., and Agris, P. F. (2004) The role of modifications in codon discrimination by tRNA(Lys)UUU, Nat Struct Mol Biol 11, 1186-1191.

[26] Shatkin, A. J. (1976) Capping of eucaryotic mRNAs, Cell 9, 645-653.

[27] Ghosh, A., and Lima, C. D. (2010) Enzymology of RNA cap synthesis, Wiley Interdiscip Rev RNA 1, 152-172.

[28] Tomikawa, C., Yokogawa, T., Kanai, T., and Hori, H. (2010) N7-Methylguanine at position 46 (m7G46) in tRNA from Thermus thermophilus is required for cell viability at high temperatures through a tRNA modification network, Nucleic Acids Res 38, 942-957.

[29] Leulliot, N., Chaillet, M., Durand, D., Ulryck, N., Blondeau, K., and van Tilbeurgh, H. (2008) Structure of the yeast tRNA m7G methylation complex, Structure 16, 52-61.

[30] Cartlidge, R. A., Knebel, A., Peggie, M., Alexandrov, A., Phizicky, E. M., and Cohen, P. (2005) The tRNA methylase METTL1 is phosphorylated and inactivated by PKB and RSK in vitro and in cells, EMBO J 24, 1696-1705.

[31] Shi, H., and Moore, P. B. (2000) The crystal structure of yeast phenylalanine tRNA at 1.3 Å resolution: a classic structure revisited, RNA 6, 1091-1015.

[32] Chawla, M., Oliva, R., Bujnicki, J. M., and Cavallo, L. (2015) An atlas of RNA base pairs involving modified nucleobases with optimal geometries and accurate energies, Nucleic Acids Res 43, 6714-6729.

[33] Bai, Y., Fox, D. T., Lacy, J. A., Van Lanen, S. G., and Iwata-Reuyl, D. (2000) Hypermodification of tRNA in Thermophilic archaea. Cloning, overexpression, and characterization of tRNA-guanine transglycosylase from Methanococcus jannaschii, J Biol Chem 275, 28731-28738. 
[34] Lee, B. W., Van Lanen, S. G., and Iwata-Reuyl, D. (2007) Mechanistic studies of Bacillus subtilis QueF, the nitrile oxidoreductase involved in queuosine biosynthesis, Biochemistry 46, 12844-12854.

[35] Van Lanen, S. G., Reader, J. S., Swairjo, M. A., de Crécy-Lagard, V., Lee, B., and Iwata-Reuyl, D. (2005) From cyclohydrolase to oxidoreductase: discovery of nitrile reductase activity in a common fold, Proc Natl Acad Sci U S A 102, 4264-4269.

[36] Nichol, C. A., Smith, G. K., and Duch, D. S. (1985) Biosynthesis and metabolism of tetrahydrobiopterin and molybdopterin, Annu Rev Biochem 54, 729-764.

[37] McCarty, R. M., Somogyi, A., Lin, G., Jacobsen, N. E., and Bandarian, V. (2009) The deazapurine biosynthetic pathway revealed: in vitro enzymatic synthesis of $\operatorname{PreQ}(0)$ from guanosine 5'-triphosphate in four steps, Biochemistry 48, 3847-3852.

[38] Sofia, H. J., Chen, G., Hetzler, B. G., Reyes-Spindola, J. F., and Miller, N. E. (2001) Radical SAM, a novel protein superfamily linking unresolved steps in familiar biosynthetic pathways with radical mechanisms: functional characterization using new analysis and information visualization methods, Nucleic Acids Res 29, $1097-$ 1106.

[39] Slany, R. K., Bösl, M., Crain, P. F., and Kersten, H. (1993) A new function of Sadenosylmethionine: the ribosyl moiety of AdoMet is the precursor of the cyclopentenediol moiety of the tRNA wobble base queuine, Biochemistry 32, 78117817.

[40] Miles, Z. D., McCarty, R. M., Molnar, G., and Bandarian, V. (2011) Discovery of epoxyqueuosine (oQ) reductase reveals parallels between halorespiration and tRNA modification, Proc Natl Acad Sci U S A 108, 7368-7372.

[41] Kirtland, G. M., Morris, T. D., Moore, P. H., O'Brian, J. J., Edmonds, C. G., McCloskey, J. A., and Katze, J. R. (1988) Novel salvage of queuine from queuosine and absence of queuine synthesis in Chlorella pyrenoidosa and Chlamydomonas reinhardtii, $J$ Bacteriol 170, 5633-5641.

[42] Shindo-Okada, N., Okada, N., Ohgi, T., Goto, T., and Nishimura, S. (1980) Transfer ribonucleic acid guanine transglycosylase isolated from rat liver, Biochemistry 19, 395-400.

[43] Watanabe, M., Matsuo, M., Tanaka, S., Akimoto, H., Asahi, S., Nishimura, S., Katze, J. R., Hashizume, T., Crain, P. F., McCloskey, J. A., and Okada, N. (1997) Biosynthesis of archaeosine, a novel derivative of 7-deazaguanosine specific to archaeal tRNA, proceeds via a pathway involving base replacement on the tRNA polynucleotide chain, J Biol Chem 272, 20146-20151.

[44] Watanabe, M., Nameki, N., Matsuo-Takasaki, M., Nishimura, S., and Okada, N. (2001) tRNA recognition of tRNA-guanine transglycosylase from a hyperthermophilic archaeon, Pyrococcus horikoshii, J Biol Chem 276, 2387-2394.

[45] Phillips, G., Chikwana, V. M., Maxwell, A., El-Yacoubi, B., Swairjo, M. A., IwataReuyl, D., and de Crécy-Lagard, V. (2010) Discovery and characterization of an amidinotransferase involved in the modification of archaeal tRNA, $J$ Biol Chem 285, 12706-12713.

[46] Phillips, G., Swairjo, M. A., Gaston, K. W., Bailly, M., Limbach, P. A., Iwata-Reuyl, D., and de Crécy-Lagard, V. (2012) Diversity of archaeosine synthesis in crenarchaeota, ACS Chem Biol 7, 300-305. 
[47] Bon Ramos, A., Boa, L., Turner, B., de Crécy-Lagard, V., and Iwata-Reuyl , D. (2017) QueF-Like, a non-homologous archaeosine synthase from the crenarchaeota, Biomolecules 7.

[48] Oliva, R., Tramontano, A., and Cavallo, L. (2007) Mg2+ binding and archaeosine modification stabilize the G15 C48 Levitt base pair in tRNAs, RNA 13, 1427-1436.

[49] Koshlap, K. M., Guenther, R., Sochacka, E., Malkiewicz, A., and Agris, P. F. (1999) A distinctive RNA fold: the solution structure of an analogue of the yeast tRNAPhe T Psi C domain, Biochemistry 38, 8647-8656.

[50] Serra, M. J., Baird, J. D., Dale, T., Fey, B. L., Retatagos, K., and Westhof, E. (2002) Effects of magnesium ions on the stabilization of RNA oligomers of defined structures, RNA 8, 307-323.

[51] Lemay, J. F., Penedo, J. C., Tremblay, R., Lilley, D. M., and Lafontaine, D. A. (2006) Folding of the adenine riboswitch, Chem Biol 13, 857-868.

[52] Maglott, E. J., Deo, S. S., Przykorska, A., and Glick, G. D. (1998) Conformational transitions of an unmodified tRNA: implications for RNA folding, Biochemistry 37, 16349-16359.

[53] Römer, R., and Hach, R. (1975) tRNA conformation and magnesium binding. A study of a yeast phenylalanine-specific tRNA by a fluorescent indicator and differential melting curves, Eur J Biochem 55, 271-284.

[54] Filimonov, V. V., Privalov, P. L., Hinz, H. J., von der Haar, F., and Cramer, F. (1976) Calorimetric investigations on thermal stability of tRNAIle (yeast) and tRNASer (yeast), Eur J Biochem 70, 25-31.

[55] Maglott, E. J., and Glick, G. D. (1997) A new method to monitor the rate of conformational transitions in RNA, Nucleic Acids Res 25, 3297-3301.

[56] Stein, A., and Crothers, D. M. (1976) Conformational changes of transfer RNA. The role of magnesium(II), Biochemistry 15, 160-168.

[57] Draper, D. E. (1996) Strategies for RNA folding, Trends Biochem Sci 21, 145-149.

[58] Crothers, D. M., Cole, P. E., Hilbers, C. W., and Shulman, R. G. (1974) The molecular mechanism of thermal unfolding of Escherichia coli formylmethionine transfer RNA, J Mol Biol 87, 63-88.

[59] Hilbers, C. W., Robillard, G. T., Shulamn, R. G., Blake, R. D., Webb, P. K., Fresco, R., and Riesner, D. (1976) Thermal unfolding of yeast glycine transfer RNA, Biochemistry 15, 1874-1882.

[60] Harden, A., and Young, W. J. (1906) The alcholic ferment of yeast-juice. Part II - The coferment of yeast juice, Proceedings of the Royal Society B - Biological Sciences 77, 369-375.

[61] Elvehjem CA , Madden RJ , Strong FM , and ., W. D. (1938) The isolation and identification of the anti-black tongue factor. The Journal of Biological Chemistry 123, 137-149.

[62] Preiss, J., and Handler, P. (1958) Biosynthesis of diphosphopyridine nucleotide. I. Identification of intermediates, J Biol Chem 233, 488-492.

[63] Preiss, J., and Handler, P. (1958) Biosynthesis of diphosphopyridine nucleotide. II. Enzymatic aspects, J Biol Chem 233, 493-500. 
[64] Kurnasov, O., Goral, V., Colabroy, K., Gerdes, S., Anantha, S., Osterman, A., and Begley, T. P. (2003) NAD biosynthesis: identification of the tryptophan to quinolinate pathway in bacteria, Chem Biol 10, 1195-1204.

[65] Liu, H., Woznica, K., Catton, G., Crawford, A., Botting, N., and Naismith, J. H. (2007) Structural and kinetic characterization of quinolinate phosphoribosyltransferase (hQPRTase) from homo sapiens, J Mol Biol 373, 755-763.

[66] Olland, A. M., Underwood, K. W., Czerwinski, R. M., Lo, M. C., Aulabaugh, A., Bard, J., Stahl, M. L., Somers, W. S., Sullivan, F. X., and Chopra, R. (2002) Identification, characterization, and crystal structure of Bacillus subtilis nicotinic acid mononucleotide adenylyltransferase, J Biol Chem 277, 3698-3707.

[67] De Ingeniis, J., Kazanov, M. D., Shatalin, K., Gelfand, M. S., Osterman, A. L., and Sorci, L. (2012) Glutamine versus ammonia utilization in the NAD synthetase family, PLoS One 7, e39115.

[68] Gossmann, T. I., Ziegler, M., Puntervoll, P., de Figueiredo, L. F., Schuster, S., and Heiland, I. (2012) NAD $(+)$ biosynthesis and salvage--a phylogenetic perspective, FEBS J 279, 3355-3363.

[69] Warburg, and Christian. (1931) Biochemical Journal 242, 206.

[70] Meldrum, N. U., and Tarr, H. L. (1935) The reduction of glutathione by the WarburgChristian system, Biochem J 29, 108-115.

[71] Magni, G., Amici, A., Emanuelli, M., Raffaelli, N., and Ruggieri, S. (1999) Enzymology of NAD+ synthesis, Adv Enzymol Relat Areas Mol Biol 73, 135-182, xi.

[72] Spaans, S. K., Weusthuis, R. A., van der Oost, J., and Kengen, S. W. (2015) NADPHgenerating systems in bacteria and archaea, Front Microbiol 6, 742.

[73] Kanehisa, M., and Goto, S. (2000) KEGG: kyoto encyclopedia of genes and genomes, Nucleic Acids Res 28, 27-30.

[74] Fliegert, R., Gasser, A., and Guse, A. H. (2007) Regulation of calcium signalling by adenine-based second messengers, Biochem Soc Trans 35, 109-114.

[75] Koch-Nolte, F., Fischer, S., Haag, F., and Ziegler, M. (2011) Compartmentation of NAD+-dependent signalling, FEBS Lett 585, 1651-1656.

[76] Sousa, F. G., Matuo, R., Soares, D. G., Escargueil, A. E., Henriques, J. A., Larsen, A. K., and Saffi, J. (2012) PARPs and the DNA damage response, Carcinogenesis 33, 1433-1440.

[77] Bheda, P., Jing, H., Wolberger, C., and Lin, H. (2016) The Substrate Specificity of Sirtuins, Annu Rev Biochem 85, 405-429.

[78] Sacconnay, L., Carrupt, P. A., and Nurisso, A. (2016) Human sirtuins: Structures and flexibility, J Struct Biol 196, 534-542.

[79] Rex M. C. Dawson, D. C. E., William H. Elliott, and K. M. Jones (1989) Data for Biochemical Research, 3rd ed.

[80] Kaplan, N. O., Colowick, S. P., and Barnes, C. C. (1951) Effect of alkali on diphosphopyridine nucleotide, J Biol Chem 191, 461-472.

[81] Wolf, B., Lesnaw, J. A., and Reichmann, M. E. (1970) A mechanism of the irreversible inactivation of bovine pancreatic ribonuclease by diethylpyrocarbonate. A general reaction of diethylpyrocarbonate . A general reaction of diethylpyrocarbonate with proteins, Eur J Biochem 13, 519-525. 
[82] Migawa, M. T., Hinkley, J. M., Hoops, G. C., and Townsend, L. B. (1996) A Two Step Synthesis of the Nucleoside Q Precursor 2-Amino-5-cyanopyrrolo[2,3d]pyrimidin 4-one (PreQ o ), An International Journal for Rapid Communication of Synthetic Organic Chemistry 26, 3317-3322.

[83] Sherlin, L. D., Bullock, T. L., Nissan, T. A., Perona, J. J., Lariviere, F. J., Uhlenbeck, O. C., and Scaringe, S. A. (2001) Chemical and enzymatic synthesis of tRNAs for high-throughput crystallization, $R N A$ 7, 1671-1678.

[84] Bhaskaran, H., and Perona, J. J. (2011) Two-step aminoacylation of tRNA without channeling in Archaea, J Mol Biol 411, 854-869.

[85] Bhaskaran, H., Rodriguez-Hernandez, A., and Perona, J. J. (2012) Kinetics of tRNA folding monitored by aminoacylation, $R N A$ 18, 569-580.

[86] Grilley, D., Soto, A. M., and Draper, D. E. (2009) Direct quantitation of Mg2+-RNA interactions by use of a fluorescent dye, Methods Enzymol 455, 71-94.

[87] Hileman, T. H., and Santangelo, T. J. (2012) Genetics Techniques for Thermococcus kodakarensis, Front Microbiol 3, 195.

[88] Kazayama, A., Yamagami, R., Yokogawa, T., and Hori, H. (2015) Improved solidphase DNA probe method for tRNA purification: large-scale preparation and alteration of DNA fixation, J Biochem 157, 411-418.

[89] Aeby, E., Palioura, S., Pusnik, M., Marazzi, J., Lieberman, A., Ullu, E., Söll, D., and Schneider, A. (2009) The canonical pathway for selenocysteine insertion is dispensable in Trypanosomes, Proc Natl Acad Sci U S A 106, 5088-5092.

[90] Hinz, H. J., Filimonov, V. V., and Privalov, P. L. (1977) Calorimetric studies on melting of tRNA Phe (yeast), Eur J Biochem 72, 79-86.

[91] Cole, P. E., Yang, S. K., and Crothers, D. M. (1972) Conformational changes of transfer ribonucleic acid. Equilibrium phase diagrams, Biochemistry 11, 43584368.

[92] Sampson, J. R., and Uhlenbeck, O. C. (1988) Biochemical and physical characterization of an unmodified yeast phenylalanine transfer RNA transcribed in vitro, Proc Natl Acad Sci US A 85, 1033-1037.

[93] Voigts-Hoffmann, F., Hengesbach, M., Kobitski, A. Y., van Aerschot, A., Herdewijn, P., Nienhaus, G. U., and Helm, M. (2007) A methyl group controls conformational equilibrium in human mitochondrial tRNA(Lys), J Am Chem Soc 129, 1338213383.

[94] Horie, N., Hara-Yokoyama, M., Yokoyama, S., Watanabe, K., Kuchino, Y., Nishimura, S., and Miyazawa, T. (1985) Two tRNAIle1 species from an extreme thermophile, Thermus thermophilus HB8: effect of 2-thiolation of ribothymidine on the thermostability of tRNA, Biochemistry 24, 5711-5715.

[95] Serebrov, V., Vassilenko, K., Kholod, N., Gross, H. J., and Kisselev, L. (1998) Mg2+ binding and structural stability of mature and in vitro synthesized unmodified Escherichia coli tRNAPhe, Nucleic Acids Res 26, 2723-2728.

[96] Alexandrov, A., Chernyakov, I., Gu, W., Hiley, S. L., Hughes, T. R., Grayhack, E. J., and Phizicky, E. M. (2006) Rapid tRNA decay can result from lack of nonessential modifications, Mol Cell 21, 87-96.

[97] Ishida, K., Kunibayashi, T., Tomikawa, C., Ochi, A., Kanai, T., Hirata, A., Iwashita, C., and Hori, H. (2011) Pseudouridine at position 55 in tRNA controls the contents 
of other modified nucleotides for low-temperature adaptation in the extremethermophilic eubacterium Thermus thermophilus, Nucleic Acids Res 39, 23042318.

[98] Urbonavicius, J., Armengaud, J., and Grosjean, H. (2006) Identity elements required for enzymatic formation of N2,N2-dimethylguanosine from N2-monomethylated derivative and its possible role in avoiding alternative conformations in archaeal tRNA, J Mol Biol 357, 387-399.

[99] Steinberg, S., and Cedergren, R. (1995) A correlation between N2-dimethylguanosine presence and alternate tRNA conformers, $R N A$ 1, 886-891.

[100] Kowalak, J. A., Dalluge, J. J., McCloskey, J. A., and Stetter, K. O. (1994) The role of posttranscriptional modification in stabilization of transfer RNA from hyperthermophiles, Biochemistry 33, 7869-7876.

[101] Ishitani, R., Nureki, O., Nameki, N., Okada, N., Nishimura, S., and Yokoyama, S. (2003) Alternative tertiary structure of tRNA for recognition by a posttranscriptional modification enzyme, Cell 113, 383-394.

[102] LOWRY, O. H., ROBERTS, N. R., and KAPPHAHN, J. I. (1957) The fluorometric measurement of pyridine nucleotides, J Biol Chem 224, 1047-1064.

[103] Binev, Y., Marques, M. M., and Aires-de-Sousa, J. (2007) Prediction of 1H NMR coupling constants with associative neural networks trained for chemical shifts, $J$ Chem Inf Model 47, 2089-2097.

[104] Patiny, L., and Wist, J. https://www.nmrdb.org/.

[105] Johnson, S. L., and Morrison, D. L. (1970) The alkaline reaction of nicotinamide adenine dinucleotide, a new transient intermediate, $J$ Biol Chem 245, 4519-4524.

[106] Johnson, S. L., and Rumon, K. A. (1970) Ring-opening reaction of 1-(N,Ndimethylcarbamoyl)pyridinium chloride with hydroxide. A model for the alkaline diphosphopyridine nucleotide reaction, Biochemistry 9, 847-857.

[107] Johnson, S. L., and Morrison, D. L. (1970) Substituent effects on pyridinium ringopening reactions. Facile ring opening of 1-(N,N-dimethylcarbamoyl)nicotinamide cation, Biochemistry 9, 1460-1470.

[108] Guilbert, C. C., and Johnson, S. L. (1971) Isolation and characterization of the fluorescent alkali product from diphosphopyridine nucleotide, Biochemistry 10, 2313-2316.

[109] Guilbert, C. C., and Johnson, S. L. (1977) Investigation of the open ring form of nicotinamide adenine dinucleotide, Biochemistry 16, 335-344. 